ORNL/TM-1999/333

\title{
SUMMARY OF ACSL SIMULATIONS OF THE MSRE AUXILIARY CHARCOAL BED VACUUM SYSTEM
}

\author{
by \\ B. Damiano \\ Instrumentation and Controls Division \\ Oak Ridge National Laboratory ${ }^{*}$ \\ Oak Ridge, TN 37831
}

Date Published - September 1999

\footnotetext{
*Prepared by OAK RIDGE NATIONAL LABORATORY Oak Ridge, Tennessee 37831-6285 managed by LOCKHEED MARTIN ENERGY RESEARCH CORP. for the U.S. DEPARTMENT OF ENERGY under contract number DE-AC05-96OR22464.
} 


\section{CONTENTS}

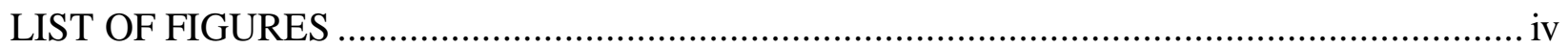

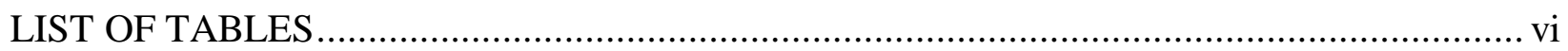

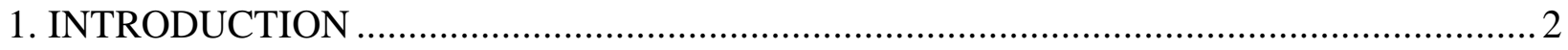

2. MSRE ACB VACUUM SYSTEM MODEL DESCRIPTION .......................................... 3

3. SIMULATION MODEL RESULTS .................................................................. 6

3.1 - Case 1 - Base Model Approaching Steady State Booster Gas Flow........................ 7

3.3 - Case 3 - Base Model, 5-Second Purge Gas Transient from Steady State Booster Gas

Flow Condition, Total Flow into Cyclone Separator Remains Constant ............. 12

3.4 - Case 4 - Base Model, 5-Second Purge Gas Transient from Steady State Booster Gas

Flow Condition; Maximum Booster and Purge Gas Flow ............................... 15

3.5 - Case 5 - Base Model without PCV4, 5-Second Purge Gas Transient from Steady

State Booster Gas Flow Condition, Total Flow into Cyclone Separator Remains

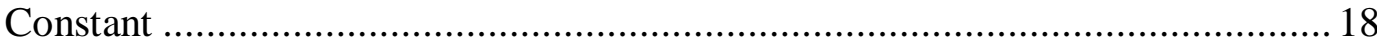

3.6 - Case 6 - Base Model without PCV4, 5-Second Purge Gas Transient from Steady

State Booster Gas Flow Condition; Maximum Booster and Purge Gas Flow ..... 21

3.7 - Case 7 - Base Model without PCV4, 5-Second Purge Gas Transient from Steady

State Booster Gas Flow Condition, Total Flow into Cyclone Separator Remains

Constant - Maximum Booster and Purge Gas Flow is 35.3 SCFM.................... 24

3.8 - Case 8 - Base Model without PCV4, 5-Second Purge Gas Transient from Steady

State Booster Gas Flow Condition; Maximum Booster and Purge Gas Flow -

Maximum Booster and Purge Gas Flow is 35.3 SCFM. .................................. 27

3.9 - Case 9 - Base Model without PCV4, 5-Second Purge Gas Transient from Steady

State Booster Gas Flow Condition; Maximum Booster and Purge Gas Flow -

Maximum Booster and Purge Gas Flow is 35.3 SCFM; Control Valves Replaced

with Low Pressure Drop Ball Valves; Cold Tap Cv $=2.3$. ............................ 30

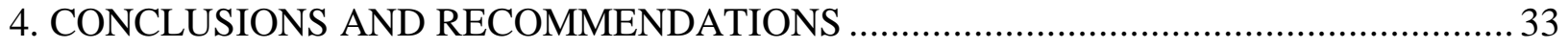

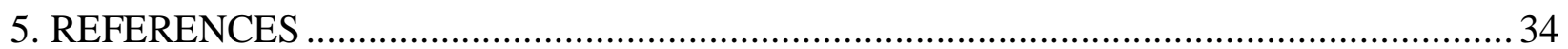

APPENDIX A - DERIVATION OF EQUATIONS USED IN THE VACUUM SYSTEM

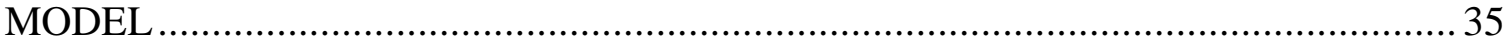

A.1 - Inlet Flow Controlled by Flow Controller.................................................... 35

A.3 - Inlet Flow Controlled by a Valve ................................................................. 38

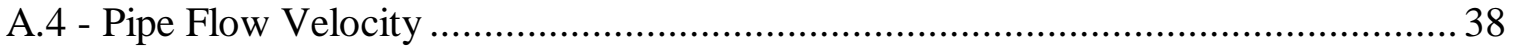

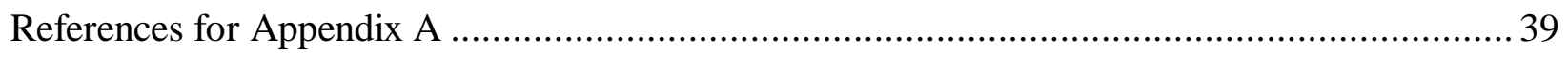


APPENDIX B - ACSL MODEL LISTING

40 


\section{LIST OF FIGURES}

Figure 1. A simplified representation of the ACB vacuuming system........................................2

Figure 2. Schematic representation of the MSRE Auxiliary Charcoal Bed Vacuum System......... 4

Figure 3. Flow characteristics of the Rotron Model DR 707 regenerative blower.........................5

Figure 4. Flow characteristics of the Nupro 8B Series Bellows Sealed Valve. .............................. 6

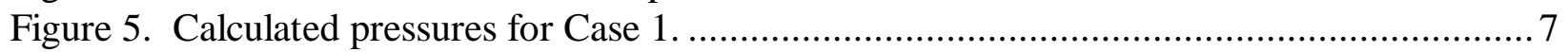

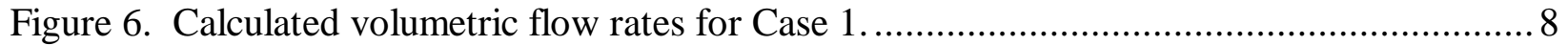

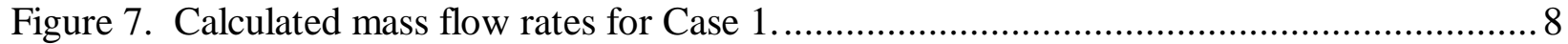

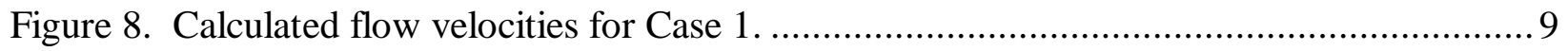

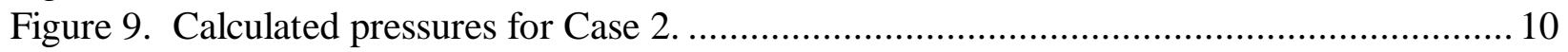

Figure 10. Calculated volumetric flow rates for Case 2...................................................... 10

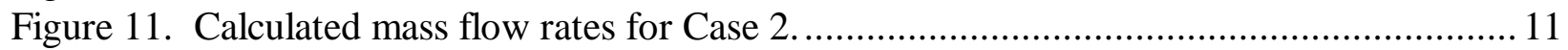

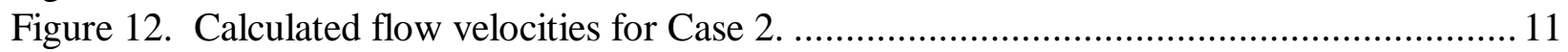

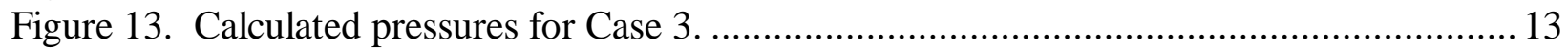

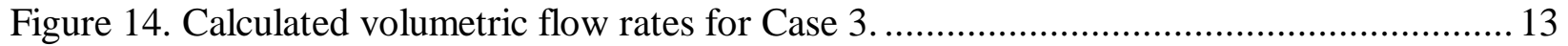

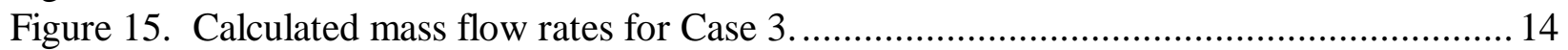

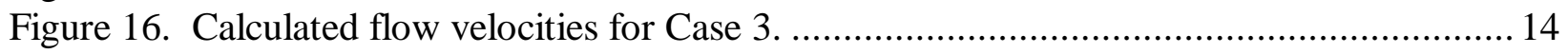

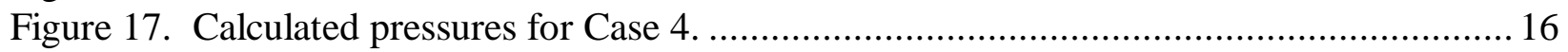

Figure 18. Calculated volumetric flow rate for Case 4........................................................ 16

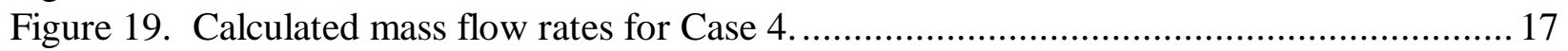

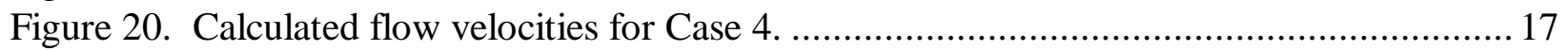

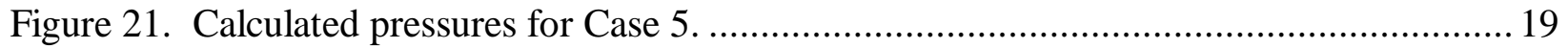

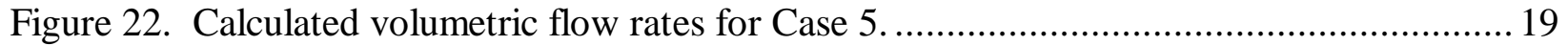

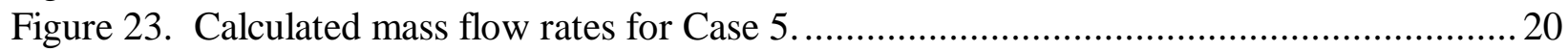

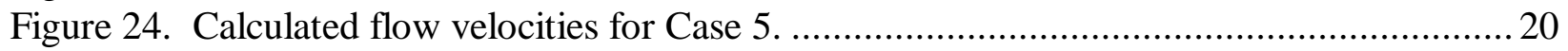

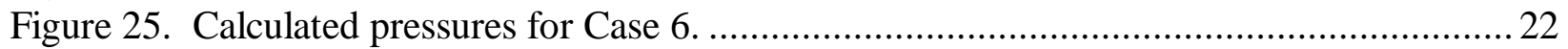

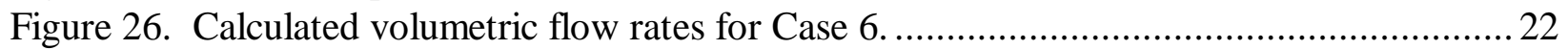

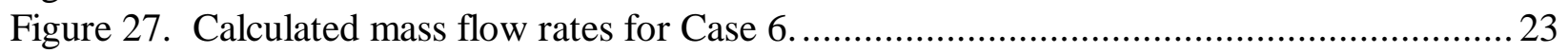

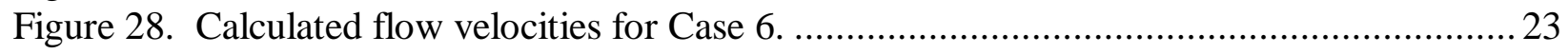

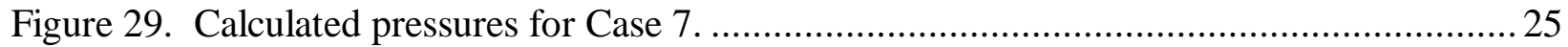

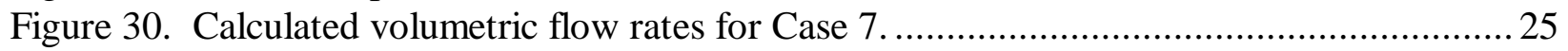

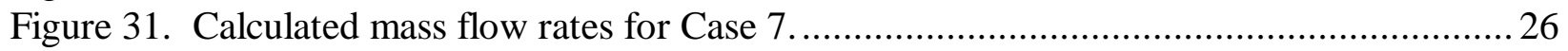

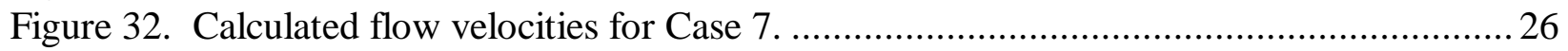

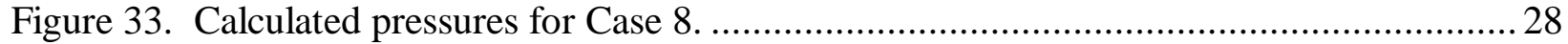

Figure 34. Calculated volumetric flow rates for Case 8 ...................................................... 28

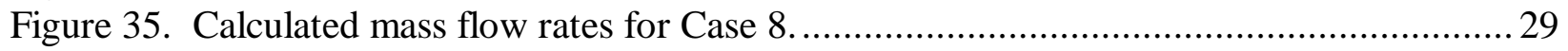

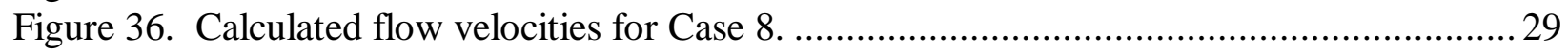

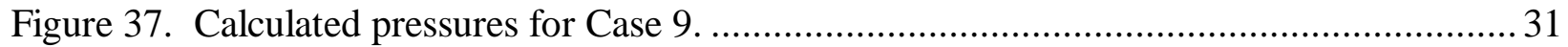

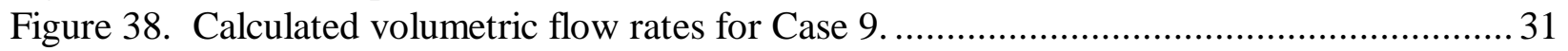

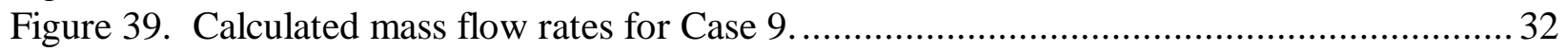

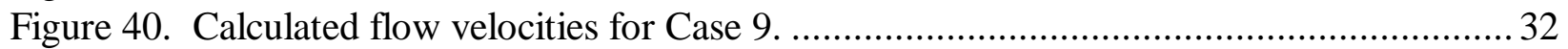

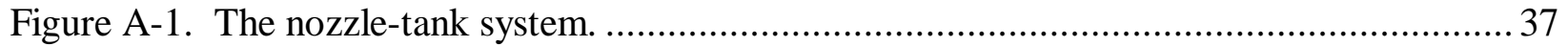




\section{LIST OF TABLES}

Table 1. Summary of the Division of the Vacuum System into Model Volumes ........................5 


\begin{abstract}
The simulation of the Auxiliary Charcoal Bed (ACB) Vacuum System was performed to evaluate the original vacuum system design, detect and identify design deficiencies, investigate the effects of proposed corrections on system performance, and generally aid in refining the system design before construction and mockup testing. The simulation was performed by using the Advanced Continuous Simulation Language (ACSL). ${ }^{1}$ The vacuum system design goals are to provide approximately 20 SCFM of both booster gas and purge gas through the system and maintain a flow of approximately $40 \mathrm{SCFM}$ with a velocity of 50 to $75 \mathrm{f} / \mathrm{sec}$ at the entrance to the cyclone separator.
\end{abstract}

The model results showed that the original system design was incapable of meeting the system performance goals. Further simulations showed that the following modifications to the original vacuum system design were required to make the system performance acceptable;

1) Remove valve PCV4.

2) Modify the flow controllers FTC3 and FTC4 from the original flow range of 0 - 17.6 SCFM (0 - 500 SLM) to 0 - 35.3 SCFM (0 - 1000 SLM).

3) Replace the bellows sealed valves SV-1, SV-3A, SV-3B, SV-4A, and SV-4B with less restrictive ball valves.

The simulation results saved considerable time and effort by identifying flaws in the original system design. Early identification of these flaws and the use of the simulation model to investigate possible solutions allowed corrective modifications to be made before construction of the mock up test facility. 


\section{INTRODUCTION}

A simulation of the Auxiliary Charcoal Bed (ACB) Vacuum System was performed to evaluate the original vacuum system design, detect and identify design deficiencies, investigate the effects of proposed corrections on system performance, and generally aid in refining the system design before construction and mockup testing. The simulation was performed by using the Advanced Continuous Simulation Language (ACSL). ${ }^{1}$ The movement of charcoal from the auxiliary charcoal bed was not included in the model. The vacuum system design goals are to provide approximately 20 SCFM of both booster gas and purge gas through the system and maintain a flow of approximately $40 \mathrm{SCFM}$ with a velocity of 50 to $75 \mathrm{ft} / \mathrm{sec}$ at the entrance to the cyclone separator.

This report describes the simulation model, presents the simulation model results, and gives recommendations concerning design changes to the original vacuum system design. A diagram of the ACB vacuum system showing the main components is shown in Figure 1. The vacuum system consists of three branches; gas enters the system through two branches and exits through the third. Booster gas enters the first branch from a gas manifold (modeled as a constant pressure source), passes through control valve FTC4, and joins the second leg. One inch schedule 40 pipe is used in this branch. Gas enters the second branch from another, separate, gas manifold, (again modeled as a constant pressure source), passes through control valve FTC3, and passes through the auxiliary charcoal bed before joining the first leg. One half inch schedule 40 pipe is used in the second branch from the gas manifold to the charcoal bed. One inch schedule 40 pipe is used from the charcoal bed to the junction with the first branch. The third branch begins at the junction of the first and second branches, passes through the cyclone separator, a HEPA filter, through

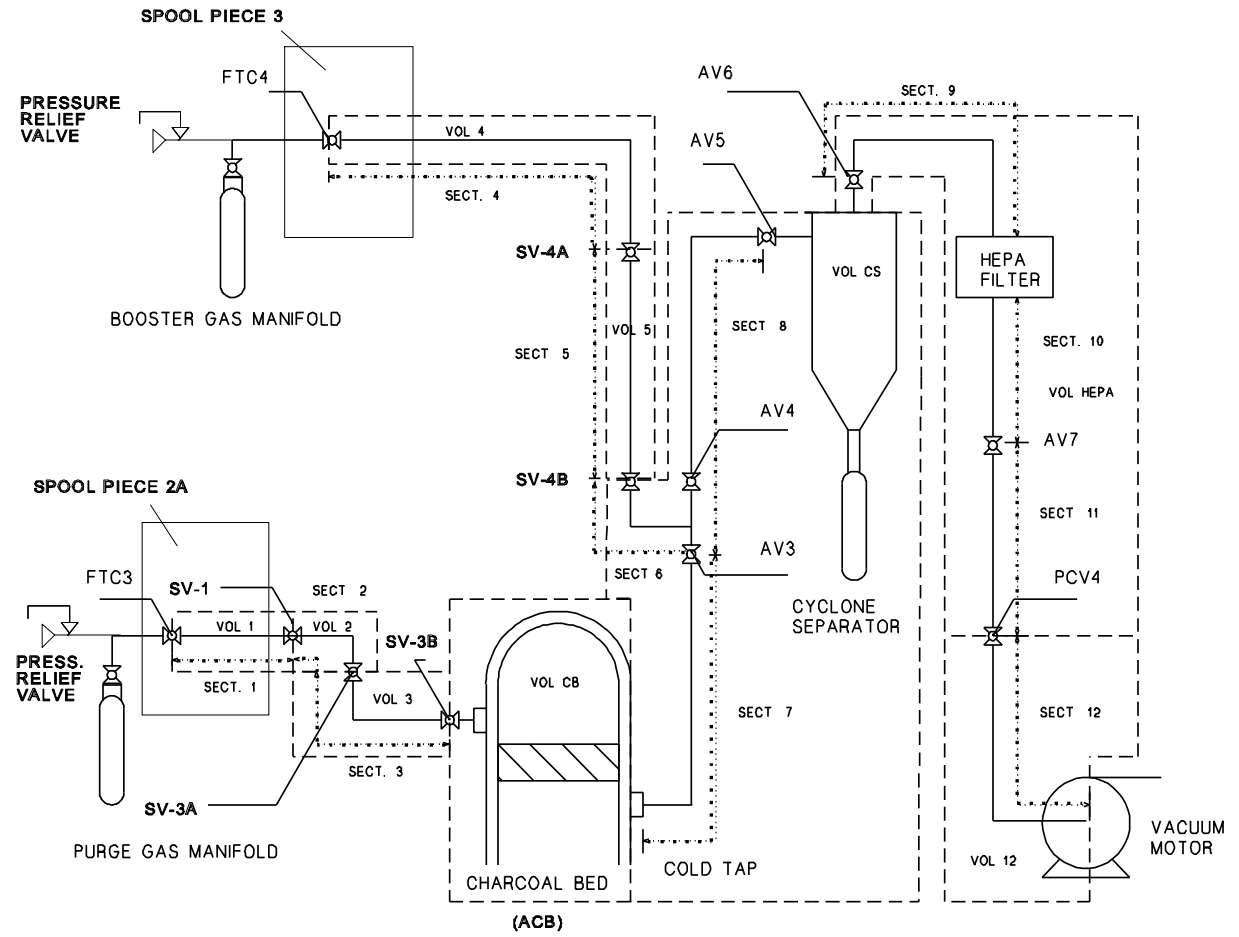


control valve PCV4, and exits the system through a vacuum motor, which is modeled as a constant pressure sink. One and one half inch schedule 40 pipe is used in the third branch up to the cyclone separator; two inch schedule 40 pipe is used in the remainder of the second branch.

The system is tentatively planned to be used in a pulsed mode. Booster gas will be flowing at steady-state conditions through the first and third branches. The booster gas provides a constant flow to sweep out the system and supplies the cyclone separator with a minimum flow. Control valve FTC3 will be momentarily opened, sending a pulse of gas through the charcoal bed. This gas pulse is anticipated to sweep some charcoal out of the charcoal bed and transport it past the junction of the first and second branches, where the booster gas will transport it to the cyclone separator. In the separator, the charcoal will be spun out of the gas flow, which will then pass through the HEPA filter before leaving the system. The pulsed mode of operation allows the deposition of radioactive material to be closely monitored.

The equations used to model the flow through the system are given in Appendix A. A model/system description is given in Section 2 and results for nine simulations are presented in Section 3. Conclusions and vacuum system modification recommendations based on the simulation results are presented in Section 4.

\section{MSRE ACB VACUUM SYSTEM MODEL DESCRIPTION}

The ACB vacuum system is modeled by a series of connected nozzle/tank modules. A schematic of the vacuum system model is shown in Figure 2. The system is divided into nine separate volumes, each modeled by a nozzle/tank, flow controller/tank, or valve/tank module. The main volumes are the charcoal bed, the cyclone separator, and the HEPA filter. Other volumes represent pipe lengths between the main volumes. Note that the model section numbers shown in Figure 2 are also indicated in Figure 1 to clearly identify the division of the vacuum system for modeling.

Booster gas enters through flow control controller FTC4, passes through pipe sections 4 and 5 and mixes with the gas exiting the second branch in pipe section 6. Pipe sections 4 and 5 are separated by valve SV-4A and pipe sections 5 and 6 are separated by valve SV-4B.

Purge gas enters through flow controller FTC3, passes through pipe sections 1, 2, and 3, and enters the auxiliary charcoal bed. Pipe sections 1 and 2 are separated by valve SV-1, pipe sections 2 and 3 are separated by valve SV-3A, and pipe section 3 and the ACB are separated by valve SV-3B. The flow passes through the auxiliary charcoal bed, the cold tap, and pipe section 7 before mixing with the booster gas at the junction of pipe sections 6,7 , and 8 .

After mixing, the flow passes into the cyclone separator where the entrained charcoal is spun out of the gas flow, which then passes through pipe section 9 before entering the HEPA filter. After leaving the HEPA filter, the flow passes through pipe sections 10 and 11, pressure control valve PCV4, pipe section 12, and exits the system through the vacuum motor. Pipe sections 11 and 12 
are separated by valve PCV4; the vacuum motor is assumed to discharge to constant conditions $P_{0}, T_{0}$, and $?_{0}$. The division of the vacuum system into volumes is summarized in Table 1.

There are three types of tank volumes used in the model. In the first tank volume type, the flow into the tank volume is controlled by a flow controller; the performance of each flow controller is specified in the ACSL model. In the second tank volume type, the flow into the tank volume is controlled by the flow characteristics of a valve upstream of the tank volume. Valves SV-1, SV3A, SV-3B, SV-4A, and SV-4B are size 8 Nupro B Series Bellows Sealed Valves; during the simulation valve PCV4 was not specified but was assumed to have the same flow characteristics as the other valves. The valve flow characteristics are shown in Figure 3. In the third tank volume type, the flow into the tank volume is modeled as flow through an ideal nozzle; the nozzle

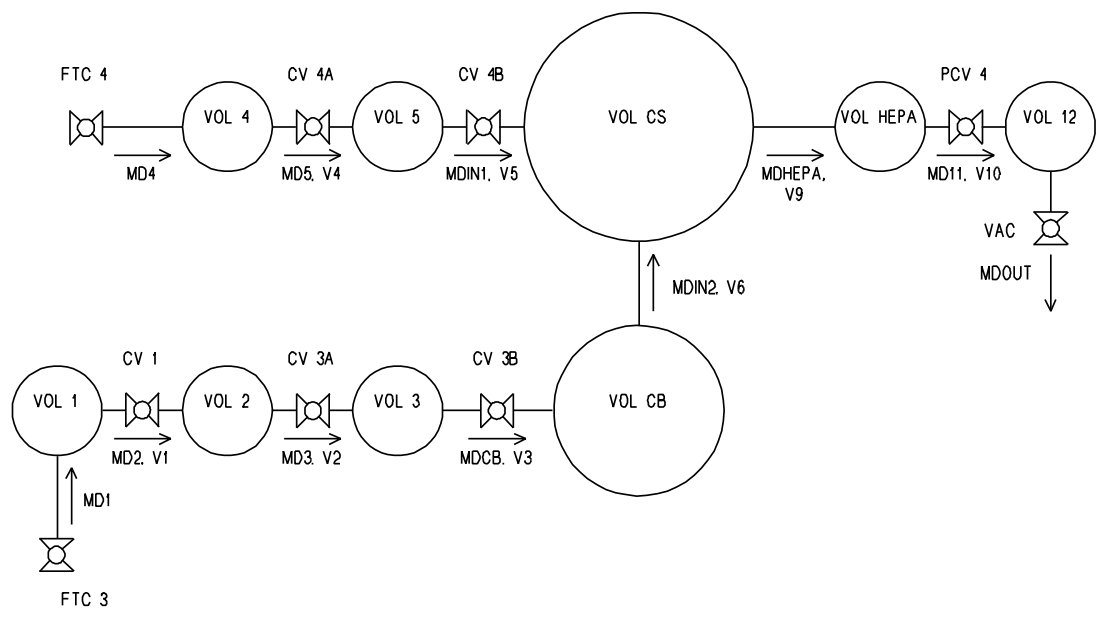

size is assumed equal to the pipe area at the tank volume inlet. Note that the cyclone separator volume is unique because it has two inlet flows; the booster gas flow is controlled by valve SV-4B and the purge gas flow enters from the ACB.

Table 1

Summary of the Division of the Vacuum System into Model Volumes

\begin{tabular}{|c|c|c|c|}
\hline Volume Name & Tank Volume Type & Inlet Flow Controlled by & Physical Volumes \\
\hline 1 & 1 & FTC3 & Volume of pipe section 1 \\
\hline 2 & 2 & SV-1 & Volume of pipe section 2 \\
\hline
\end{tabular}




\begin{tabular}{|c|c|c|c|}
\hline 3 & 2 & SV-3A & Volume of pipe section 3 \\
\hline $\begin{array}{c}\text { Auxiliary Charcoal } \\
\text { Bed (ACB) }\end{array}$ & 2 & SV-3B & $\begin{array}{c}\text { Volume of ACB and the pipe } \\
\text { volume from SV-3B to the ACB }\end{array}$ \\
\hline 4 & 1 & FTC4 & Volume of pipe section 4 \\
\hline 5 & $2 \& 3$ & SV-4A & Volume of pipe section 5 \\
\hline $\begin{array}{c}\text { Cyclone Separator } \\
\text { (CS) }\end{array}$ & 3 & SV-4B \& Nozzle & $\begin{array}{c}\text { Volume of pipe sections 6, 7, 8 } \\
\text { and the cyclone separator volume. }\end{array}$ \\
\hline $\begin{array}{c}\text { HEPA Filter } \\
\text { (HEPA) }\end{array}$ & 2 & Nozzle & $\begin{array}{c}\text { Volume of pipe sections 9, 10, 11 } \\
\text { and the HEPA filter volume. }\end{array}$ \\
\hline 12 & PCV4 & Volume of pipe section 12. \\
\hline
\end{tabular}

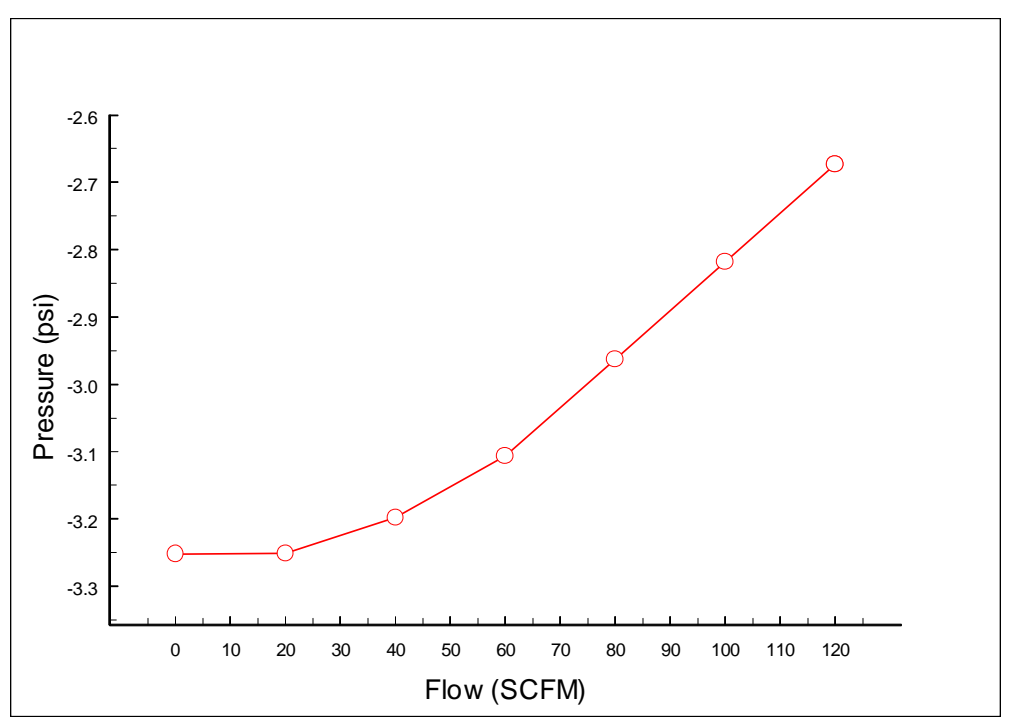

The vacuum motor located at the exit of volume is a Rotron Model Dr 707 regenerative blower. The flow characteristics of this blower are shown in Figure 4. The flow exiting volume 12 is calculated from the pressure drop across the blower. The ACSL code that implements the model is listed in Appendix B. 


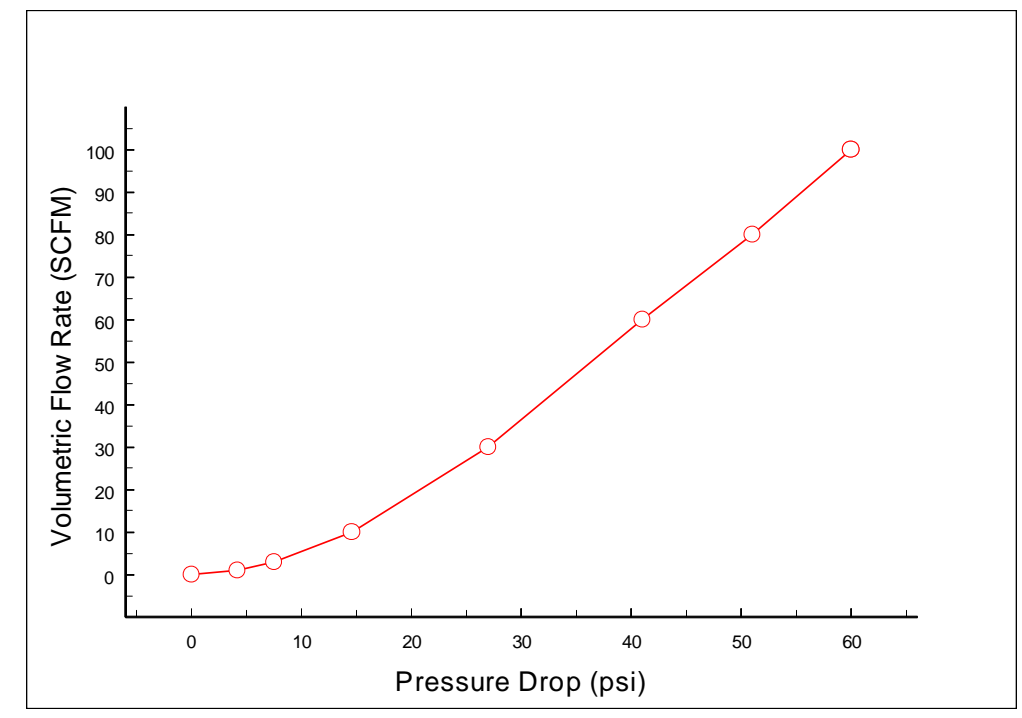

\section{SIMULATION MODEL RESULTS}

This section presents the simulation model results. It was found that the set of equations describing the vacuum system performance was relatively "stiff" and required the use of the Gear's Stiff integration routine, an integration routine particularly suited for stiff systems. Stiff systems occur when the system matrix relating system input to system output is nearly singular. Such systems are characterized by a wide range of time constants which can result in constant step size integration algorithms, such as fourth-order Runge-Kutta, to become unstable. The source of this difficulty appears to be the wide range of system volumes; the pressures and flows associated with the smaller volumes have rapid response times while the pressures and flows associated with the larger volumes respond relatively slowly.

The Gear's Stiff algorithm uses variable size time steps. By using small time steps during rapid transients and larger time steps after these transients have died out, an accurate solution can be obtained efficiently. This routine requires the user to specify the accuracy of the integration algorithm; the values selected represent a compromise between accuracy and computation time. This compromise is evident in the mass flow rate and volumetric flow rate results, which are not always "smooth". The overall results are believed to represent the overall behavior of the vacuum system. The pressures of each volume, the volumetric flow rates, the mass flow rates, and the flow velocities are shown for each case. The descriptions of each case and their results are given in this section.

\section{1 - Case 1 - Base Model Approaching Steady State Booster Gas Flow}

The first case shows the approach to steady state with the booster gas flow at 17.66 SCFM and 
the purge gas flow at zero and was performed to examine the original system performance. Valves FTC3, FTC4, and PCV4 are initially closed. The initial pressure in each volume is 14.7 psia, the initial temperature is 530 degrees R. Valve FTC4 begins opening at $t=0 \mathrm{sec}$., and opens linearly to full open over a time period of 2.0 seconds. Valve PCV4 begins opening at $t=0$ seconds, and opens linearly to full open over a time period of 1.0 seconds. The simulation is continued for 50 seconds. The results are shown in Figures 5, 6, 7, and 8.

The pressures, volumetric flow rates, mass flow rates, and velocities increase smoothly and approach their steady state values at approximately $t=50$ seconds. The main part of the system (Volumes CB, CS, and HEPA) have a steady state operating pressure of approximately 34 psia. Note the unacceptably high pressure of nearly 50 psia in Volume 4 (P4). Pressure of this magnitude may result in the operation of the 65 psig relief valve in spool piece SP3 (the pressure upstream of FTC4 will be 10 to 40 psi greater than P4). This high inlet pressure is caused by the relatively large pressure drops across valves SV-4A, SV-4B, and PCV4.

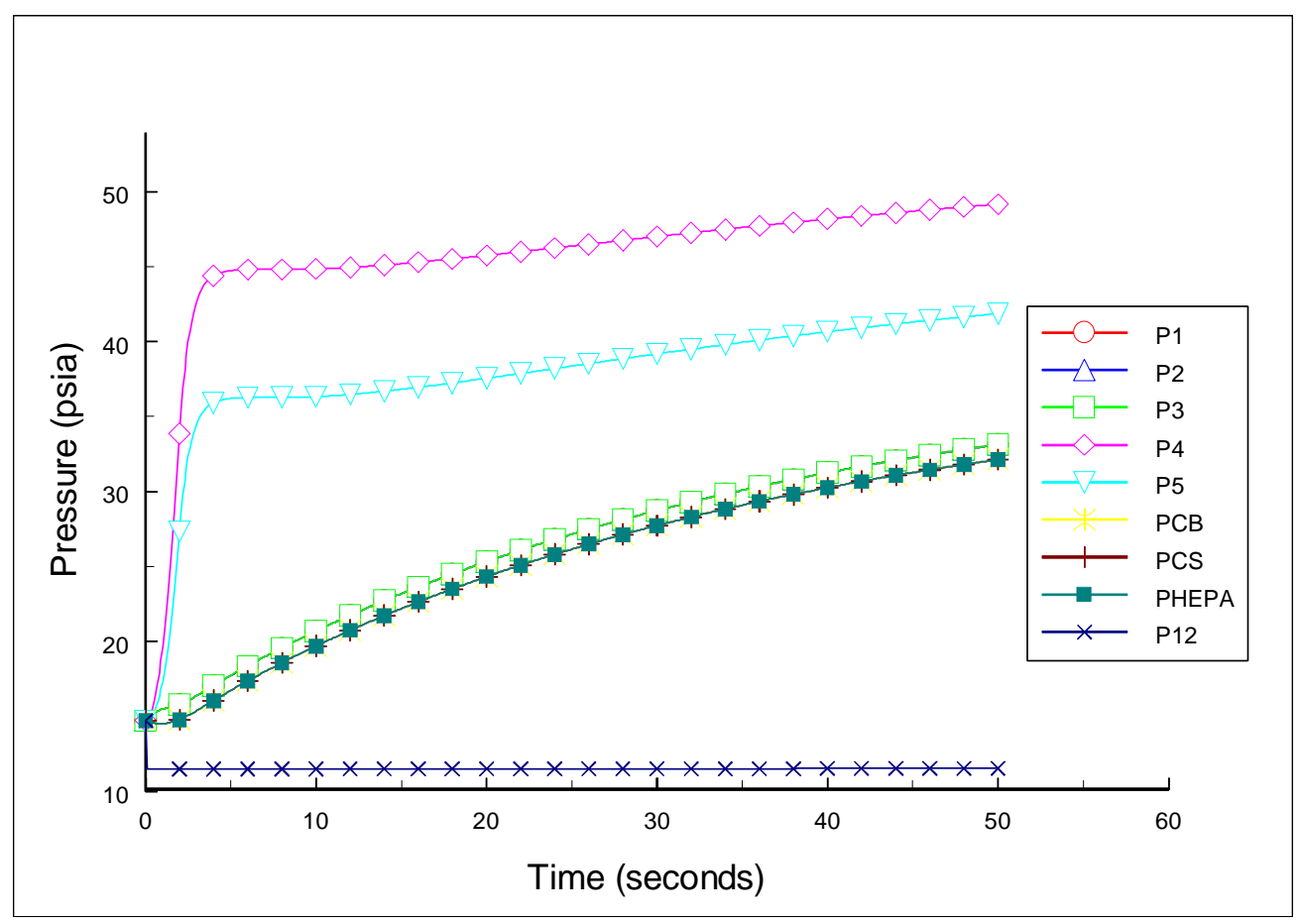



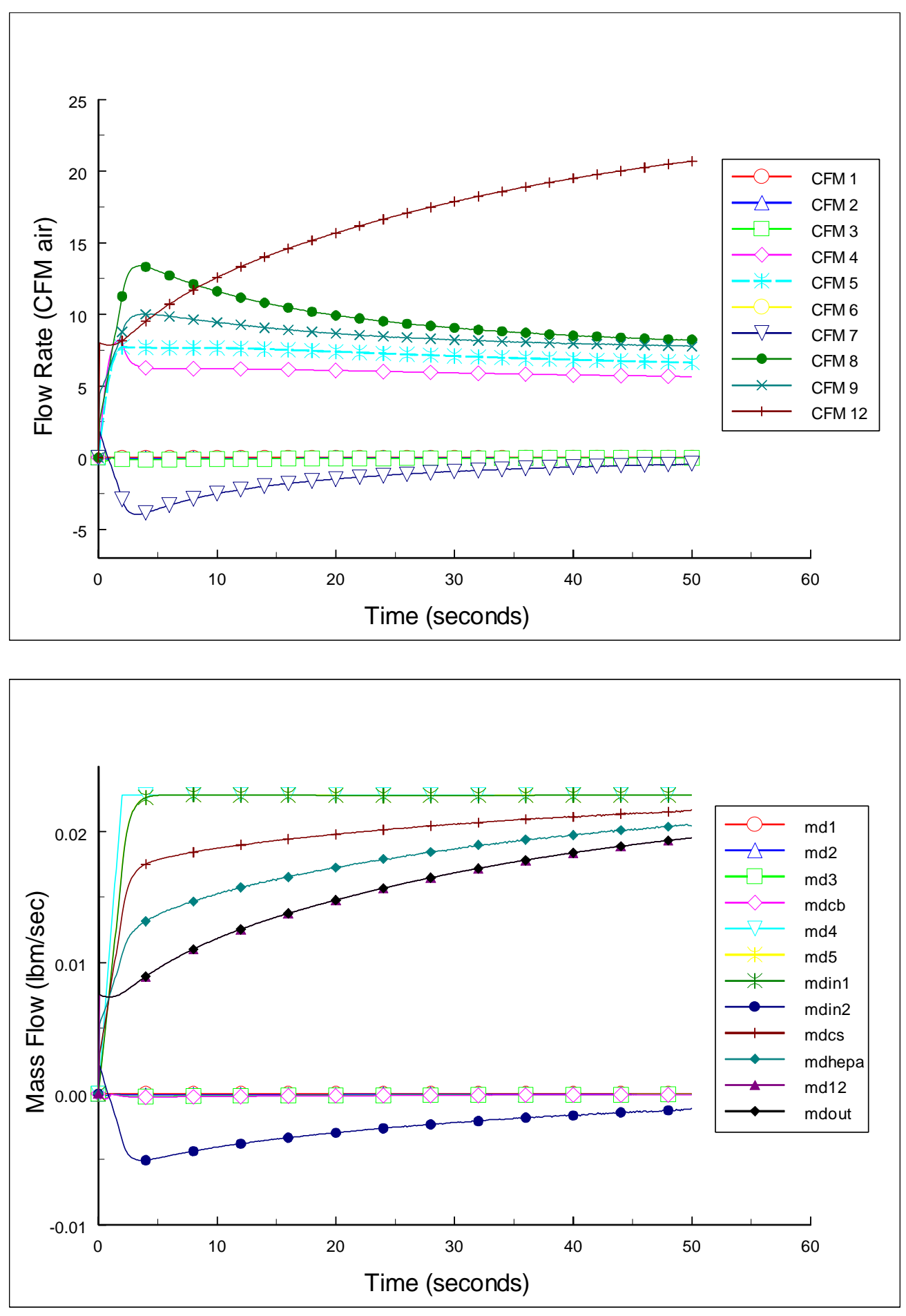


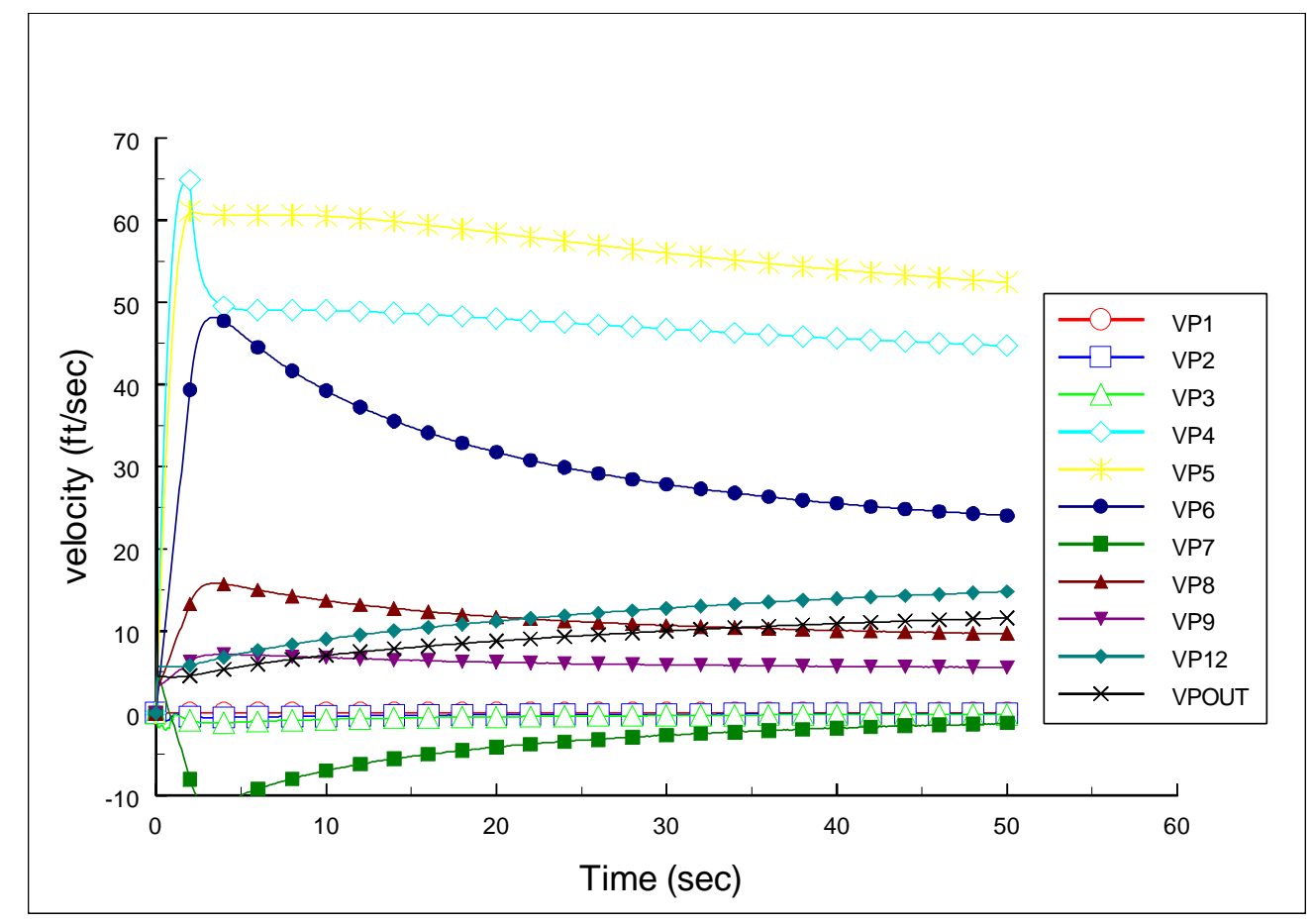

3.2 - Case 2 - Base Model without PCV4 Approaching Steady State Booster Gas Flow

Case two investigates the effect of removing PCV4 on system performance. The results are shown in Figures 9, 10, 11, and 12. The pressures, volumetric flow rates, mass flow rates, and velocities increase smoothly and approach their steady state values at approximately $t=4$ seconds, a considerable improvement in system response time. The system pressures have been reduced by the pressure drop that occurred across PCV4 in Case 1; the steady state value of P4 has been reduced from 50 psia to 45 psia. Thus, removing PCV4 reduces the system pressure and reduces time required for the system to reach steady state. 

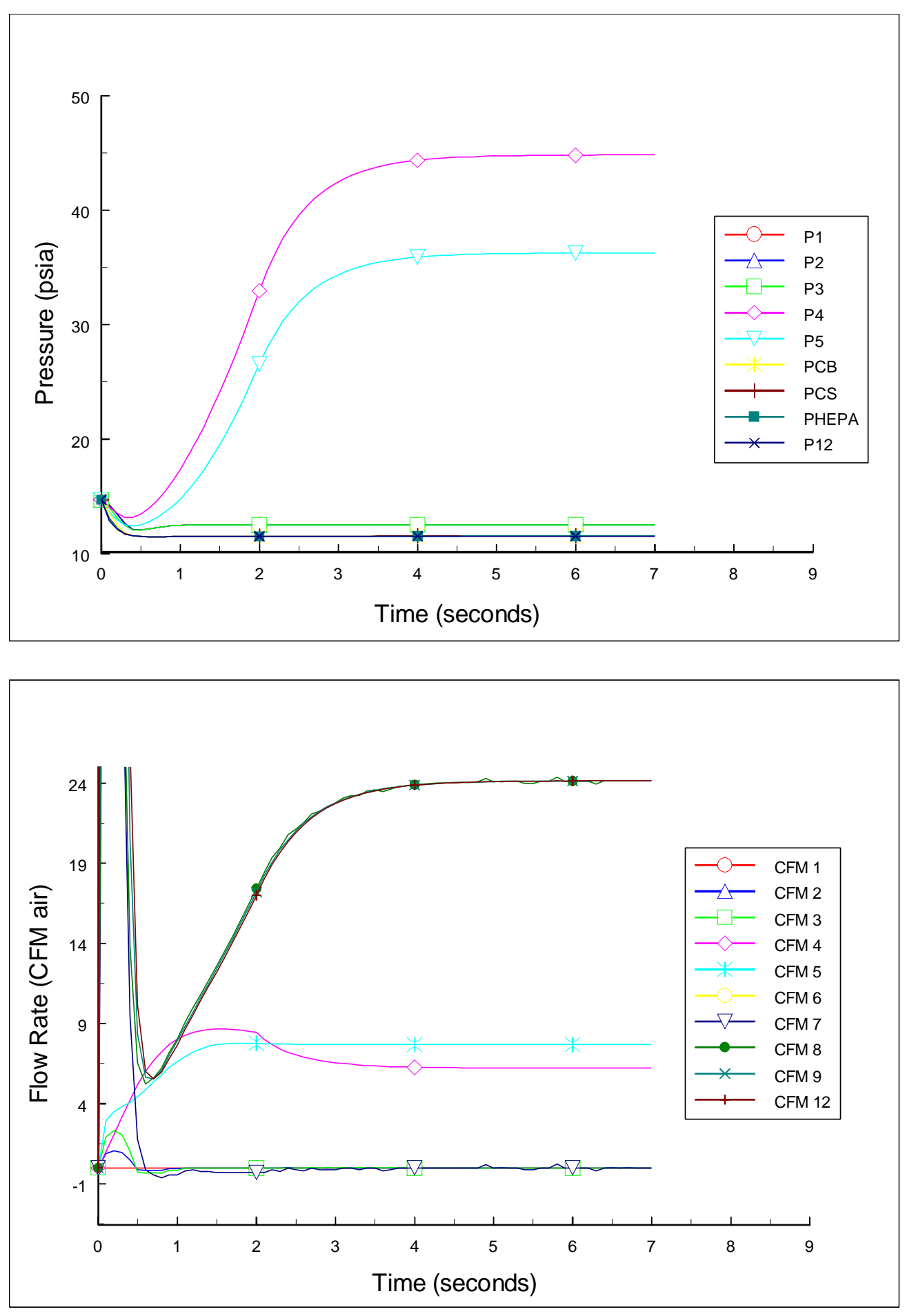

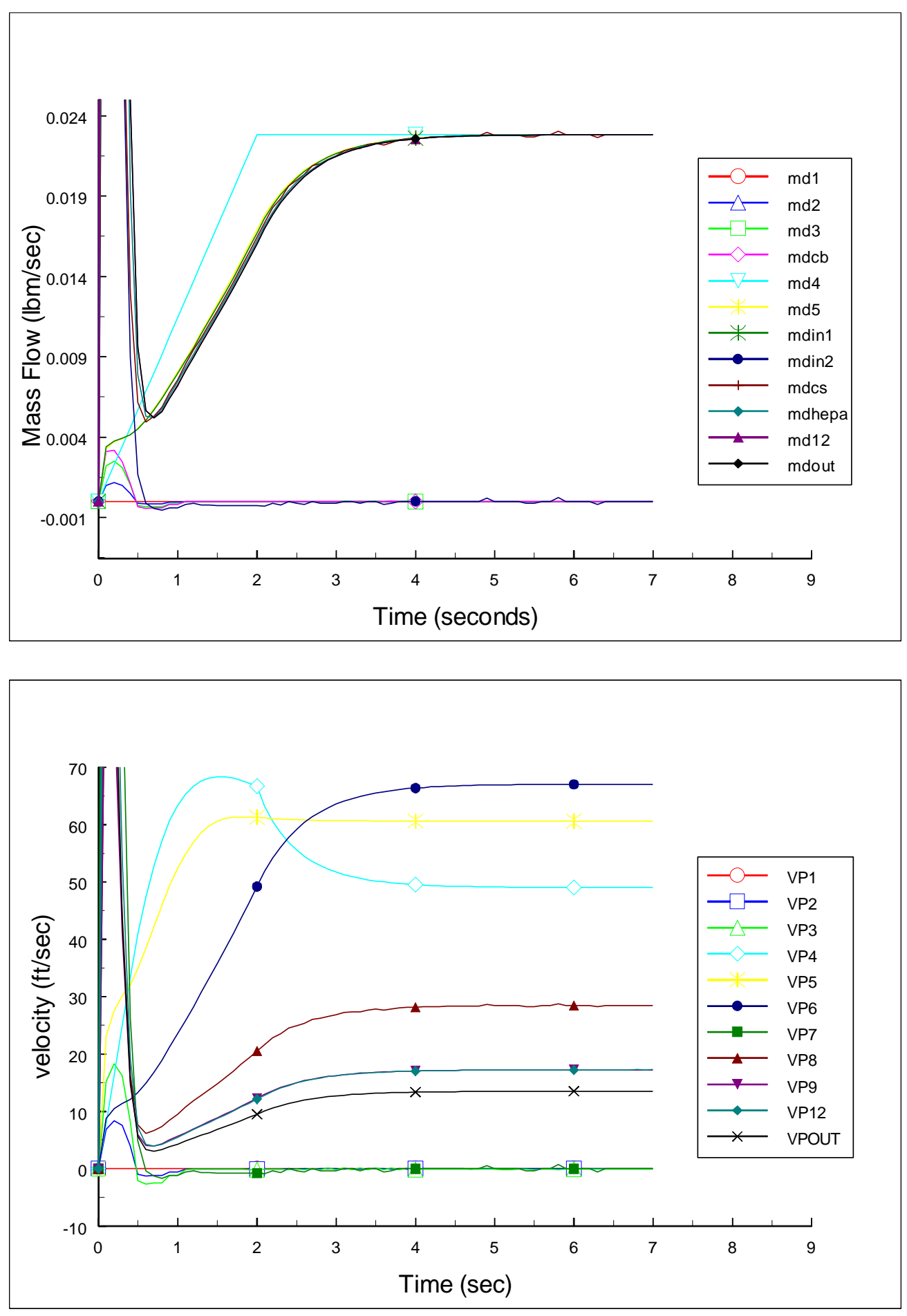

3.3 - Case 3 - Base Model, 5-Second Purge Gas Transient from Steady State Booster Gas Flow Condition, Total Flow into Cyclone Separator Remains Constant

Case three simulates operating the system with a constant flow of 17.65 SCFM through the 
cyclone separator. A 5 second purge gas transient starts after the booster gas flow has reached a steady state. Valve FTC3 begins opening at $t=50$ seconds and opens linearly to half open over a period of 0.5 seconds, resulting in a flow of 8.83 SCFM into Volume 1. Valve FTC4 closes to half open while FTC3 opens to maintain a constant flow through the cyclone separator. Valve FTC3 begins closing at $t=55$ seconds and closes linearly over a period of 0.5 seconds. Valve FTC4 opens while FTC4 closes to maintain a constant flow into the cyclone separator. The results are shown in Figures 13, 14, 15, and 16.

Figure 13 shows the pressure in Volume $1(P 1)$ rising to approximately 40 psia over a 2 second period during the flow transient. Pressures downstream from Volume 1 ( $P 2, P 3, P C B)$ show smaller magnitude pressure increases (determined by the pressure drops across valves $\mathrm{SV}-1, \mathrm{SV}$ 3A, and SV-3B) which lag the pressure increase of Volume 1. The steady state pressure of Volume $4(P 4)$ is approximately 48 psia. The decay back to the pre-transient conditions also takes approximately 2 seconds.

The volumetric flow rate and mass flow rates show similar transient behavior (Figures 14 and 15). The flow into Volumes 1 and 4 (CFMI and CFM4) show the modeled flow controller response of a .5 second ramp between initial and final set points. The flow rates downstream of the flow controllers show approximately a 2 second lag in their response. The flow exiting the ACB (CFM7 and mdin2) show a sharp rise initially after the transient and quickly roll off to their final values. The volumetric flow rate through the ACB remains relatively constant at approximately 8.5 CFM.

Figure 16 shows the flow velocities. Note that the steady state flow velocity into the cyclone separator (VP8) is only approximately $10 \mathrm{ft} / \mathrm{sec}$ and remains relatively constant during the transient.

These results show that the desired flow conditions of approximately 40 CFM entering the cyclone separator with a velocity of 50 to $75 \mathrm{ft} / \mathrm{sec}$ will not be met by this system under the flow conditions described in Case 3. In addition to not meeting the flow conditions, the inlet pressures may exceed the cracking pressure of the pressure relief valves in spool piece SP2A. 

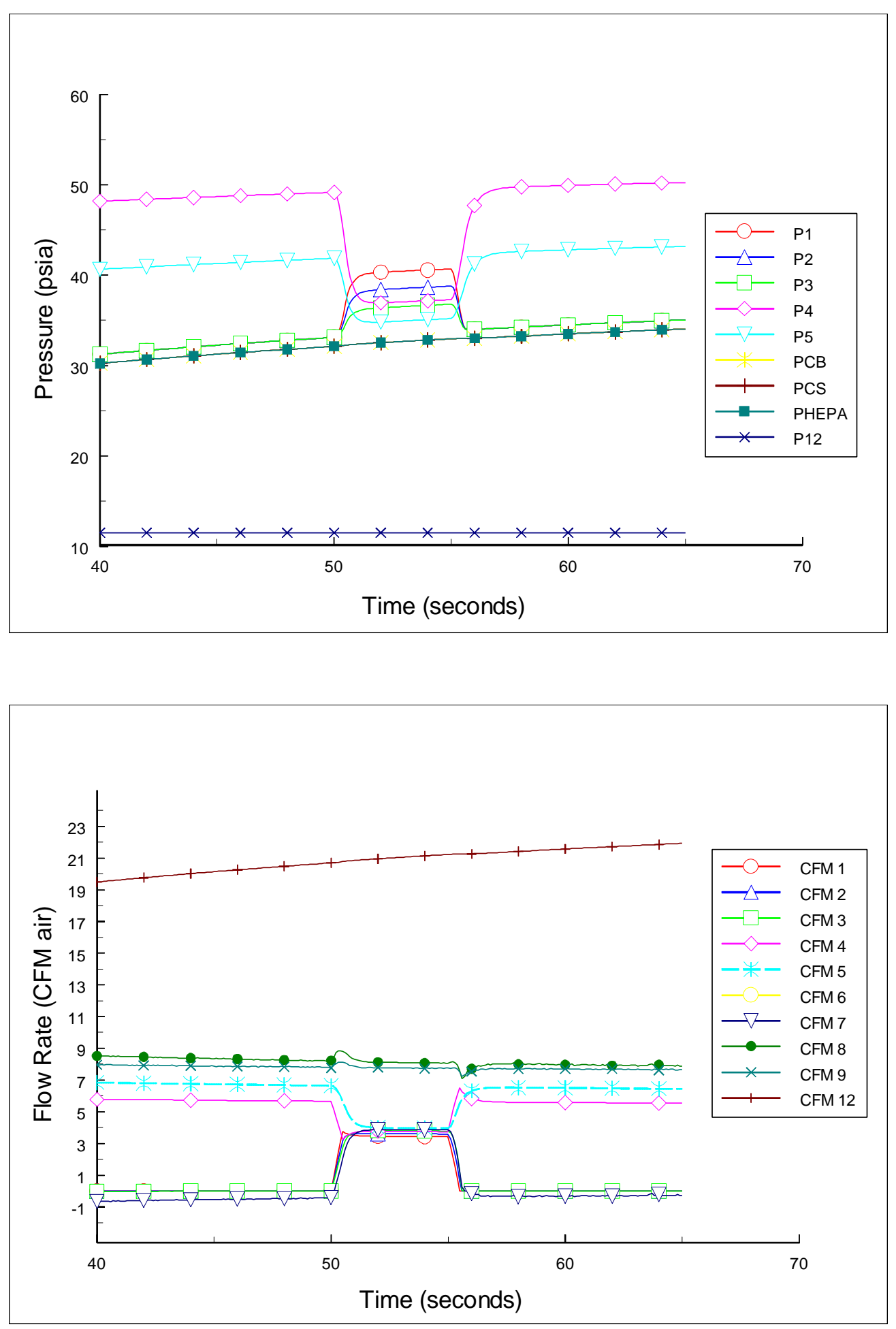


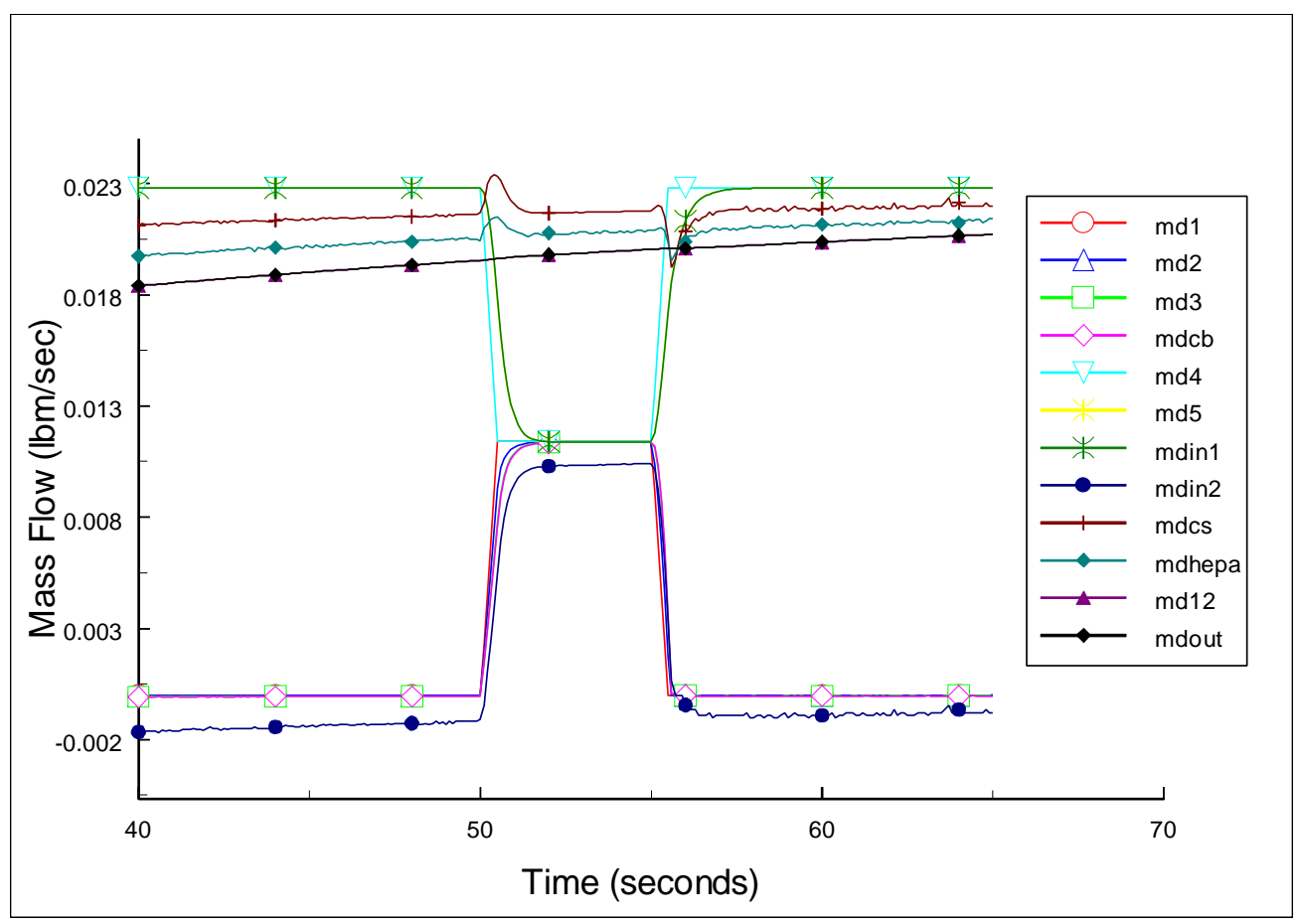




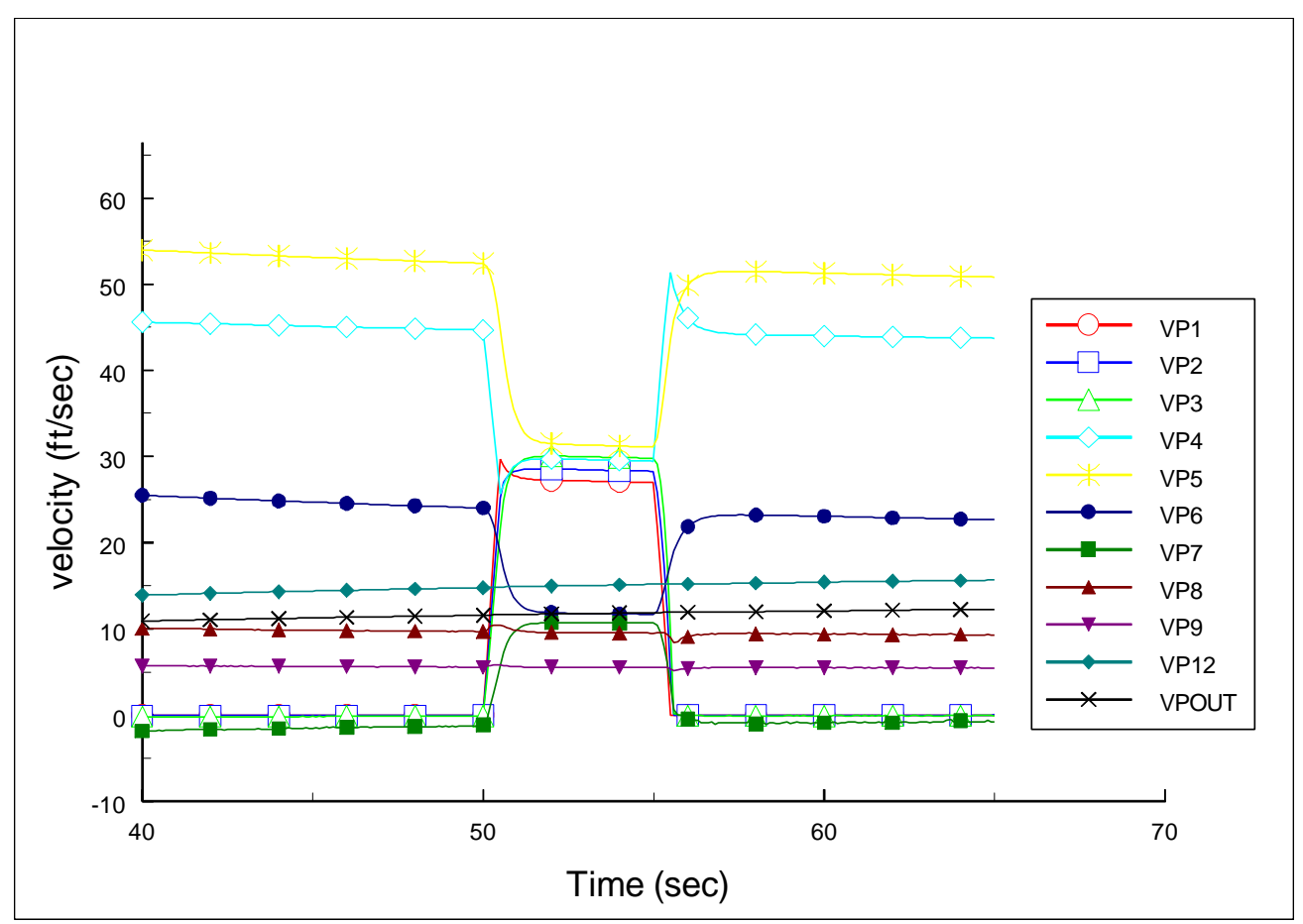

\section{4 - Case 4 - Base Model, 5-Second Purge Gas Transient from Steady State Booster Gas Flow Condition; Maximum Booster and Purge Gas Flow}

Case four simulates operating the original system with maximum booster and purge gas flow. The fourth case consists of a 5 second purge gas transient begun after the booster gas flow has reached a steady state. Valve FTC3 begins opening at $t=50$ seconds and opens linearly to full open over a period of 0.5 seconds, resulting in a flow of 17.66 SCFM into Volume 1. Valve FTC4 remains fully open during the transient. Valve FTC3 begins closing at $t=55$ seconds and closes linearly over a period of 0.5 seconds. The results are shown in Figures 17, 18, 19, and 20.

Figure 17 shows the pressure in Volume $1(P 1)$ rising to near 60 psia during the flow transient. Pressures downstream from Volume $1(P 2, P 3$, and $P C B)$ show smaller magnitude pressure increases (determined by the pressure drops across valves SV-1, SV-3A, and SV-3B) which lag the pressure increase of Volume 1. The pressure in the ACB remains increases by approximately 5 psi during the transient. Note that increasing the flow through FTC3 results in a 5 psi increase in $\mathrm{ACB}$ pressure during the transient compared to Case 2.

The volumetric flow rate and mass flow rates show similar transient behavior (Figures 18 and 19). Similar to Case 3, the flow into Volumes 1 and 4 show the modeled flow controller response of a .5 second ramp between initial and final set points. The flow rates downstream of the flow controllers show a 2 to 5 second lag in their response to the transient. The volumetric flow rate through the ACB (CFM7) experiences an initial sharp rise followed by a less-rapid increase, reaching a peak value of approximately $5 \mathrm{CFM}$ at the end of the transient; a longer transient would result in a greater peak flow rate through the ACB. Note that the flow entering the cyclone separator (CFM8 and $m d c s$ ) experiences a sharp increase because of the increased total 
flow through the system during the transient.

Figure 20 shows the flow velocities. The steady state flow velocity into the cyclone separator (VP8) is only approximately $10 \mathrm{ft} / \mathrm{sec}$ but in Case 4 increases to approximately $14 \mathrm{ft} / \mathrm{sec}$ during the transient.

These results show that the desired flow conditions of approximately 40 SCFM entering the cyclone separator with a velocity of 50 to $75 \mathrm{ft} / \mathrm{sec}$ will not be met by this system under the flow conditions described in Case 4. In addition to not meeting the flow conditions, the inlet pressures may exceed the cracking pressure of the pressure relief valves in spool pieces SP2A and SP3.

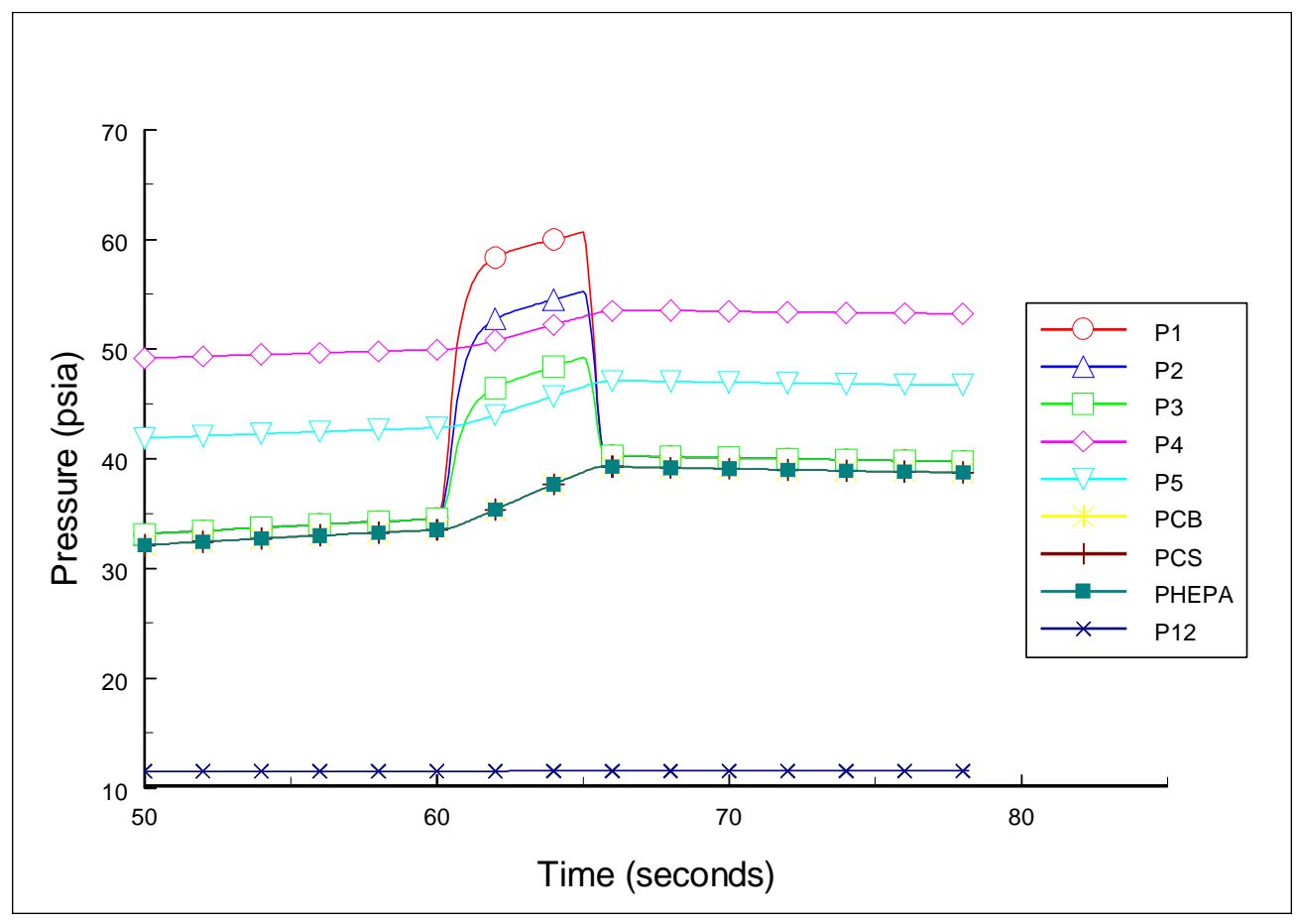



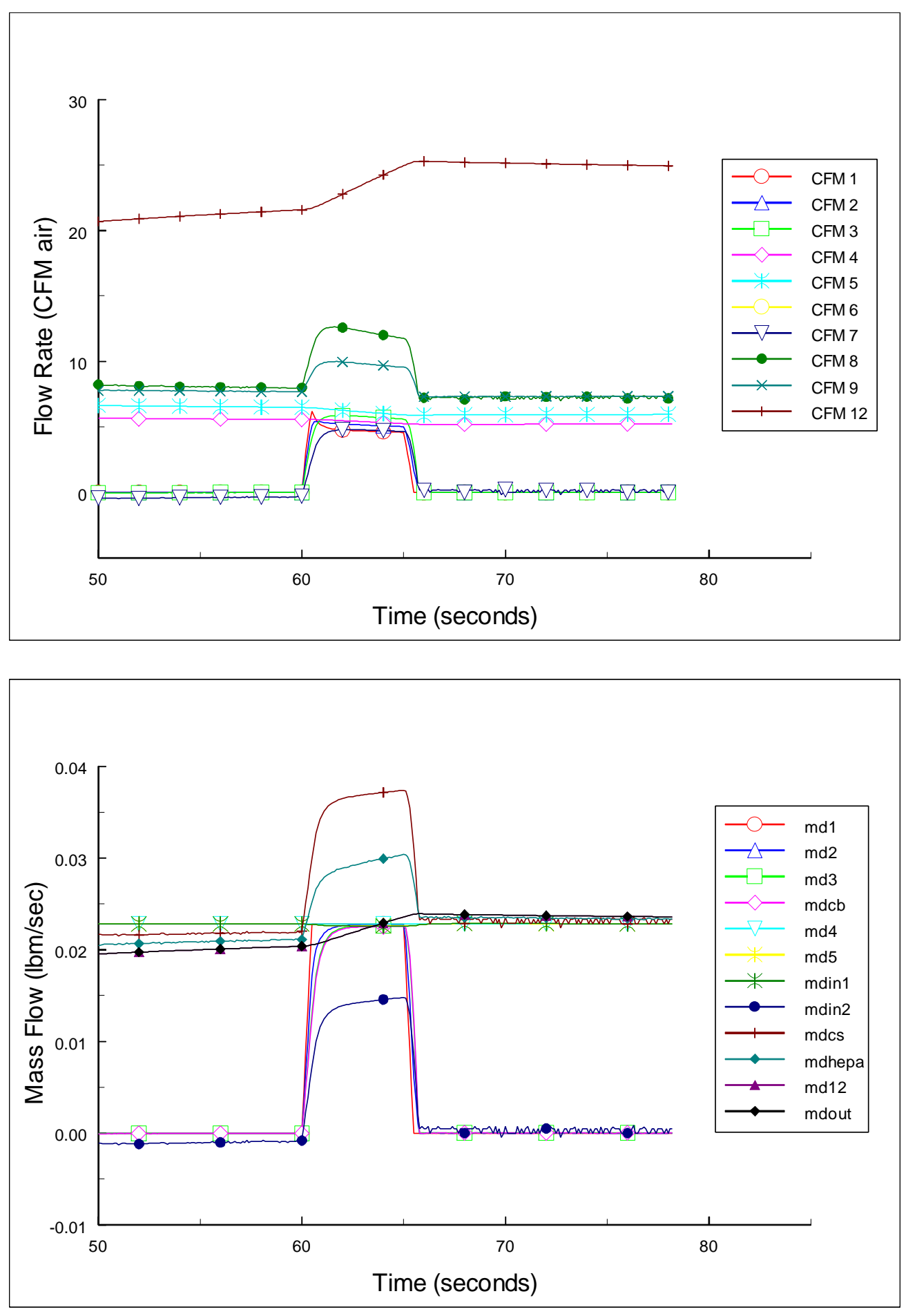


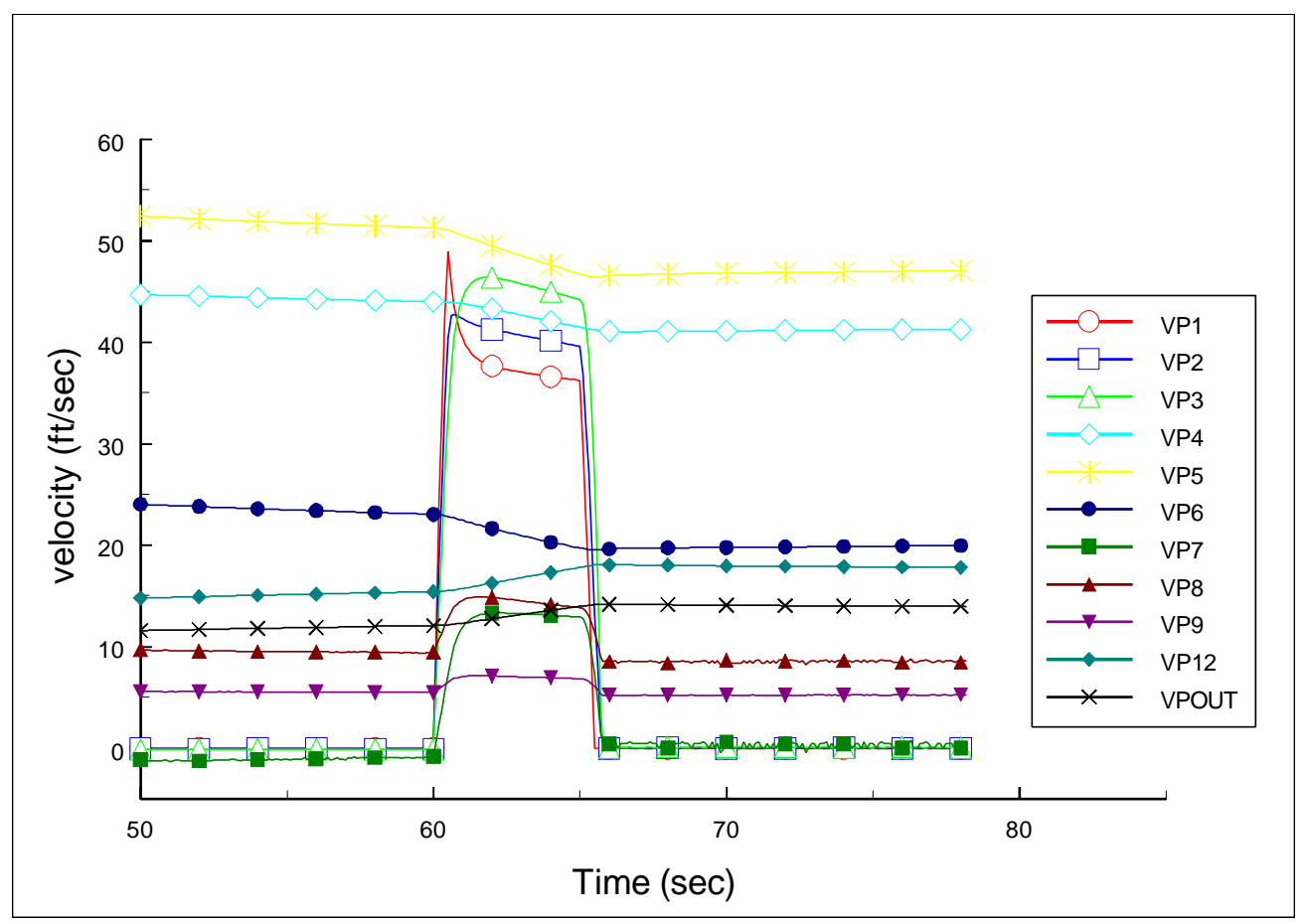

\section{5 - Case 5 - Base Model without PCV4, 5-Second Purge Gas Transient from Steady State Booster Gas Flow Condition, Total Flow into Cyclone Separator Remains Constant}

Case five investigates system performance without PCV4 while holding the total flow into the cyclone separator constant at 17.65 SCFM. A 5 second purge gas transient starts after the booster gas flow has reached a steady state. In Case 5, the total flow through the cyclone separator during the purge gas transient remains constant at 17.65 SCFM. Valve FTC3 begins opening at $t=15$ seconds and opens linearly to half open over a period of 0.5 seconds, resulting in a flow of 8.83 SCFM into Volume 1. Valve FTC4 closes while FTC3 opens to maintain a constant flow through the cyclone separator. Valve FTC3 begins closing at $t=20$ seconds and closes linearly over a period of 0.5 seconds. Valve FTC4 opens while FTC4 closes to maintain a constant flow into the cyclone separator. The results are shown in Figures 21, 22, 23, and 24.

Figure 21 shows the pressure in Volume $1(P 1)$ rising to approximately 27 psia during the flow transient, nearly 13 psi less than the maximum value of $P 1$ from Case 3 (an identical transient case with PVC4 in place). Pressures downstream from Volume $1(P 2, P 3, P C B)$ show smaller magnitude pressure increases (determined by the pressure drops across valves SV-1, SV-3A, and $\mathrm{SV}-3 \mathrm{~B}$ ) which lag the pressure increase of Volume 1 . The steady-state value of pressure $P 4$ is approximately 45 psia. Again, the removal of PCV4 has reduced the operating pressures of each volume by approximately 5 psi. The pressure in the ACB $(P C B)$ remains relatively constant at 11 psia during the transient.

The volumetric flow rate and mass flow rates show similar transient behavior (Figures 22 and 23). The flow into Volumes 1 and 4 (CFM1 and CFM4) show the modeled flow controller response of a .5 second ramp between initial and final set points. The flow rates downstream of the flow 
controllers show a 2 to 5 second lag in their response to the transient. The flow exiting the ACB (CFM7 and mdin2) show a sharp rise initially after the transient and then roll off toward their final values. The volumetric flow rate through the ACB reaches a peak value of approximately 12 CFM. Note that the flow entering the cyclone separator (CFM8 and $m d c s$ ) remains practically constant at 24 SCFM during the transient.

Figure 24 shows the flow velocities. Note that the steady state flow velocity into the cyclone separator (VP8) is approximately $28 \mathrm{ft} / \mathrm{sec}$ and remains relatively constant during the transient.

These results show that the desired flow conditions of approximately 40 SCFM entering the cyclone separator with a velocity of 50 to $75 \mathrm{ft} / \mathrm{sec}$ will not be met by this system under the flow conditions described in Case 5. In addition to not meeting the flow conditions, the inlet pressures may exceed the cracking pressure of the pressure relief valves in spool pieces SP2A and SP3.

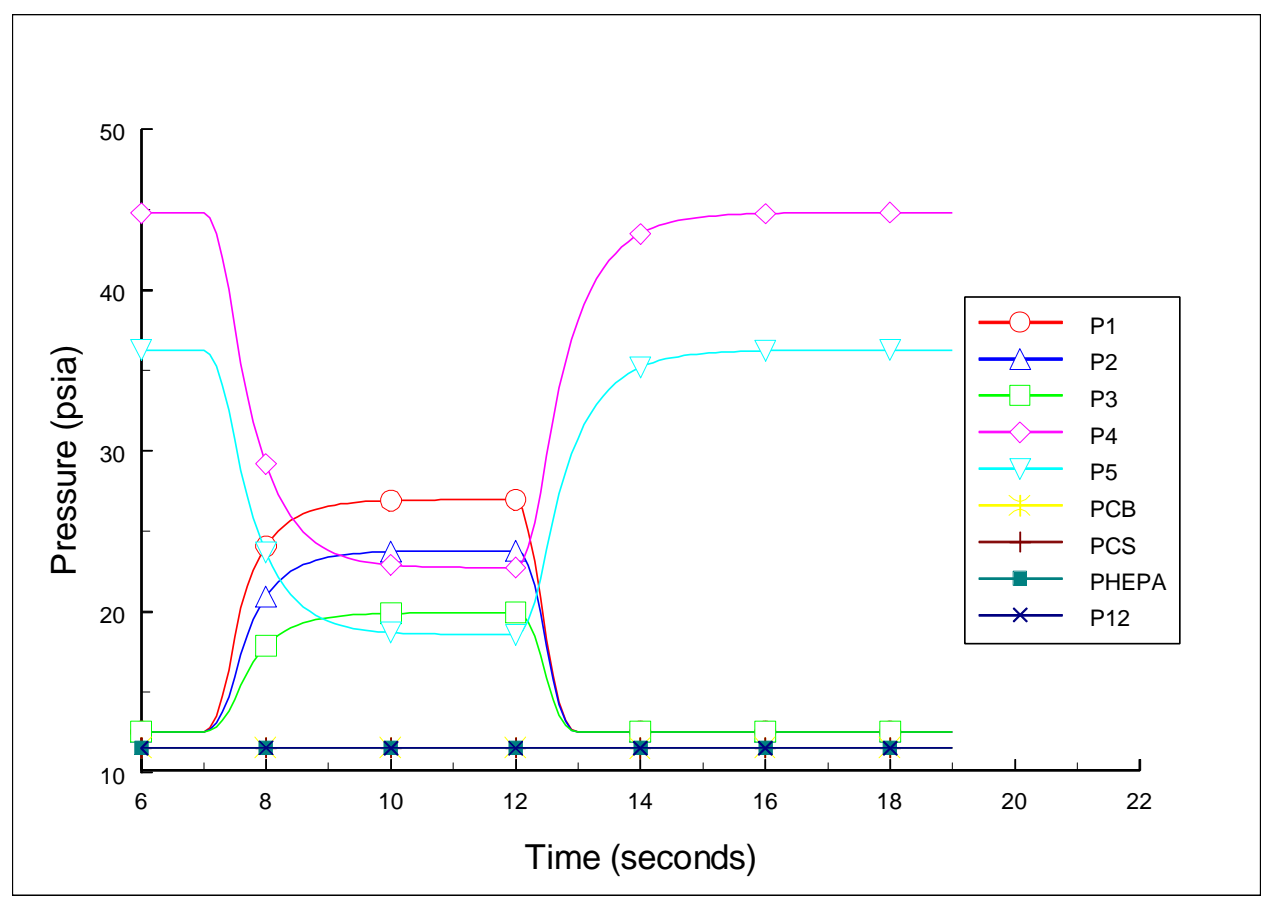



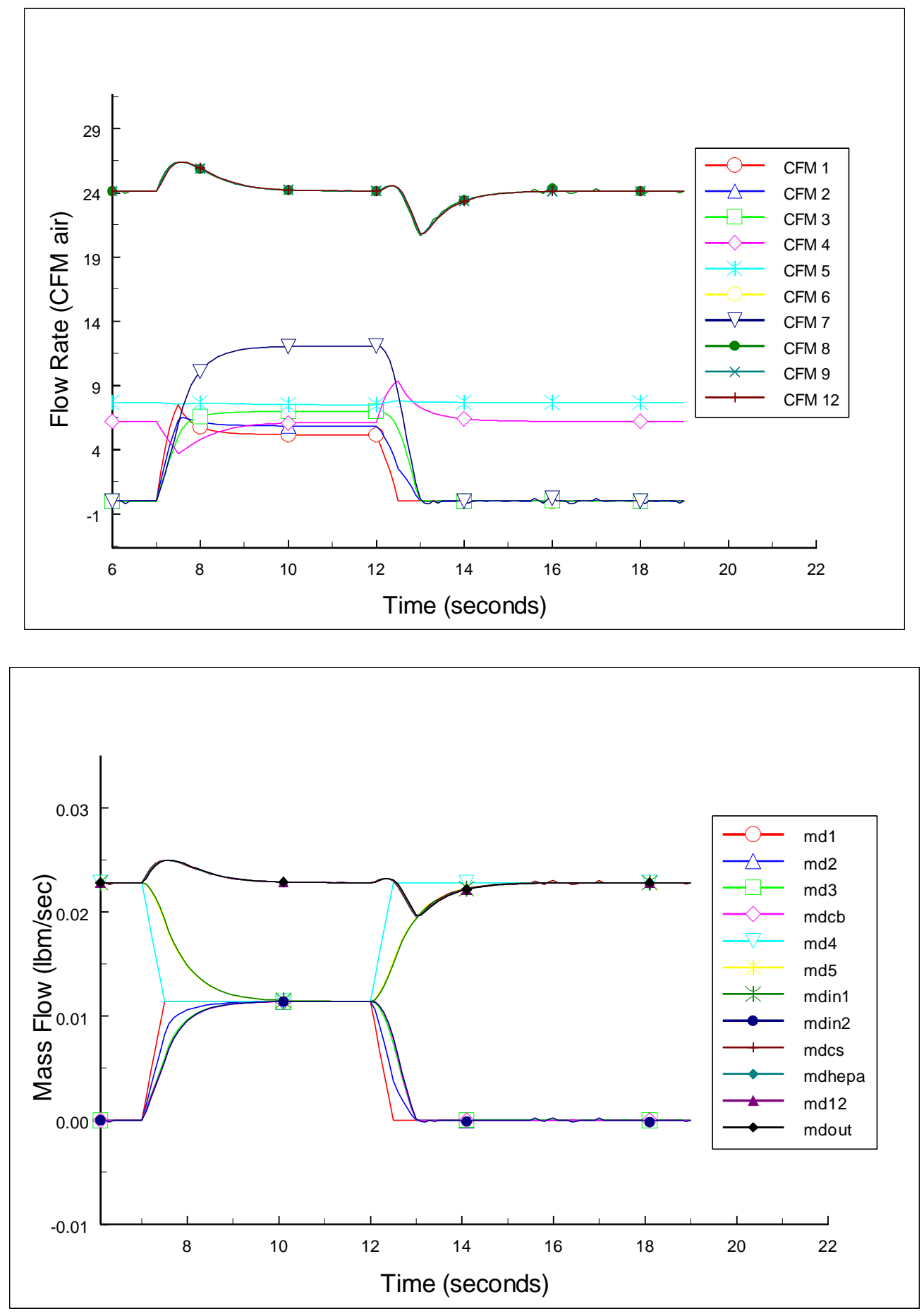


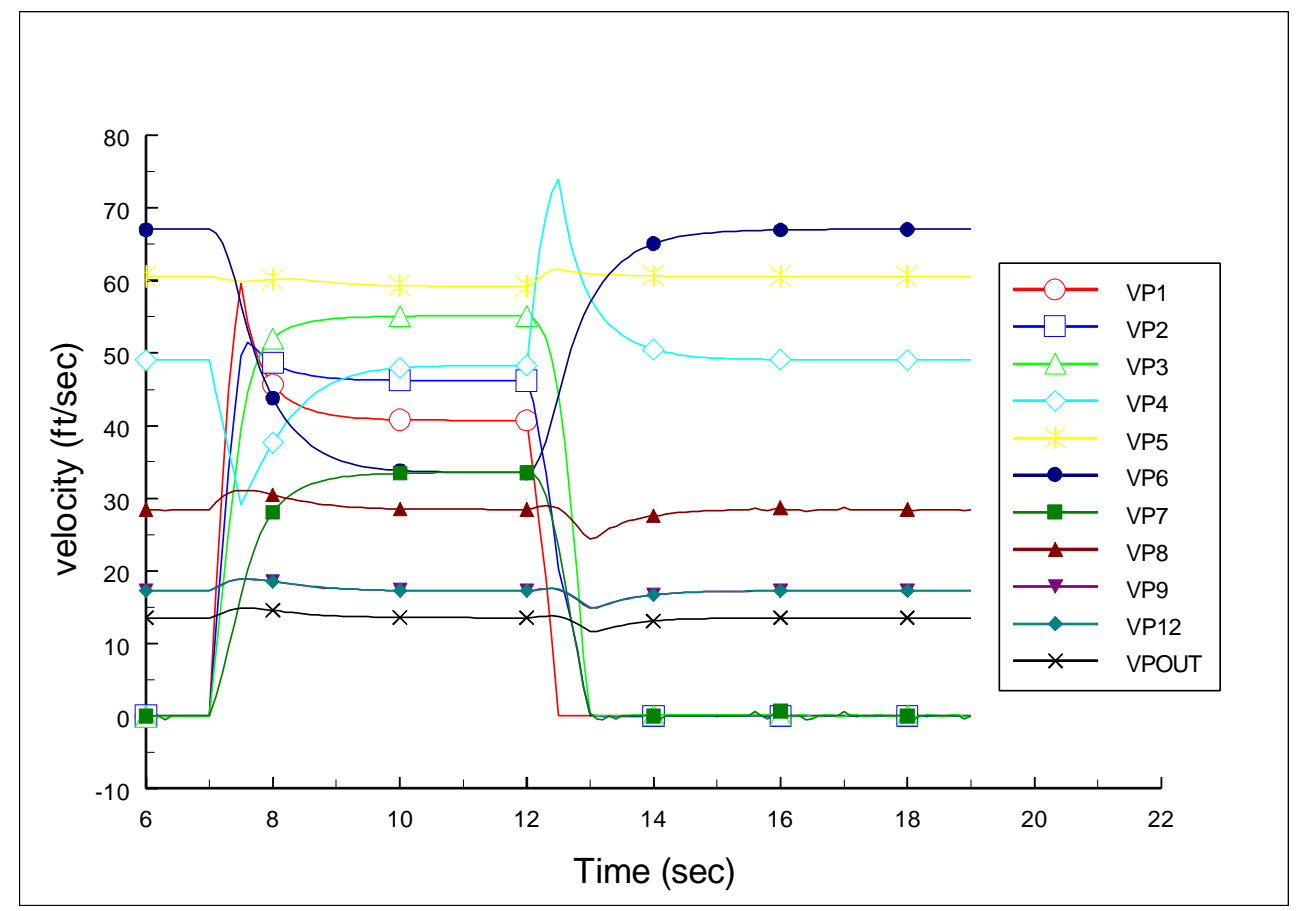

\section{6 - Case 6 - Base Model without PCV4, 5-Second Purge Gas Transient from Steady State Booster Gas Flow Condition; Maximum Booster and Purge Gas Flow}

Case six investigates system performance without PCV4 while using the maximum booster and purge gas flow. A 5 second purge gas transient starts after the booster gas flow has reached a steady state. Valve FTC3 begins opening at $t=15$ seconds and opens linearly to full open over a period of 0.5 seconds, resulting in a flow of 17.65 SCFM into volume 1. FTC4 remains fully open during the transient. Valve FTC 3 begins closing at $t=20$ seconds and closes linearly over a period of 0.5 seconds. The results are shown in Figures 25, 26, 27, and 28.

Figure 25 shows the pressure in Volume $1(P 1)$ rising to approximately 52 psia during the flow transient. This pressure compares to corresponding pressure values of 27 psia for Case 5 and nearly 60 psia for Case 4 . Pressures downstream from Volume $1(P 2, P 3$, and $P C B)$ show smaller magnitude pressure increases (determined by the pressure drops across valves SV-1, SV$3 \mathrm{~A}$, and SV-3B) which lag the pressure increase of Volume 1. The steady-state value of pressure $P 4$ is approximately $45 \mathrm{psia}$. The pressure in the ACB remains relatively constant at $11 \mathrm{psia}$ during the transient.

The volumetric flow rate and mass flow rates show similar transient behavior (Figures 26 and 27). Similar to Cases 3 - 5, the flow into Volumes 1 and 4 show the modeled flow controller response of a .5 second ramp between initial and final set points. The flow rates downstream of the flow controllers show a 2 to 5 second lag in their response to the transient. The steady-state volumetric flow rate into the cyclone separator $(C F M 8)$ is $24 \mathrm{CFM}$. The volumetric flow rate through the ACB experiences an initial sharp rise followed by a less-rapid increase, reaching a 
peak value of approximately 48 CFM. The flow entering the cyclone separator (CFM8 and mdcs) experiences a sharp increase because of the increased total flow through the system during the transient.

Figure 28 shows the flow velocities. The steady state flow velocity into the cyclone separator (VP8) is approximately $28 \mathrm{ft} / \mathrm{sec}$ but in Case 6 increases to approximately $56 \mathrm{ft} / \mathrm{sec}$ during the transient.

These results show that the desired flow conditions of approximately 40 SCFM entering the cyclone separator with a velocity of 50 to $75 \mathrm{ft} / \mathrm{sec}$ will not be met by this system under the flow conditions described in Case 6. Although the volumetric flow rate exceeds 40 CFM, the flow rate in SCFM is limited by the flow controller capacity of 35.3 SCFM. It should be noted that the system performance is nearer to the required performance without valve PCV4. In addition to not meeting the flow conditions, the inlet pressures upstream of $P 1$ and $P 4$ may exceed the cracking pressure of the pressure relief valves in spool pieces SP2A and SP3.

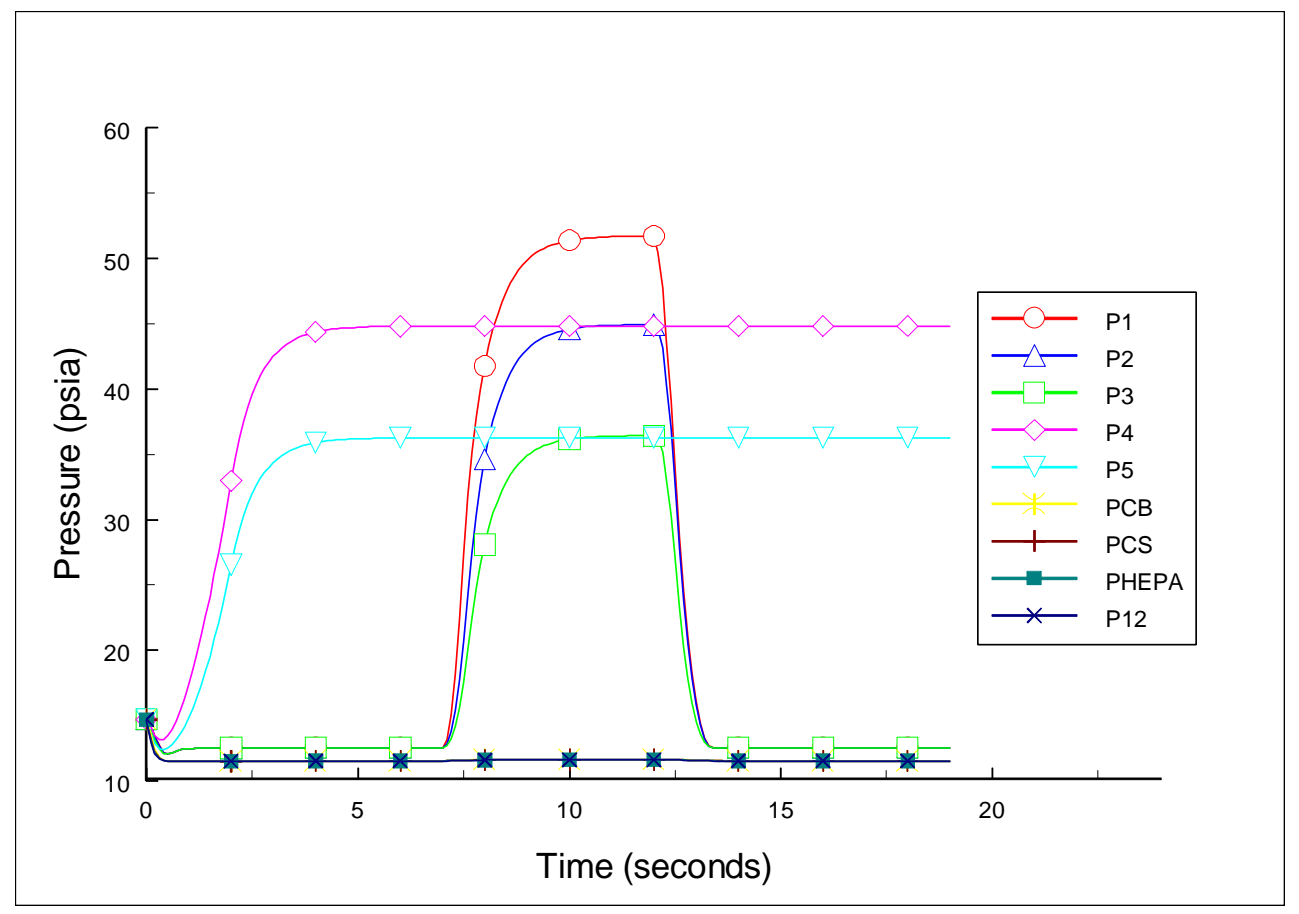



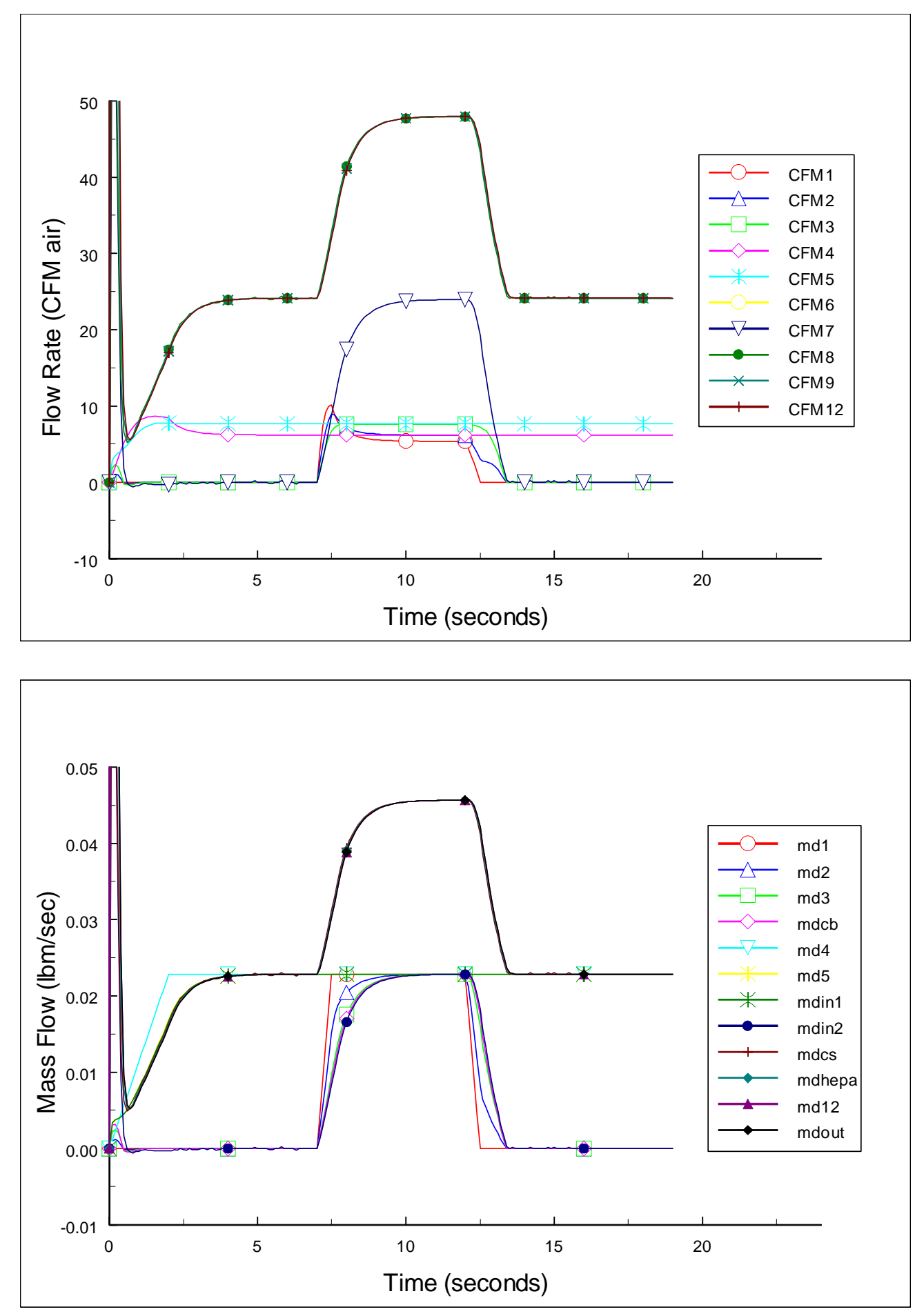


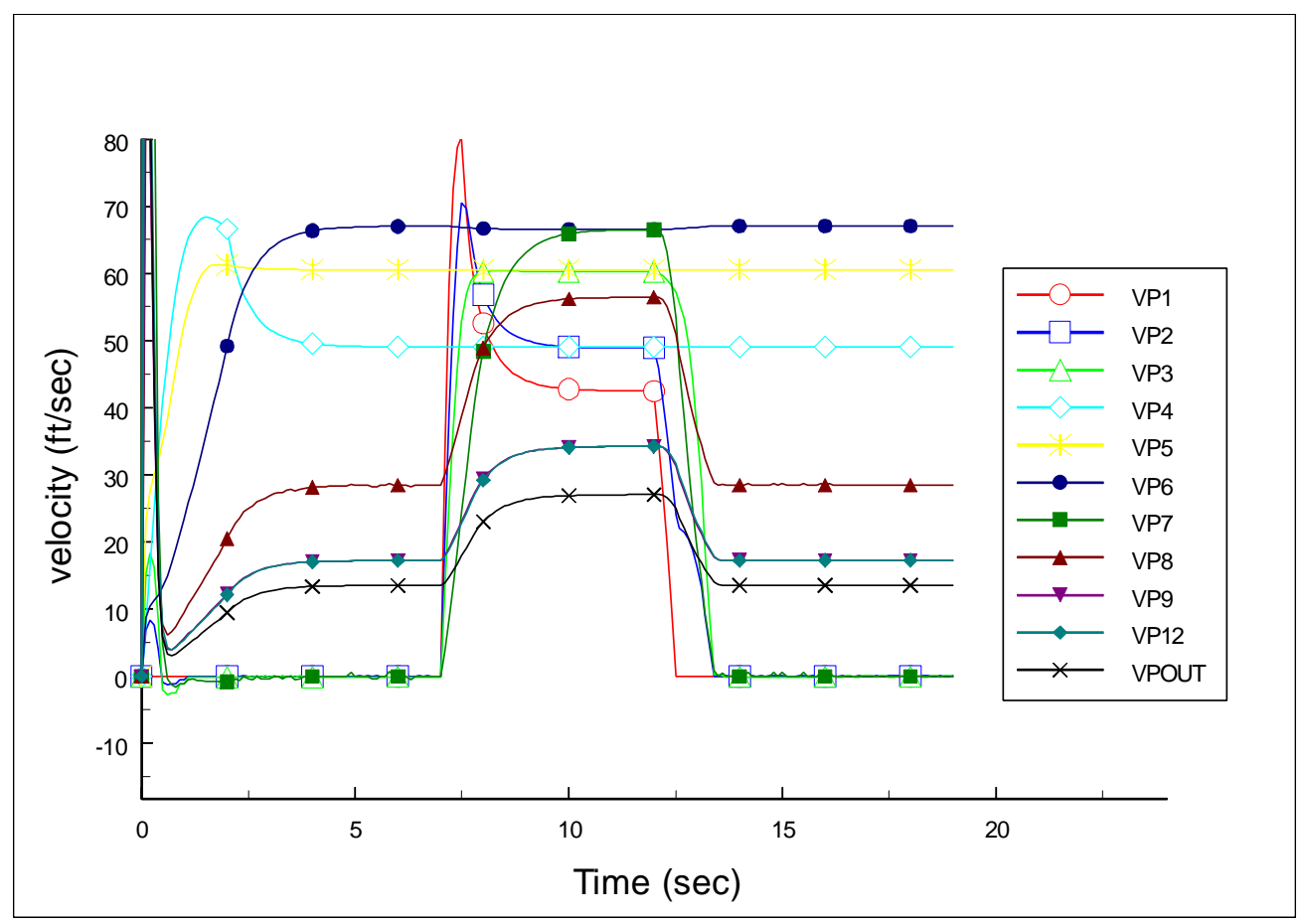

3.7 - Case 7 - Base Model without PCV4, 5-Second Purge Gas Transient from Steady State Booster Gas Flow Condition, Total Flow into Cyclone Separator Remains Constant Maximum Booster and Purge Gas Flow is 35.3 SCFM.

Case seven investigates system performance without PCV4 and with both flow controllers modified to supply 35.3 SCFM N $\mathrm{S}_{2}$. Previous results have shown that the required flow rates and velocities cannot be obtained by using the original flow controllers. A 5 second purge gas transient begins after the booster gas flow has reached a steady state. In Case 7, the total flow through the cyclone separator during the purge gas transient remains constant at 35.3 SCFM. Valve FTC3 begins opening at $t=15$ seconds and opens linearly to half open over a period of 0.5 seconds, resulting in a flow of 17.5 SCFM into Volume 1. Valve FTC4 closes while FTC3 opens to maintain a constant flow through the cyclone separator. Valve FTC3 begins closing at $t=20$ seconds and closes linearly over a period of 0.5 seconds. Valve FTC4 opens while FTC4 closes to maintain a constant flow into the cyclone separator. The results are shown in Figures 29, 30, 31 , and 32 .

Figure 29 shows the pressure in Volume $1(P 1)$ rising to near 50 psia during the flow transient. This pressure compares to corresponding pressure values of 27 psia for Case 5 and nearly 60 psia for Case 4. Pressure $P 4$ approaches 90 psia, well in excess of the 65 psig cracking pressure of the spool piece relief valve. The pressure in the ACB remains relatively constant during the transient.

The volumetric flow rate and mass flow rates show similar transient behavior (Figures 30 and 31). Similar to the previous cases, the flow into Volumes 1 and 4 show the modeled flow controller response of a .5 second ramp between initial and final set points. The flow rates downstream of 
the flow controllers show a 2 to 5 second lag in their response to the transient. The steady-state volumetric flow rate into the cyclone separator (CFM8) is $48 \mathrm{CFM}$. The volumetric flow rate through the ACB experiences an initial sharp rise followed by a less-rapid increase, reaching a peak value of approximately $24 \mathrm{CFM}$. The flow through the cyclone separator remains relatively constant at $48 \mathrm{CFM}$ during the transient.

Figure 32 shows the flow velocities. The steady state flow velocity into the cyclone separator (VP8) is approximately $58 \mathrm{ft} / \mathrm{sec}$; this value remains relatively constant during the transient.

These results show that the desired flow conditions of approximately 40 SCFM entering the cyclone separator with a velocity of 50 to $75 \mathrm{ft} / \mathrm{sec}$ can be met by this system under the flow conditions described in Case 7. However, the inlet pressures will exceed the cracking pressure of the pressure relief valves in spool pieces SP2A and SP3.

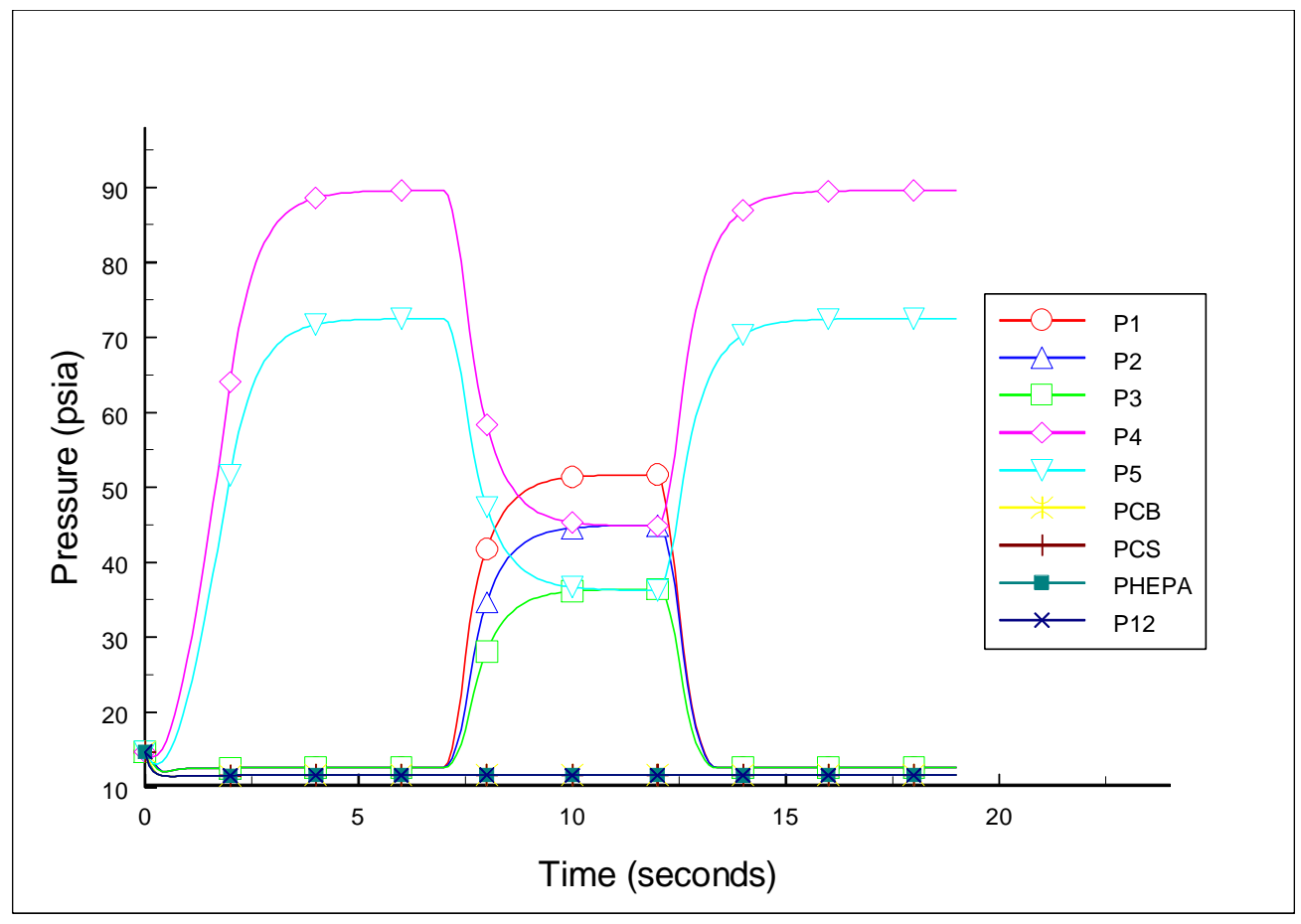



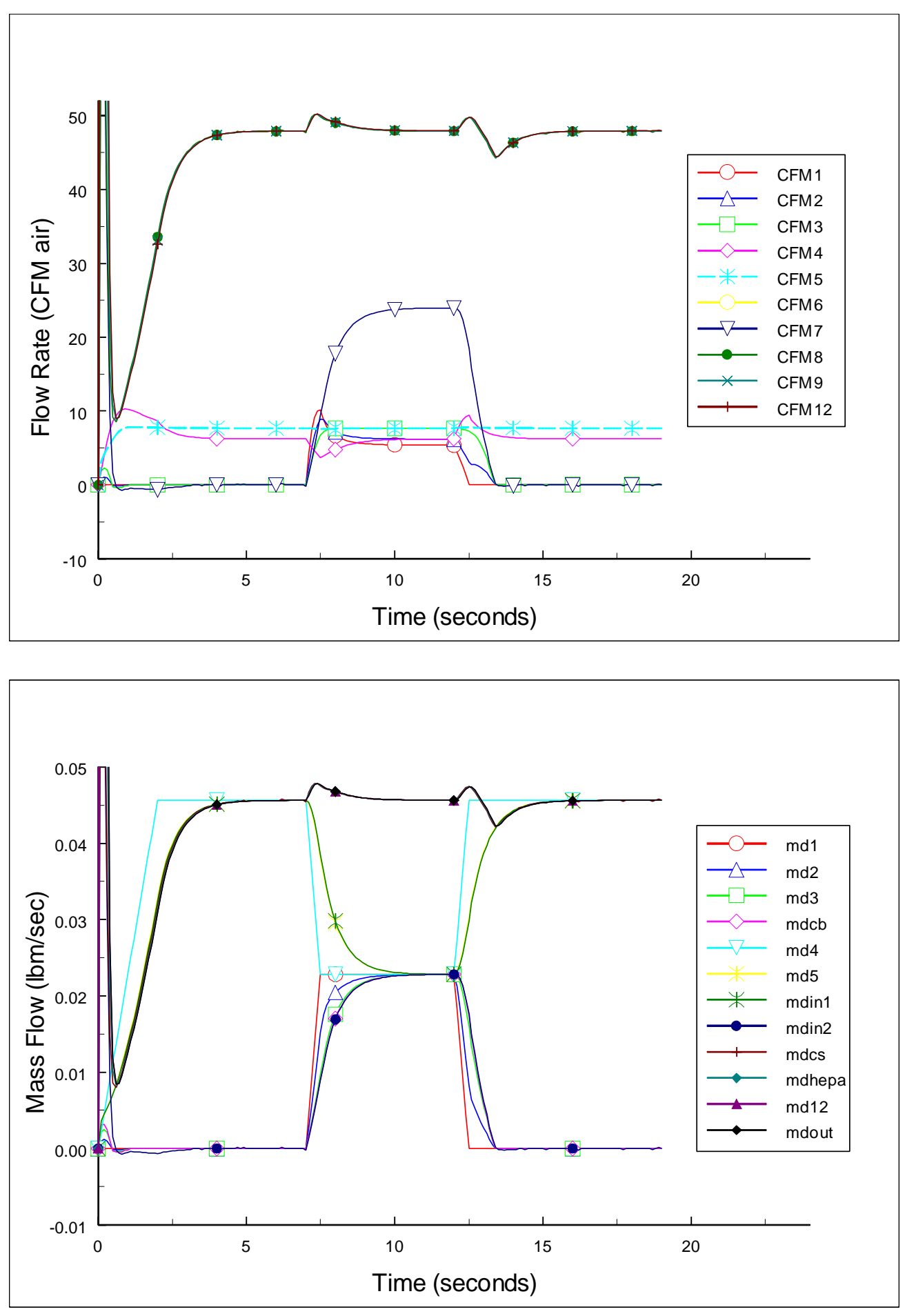


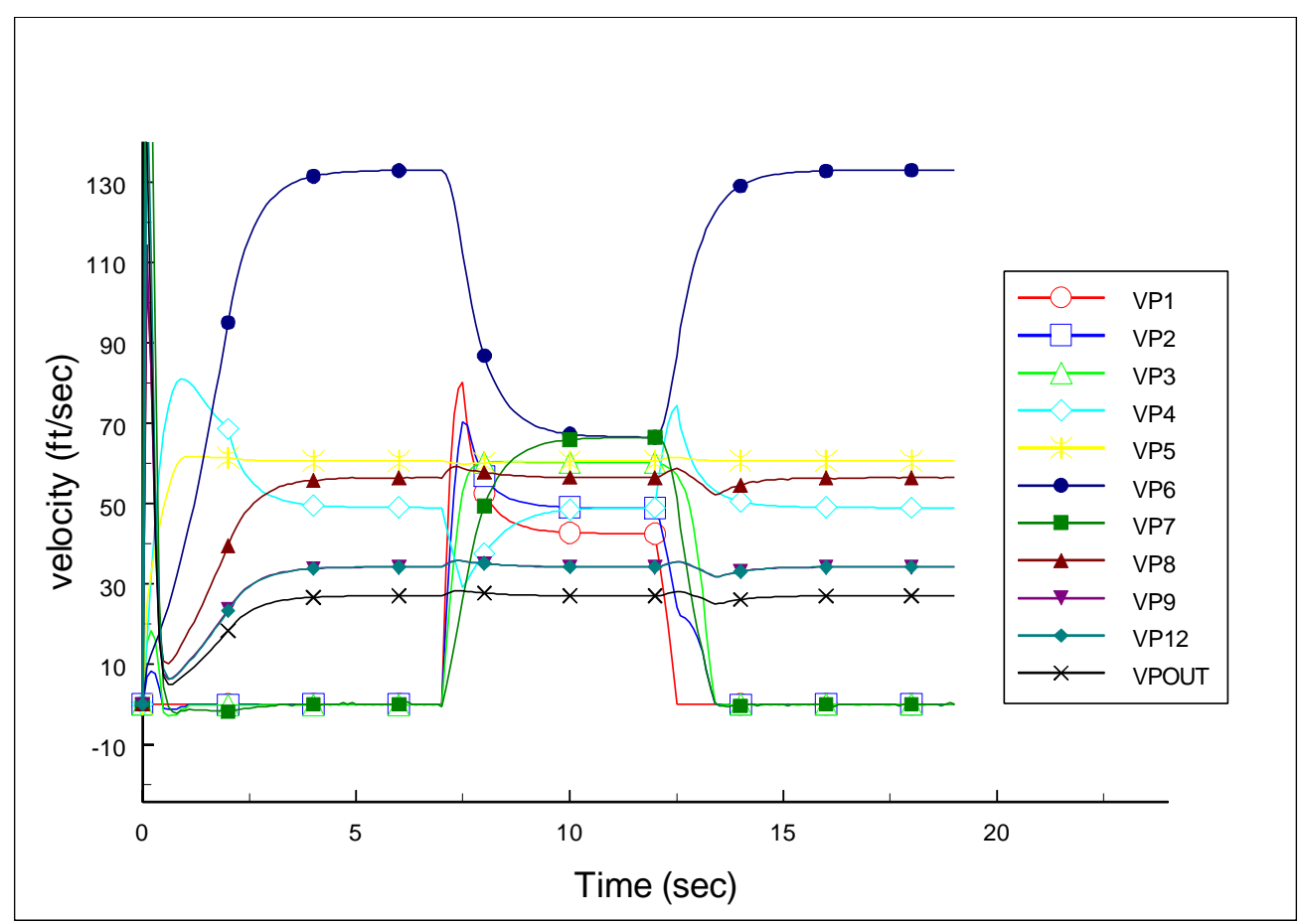

\section{8 - Case 8 - Base Model without PCV4, 5-Second Purge Gas Transient from Steady State Booster Gas Flow Condition; Maximum Booster and Purge Gas Flow - Maximum Booster and Purge Gas Flow is 35.3 SCFM.}

Case 8 investigates system performance without PCV4 and with both flow controllers modified to supply $35.3 \mathrm{SCFM} \mathrm{N}_{2}$. Although the results of Case 7 have already shown higher than acceptable inlet pressures can be expected, this case was run for completeness. A 5 second purge gas transient begins after the booster gas flow has reached a steady state. Valve FTC3 begins opening at $t=15$ seconds and opens linearly to full open over a period of 0.5 seconds, resulting in a flow of 35.3 SCFM into Volume 1. FTC4 remains fully open during the transient. Valve FTC3 begins closing at $t=20$ seconds and closes linearly over a period of 0.5 seconds. The results are shown in Figures 33, 34, 35, and 36.

Figure 33 shows the pressure in Volume $1(P 1)$ rising to over 100 psia during the flow transient. Pressure $P 4$ remains at approximately 90 psia throughout the simulation. The pressure in the ACB remains relatively constant during the transient.

The volumetric flow rate and mass flow rates show similar transient behavior (Figures 33 and 35). Similar to the previous cases, the flow into Volumes 1 and 4 show the modeled flow controller response of a .5 second ramp between initial and final set points. The flow rates downstream of the flow controllers show a 2 to 5 second lag in their response to the transient. The steady-state volumetric flow rate into the cyclone separator $(C F M 8)$ is $48 \mathrm{CFM}$. The volumetric flow rate through the ACB experiences an initial sharp rise followed by a less-rapid increase, reaching a peak value of approximately $48 \mathrm{CFM}$. The flow through the cyclone separator rises from 48 CFM to approximately 96 CFM during the transient. 
Figure 36 shows the flow velocities. The steady state flow velocity into the cyclone separator (VP8) is approximately $56 \mathrm{ft} / \mathrm{sec}$; this value increases to approximately $110 \mathrm{ft} / \mathrm{sec}$ during the transient.

These results show that the desired flow conditions of approximately 40 SCFM entering the cyclone separator with a velocity of 50 to $75 \mathrm{ft} / \mathrm{sec}$ can be met by this system under the flow conditions described in Case 8. However, as expected, the inlet pressures will exceed the cracking pressure of the pressure relief valves in spool pieces SP2A and SP3.

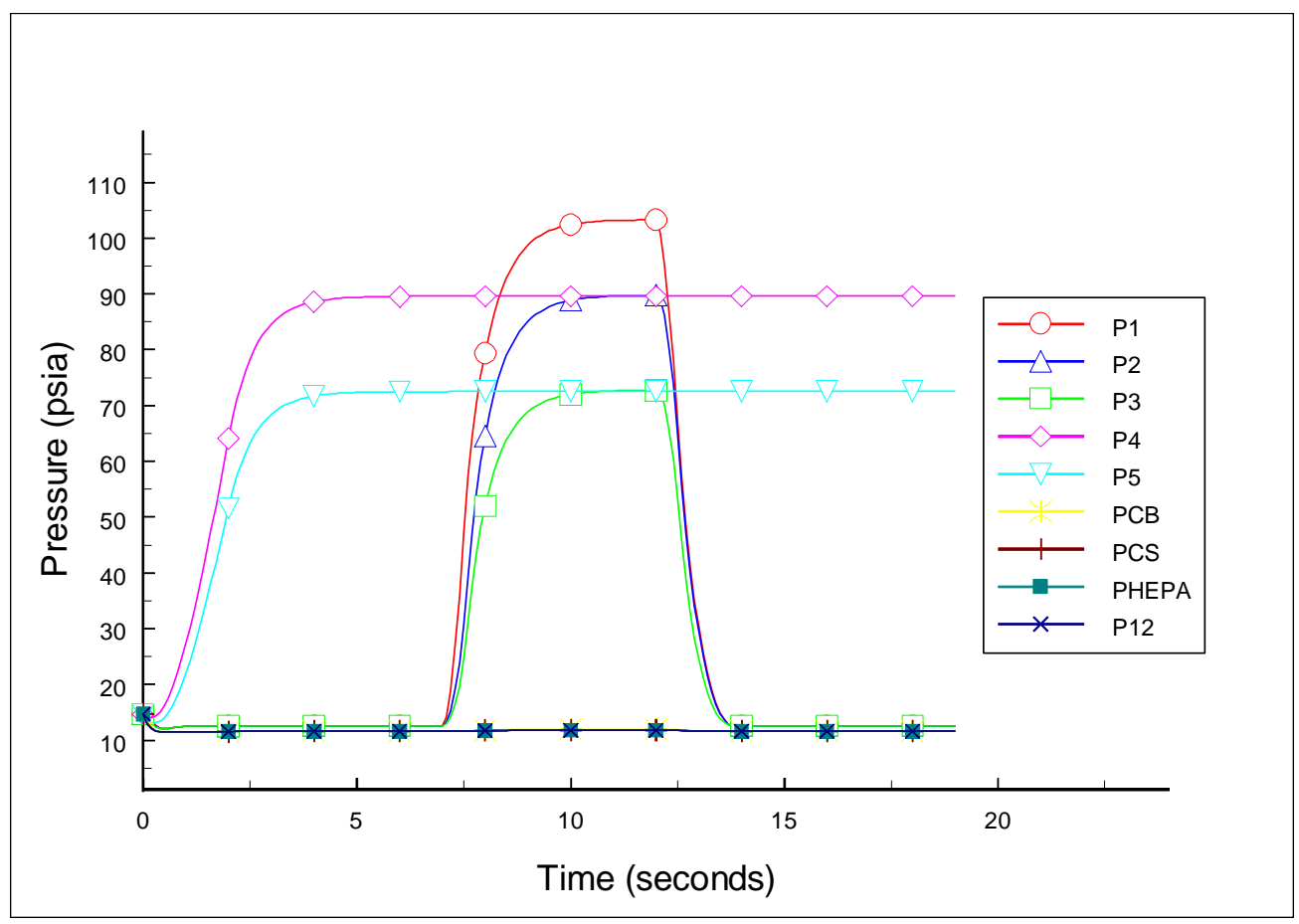



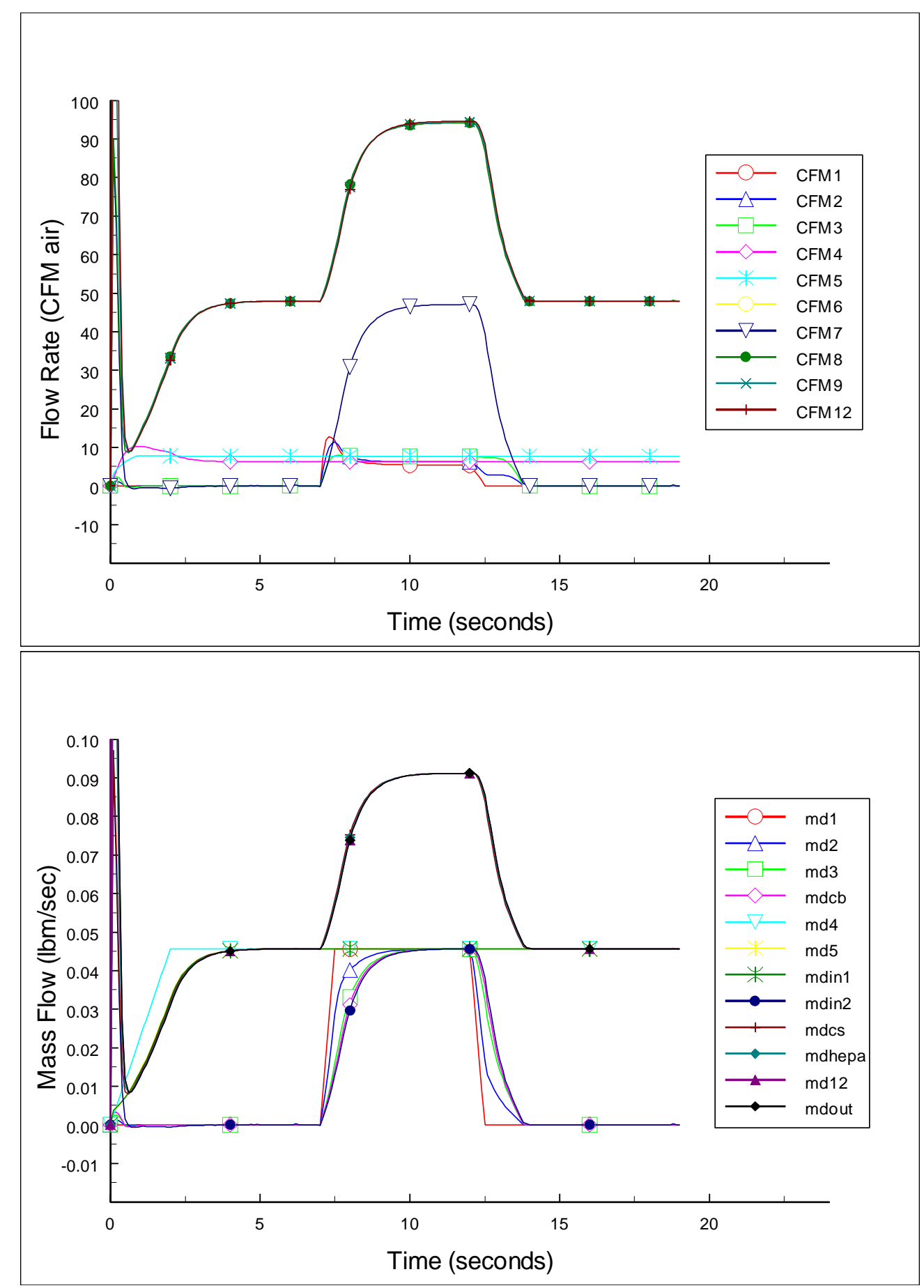


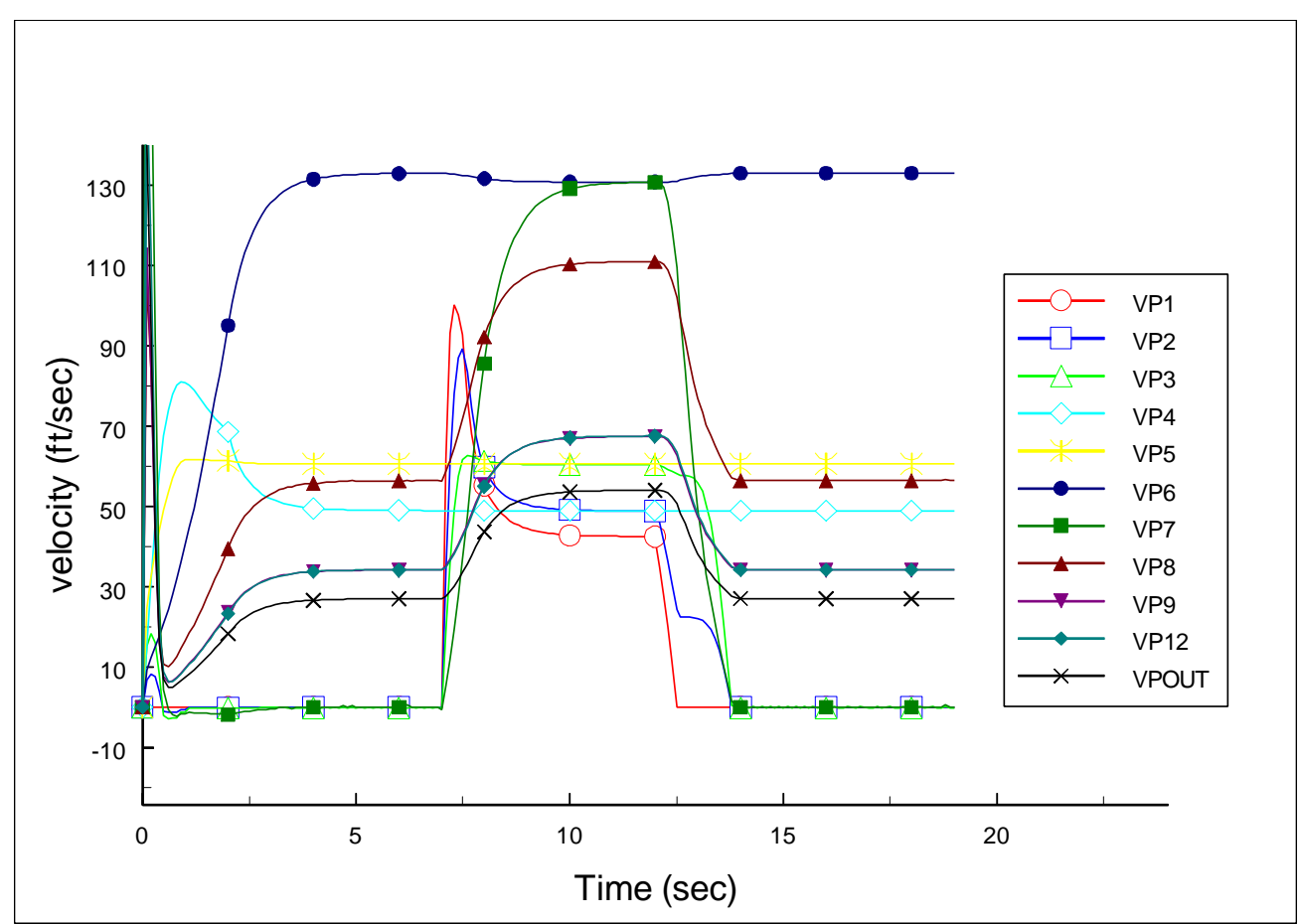

\section{9 - Case 9 - Base Model without PCV4, 5-Second Purge Gas Transient from Steady State Booster Gas Flow Condition; Maximum Booster and Purge Gas Flow - Maximum Booster and Purge Gas Flow is 35.3 SCFM; Control Valves Replaced with Low Pressure Drop Ball Valves; Cold Tap Cv $=2.3$.}

Cases seven and eight have shown that by removing PCB4 and increasing the capacity of the original flow controllers from 17.6 SCFM to 35.5 SCFM, the vacuum system can meet the cyclone separator inlet flow and velocity requirements. Unfortunately, both cases indicate that the upstream pressures will exceed the relief valve cracking pressure of 65 psig. Case 9 models the system with the original bellows sealed control valves SV-1, SV-3A, SV-3B, SV-4A, and SV-4B replaced by ball valves with $C_{v}=13.1$. This modification should reduce the pressure drop across each valve, ultimately reducing the inlet pressure. Also, this case uses measured values of pressure drop from a mock up of the ACB and cold tap assembly to obtain an equivalent value of $\mathrm{C}_{\mathrm{v}}=2.3$ for this component.

A 5 second purge gas transient begun after the booster gas flow has reached a steady state. Valve FTC3 begins opening at $t=15$ seconds and opens linearly to full open over a period of 0.5 seconds, resulting in a flow of 35.3 SCFM into Volume 1. FTC4 remains fully open during the transient. Valve FTC 3 begins closing at $t=20$ seconds and closes linearly over a period of 0.5 seconds. The results are shown in Figures 37, 38, 39, and 40.

Figure 37 shows the pressure in Volume $1(P I)$ rising to over 29 psia during the flow transient. The transient is too short for the pressures to reach steady state values. Note that pressures $P 2$ and $P 3$ closely follow $P I$ and that the replacement of the original bellows sealed valves with ball valves causes the pressure differences between $P 1, P 2$, and $P 3$ to be much smaller than in 
previous simulations. Pressure $P 4$ remains at approximately 14 psia throughout the simulation. The pressure in the ACB increases during the transient from 12 psia to 25 psia. The inlet pressures do not approach the relief valve cracking pressure.

The volumetric flow rate and mass flow rates show similar transient behavior (Figures 38 and 39). The steady-state volumetric flow rate into the cyclone separator (CFM8) is $45 \mathrm{CFM}$. The volumetric flow rate through the ACB reaches a peak value of approximately $32 \mathrm{CFM}$. Note that a longer transient would result in a greater peak flow rate. The flow through the cyclone separator rises from $48 \mathrm{CFM}$ to approximately $78 \mathrm{CFM}$ during the transient.

Figure 40 shows the flow velocities. The steady state flow velocity into the cyclone separator (VP8) is approximately $56 \mathrm{ft} / \mathrm{sec}$; this value increases to approximately $85 \mathrm{ft} / \mathrm{sec}$ during the transient and would continue to increase if the transient were of longer duration.

These results show that the desired flow conditions of approximately 40 SCFM entering the cyclone separator with a velocity of 50 to $75 \mathrm{ft} / \mathrm{sec}$ can be met by this system under the flow conditions described in Case 9 and that the inlet pressures will not exceed the cracking pressure of the pressure relief valves in spool pieces SP2A and SP3.

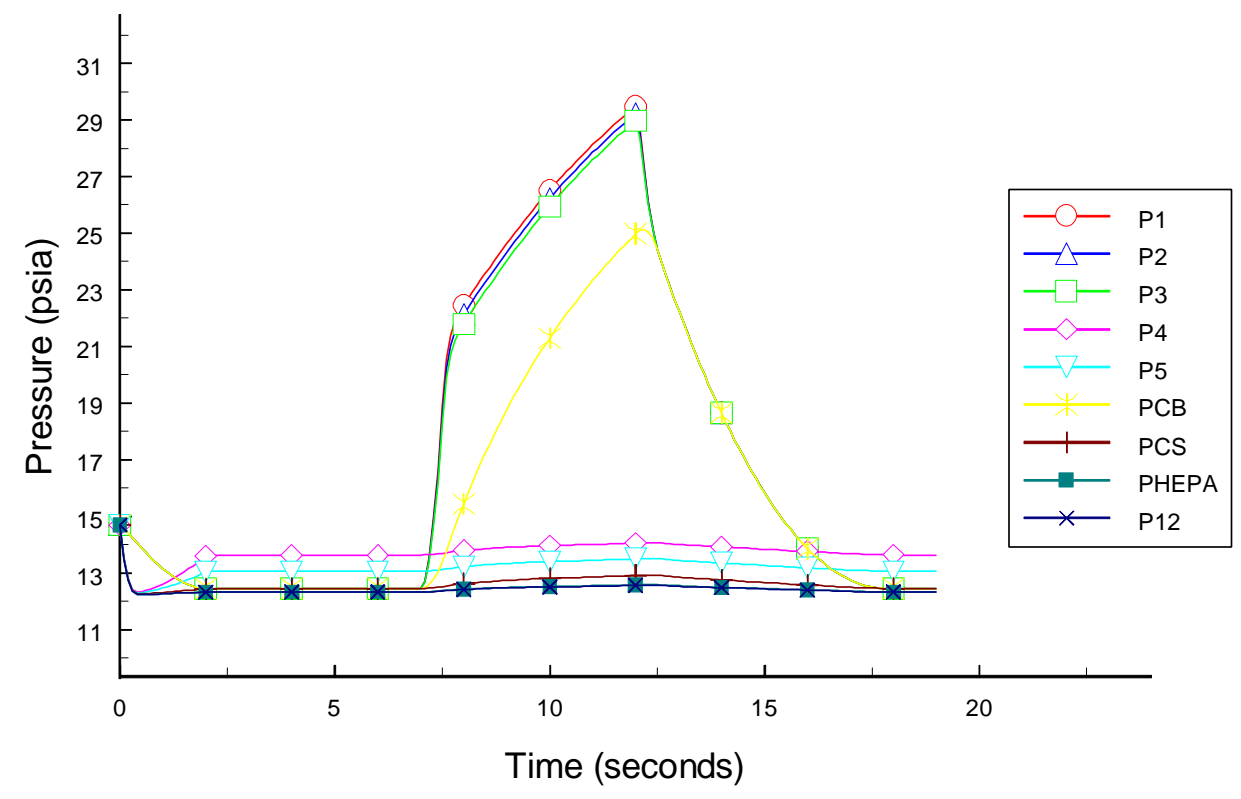



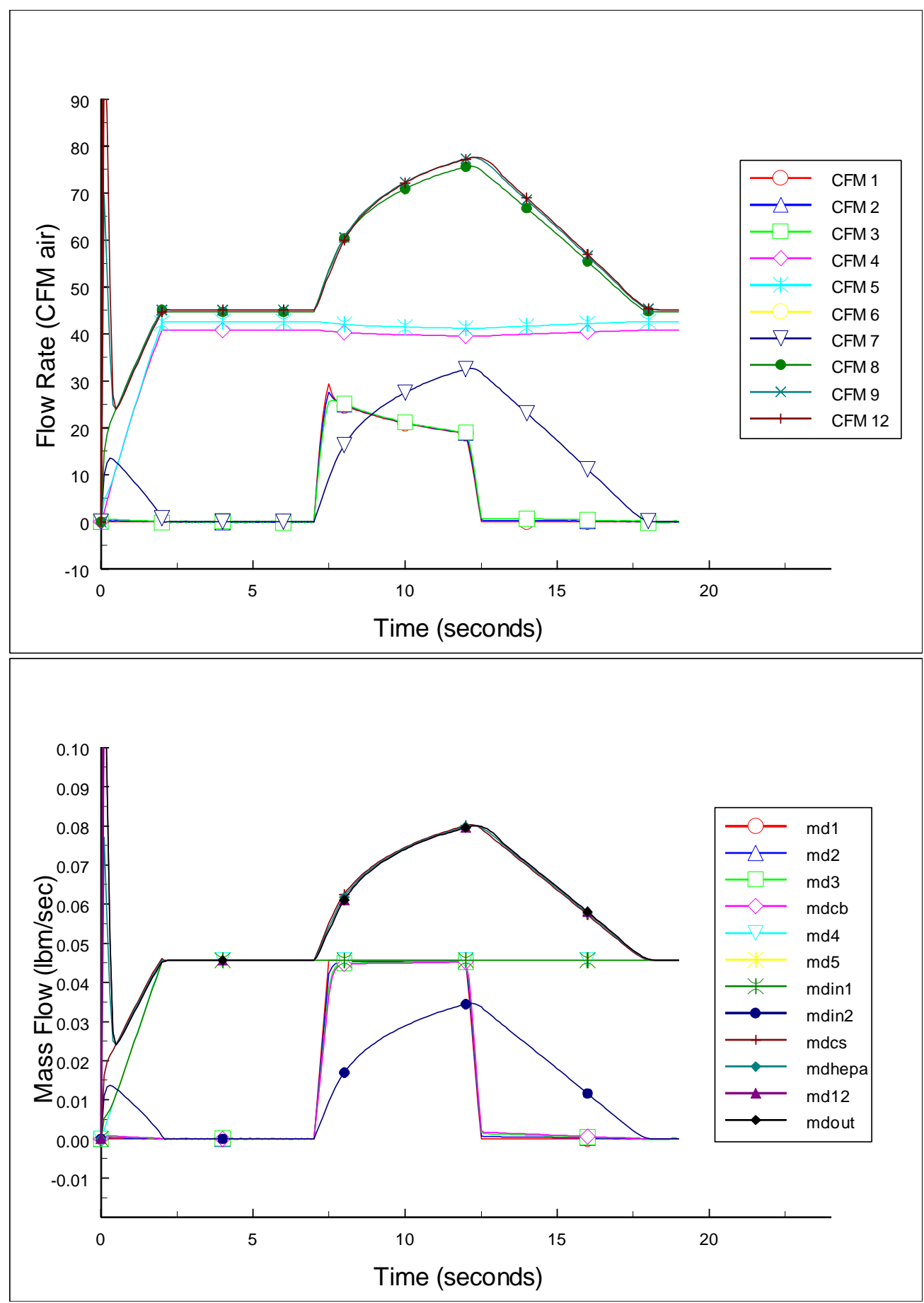


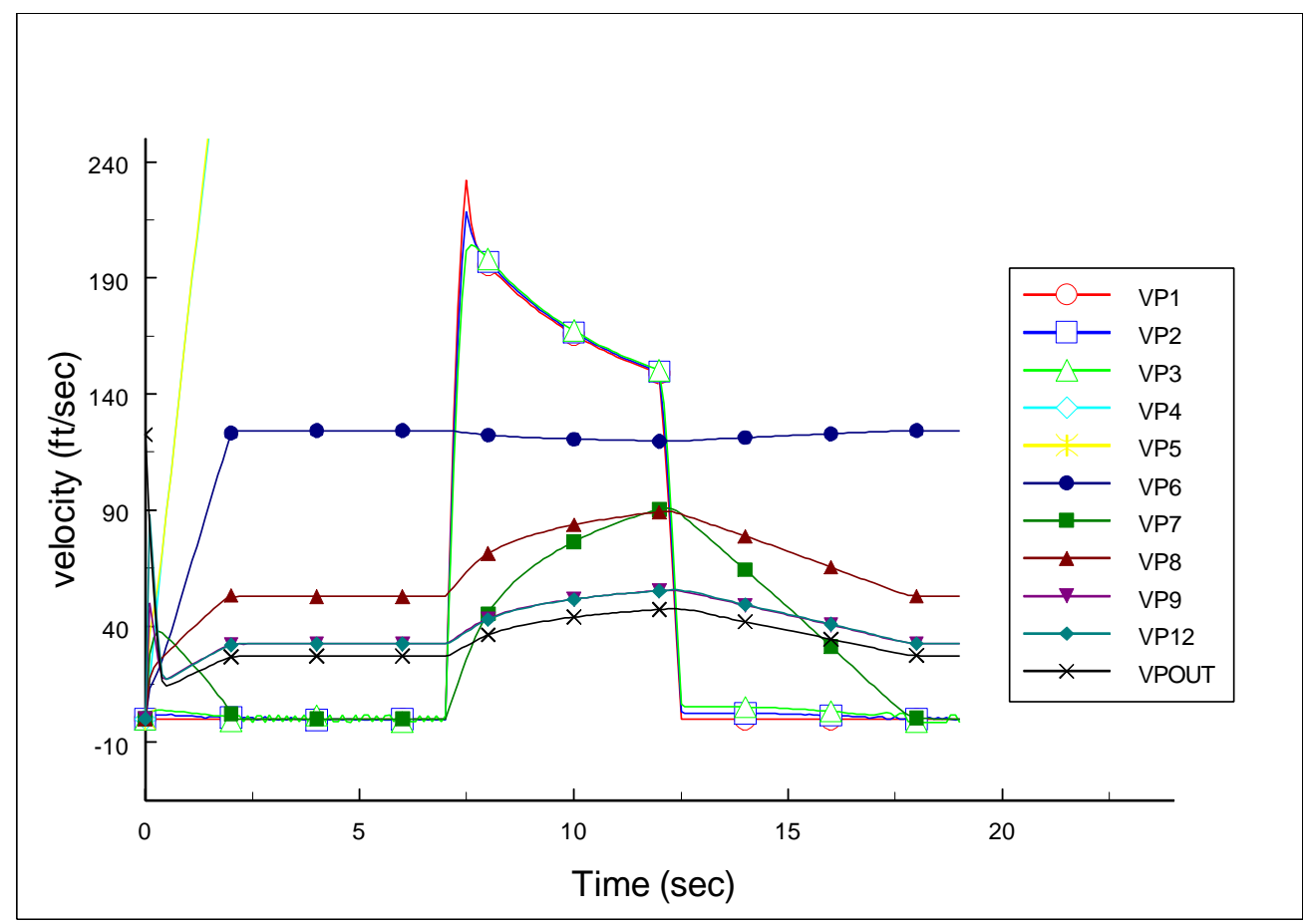

4. CONCLUSIONS AND RECOMMENDATIONS

The simulation results indicate that the original flow controllers will not meet the required flow conditions at the inlet to the cyclone separator and that the original bellows sealed valves will cause the spool piece pressures to exceed the cracking pressure of the spool piece pressure relief valves. A discussion of these problems and some possible solutions are presented in this section.

The failure of the system to meet the inlet flow requirements at the cyclone separator is a direct result of changing the booster and purge gas from helium to nitrogen. The original flow controllers have a maximum capacity of $17.55 \mathrm{SCFM} \mathrm{N}_{2}$; this capacity converts to $47 \mathrm{SCFM} \mathrm{H}_{2}$, more than sufficient to meet the original flow criteria. Modifying the flow controllers to their maximum capacity of $34.3 \mathrm{SCFM} \mathrm{N}_{2}$ will alleviate this problem. These higher flow rate cases were investigated in Cases 7, 8, and 9.

The high upstream pressures are caused by the large pressure drops through valves SV-1, SV-3A, $\mathrm{SV}-3 \mathrm{~B}, \mathrm{SV}-4 \mathrm{~A}$, and SV-4B. Aggravating the problem is the 10 to 40 psi pressure drop across the flow controller (which is not included in the ACSL simulation). The conclusion to be drawn from the simulation results of the original system is that the upstream pressures are too great; the pressure upstream of the flow controller will almost certainly exceed the cracking pressure of the relief valves, which is set at 65 psig.

The upstream pressures can be reduced somewhat by removing valve PCV4. This has the advantage of reducing the system pressure and causes the system to have a faster response. This faster response is evident in the simulations in the short time the system without PCV4 comes to equilibrium and the rapid approach to steady state conditions of the flow transients through the 
ACB.

Removing PCV4 will not be sufficient to solve the problem of high upstream pressure. The cracking pressure of the relief valves will need to be increased or the pressure drop through the system will need to be reduced, either by bypassing some of the valves, removing some of the valves, or replacing some of the valves with less restrictive valves. Case 9 shows that replacing the original bellows sealed valves with ball valves with $C_{v}$ equal to 13.1 will reduce the upstream pressures to well within acceptable levels.

In conclusion, the model results suggest that the following modifications to the original vacuum system design are required to make the system performance acceptable;

1. Remove valve PCV4.

2. Modify the flow controllers FTC3 and FTC4 from the original flow range of 0 - 17.6 SCFM (0 - 500 SLM) to 0 - 35.3 SCFM (0 - 1000 SLM).

3. Replace the bellows sealed valves SV-1, SV-3A, SV-3B, SV-4A, and SV-4B with less restrictive ball valves.

As shown by the Case 9 results, these modifications should result in acceptable system performance.

\section{REFERENCES}

1. Advanced Continuous Simulation Language Reference Manual, Ed. 10.0, Mitchell \& Gauthier Associates, Inc., Concord, Mass., 1991. 


\section{APPENDIX A - DERIVATION OF EQUATIONS USED IN THE VACUUM SYSTEM MODEL}

A modular model was developed to predict the system's macroscopic flow characteristics. Three base modules were developed; one for a volume with inlet flow controlled by a flow controller, one for a volume with inlet flow controlled by a nozzle, and one for a volume with inlet flow controlled by a valve. For each module, flow enters a tank of volume $V_{t}$ through a pipe of area $A_{1}$ and exits the tank through a pipe of area $A_{p}$. The conditions upstream of the volume are pressure $P_{0}$, temperature $T_{0}$, and density ${ }_{0}$. The tank conditions are tank pressure $P_{\mathrm{t}}$, tank temperature $T_{t}$, and tank density ${ }_{t}$. The downstream conditions are pressure $P_{\text {? }}$, temperature $T_{\text {? }}$, and density ? . Ideal gas properties are assumed.

\section{A.1 - Inlet Flow Controlled by Flow Controller}

The first module had its inlet flow controlled by a flow controller. For this type of module, the inlet flow is specified, subject to the condition that the time response of the flow controller is satisfied. For the Tylan flow controllers used in the vacuum system, the step response time is 0.5 seconds. Thus, the flow controllers were modeled as supplying a ramp over 5 seconds from the initial flow set point to the final flow set point.

A differential equation describing the change in tank mass (and therefore density) can be obtained from a mass balance on the tank. This equation is used for each of the three modules in the model. If the mass flow rate into the tank is $\mathrm{m}_{I}$ and mass flow rate out of the tank is $\mathrm{m}_{o}$, the rate of

Install Equation Editor and double-

click here to view equation.

change of gas density in the tank is simply

Install Equation Editor and double-

click here to view equation.

An energy balance can be performed on the tank to give the rate of change of tank temperature; where $h_{o}$ is the enthalpy of the gas leaving the tank, $h_{i}$ is the enthalpy of the gas entering the tank, and $U$ is the internal energy of the gas in the tank. ${ }^{1}$ The internal energy is given by

Install Equation Editor and double-

click here to view equation.

The rate of change of internal energy is given by 
Install Equation Editor and double-

click here to view equation.

Install Equation Editor and double-

click here to view equation.

Substituting Eq. (4) for the derivative of the tank internal energy into Eq. (2)

Install Equation Editor and double- Install Equation Editor and double-

Finally, substituting the relations click here to view equation. , click here to view equation. Install Equation Editor and doubleand click here to view equation. Install Equation Editor and doubleand solving for click here to view equation.

Install Equation Editor and double-

click here to view equation.

where $R$ is the gas constant. Equations (1) and (6) can be integrated to give the values of ${ }_{t}$ and $T_{t}$. The perfect gas law can then be used to obtain the tank pressure, $P_{t}$. Note: During initial model check out it was found that there was virtually no change in gas temperature because of the relatively small pressure changes that occur in the system (the significant pressure change occurs in the pressure reducing regulator, which is upstream of the model). Thus, the Eq. (6) was removed from the ACSL model to reduce the computation time.

\section{A.2 - Inlet Flow Controlled by an Ideal Nozzle}

The second module consists of an ideal nozzle controlling flow into a constant volume tank (Figure A-1). The nozzle equations describe flow through an ideal (adiabatic, isentropic, frictionless)

Install Equation Editor and double-

click here to view equation.

nozzle. The relationship between flow area and the mass flow rate $\underline{m}$ is given by

where $A$ is the nozzle area and $G$ is a parameter that depends on whether the downstream pressure is below the critical pressure. The critical pressure is calculated based in order to select the proper equation describing the mass flow rate through the nozzle. The critical pressure, $P_{c}$, is given by

Install Equation Editor and double-

click here to view equation.

where $k$ is the ratio of the heat capacity at constant pressure, $c_{p}$, to the heat capacity at constant volume, $c_{v}$, and $P_{0}$ is the upstream pressure, $P_{t}$ is the downstream pressure. ${ }^{1}$ where $k$ is the ratio of the heat capacity at constant pressure, $c_{p}$, to the heat capacity at constant volume, $c_{v}$, and $P_{0}$ is the upstream pressure, $P_{t}$ is the downstream pressure. ${ }^{1}$ If $P_{t}$ is greater than $P_{c}$, then the parameter $G$ is given by 
Install Equation Editor and double-

click here to view equation.

where $g_{0}$ is the acceleration of gravity and $?_{0}$ is the upstream density. If $P_{c}$ is greater than $P_{t}$ then

Install Equation Editor and double-

click here to view equation.

flow through the nozzle is choked and the parameter $G$ is given by Equations (7) through (10) are used to calculate the mass flow rate into the tank. Equations (1) through (6) are used to calculate the rate of change of density and temperature in the tank.

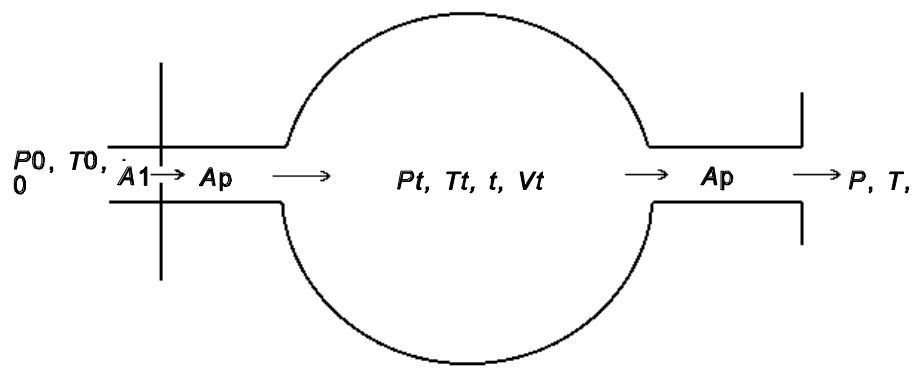

\section{A.3 - Inlet Flow Controlled by a Valve}

The third module consists of a valve controlling flow into a constant volume tank. The pressure drop across valves is calculated by using the equations given in Ref. A-2. Knowing the upstream pressure, the critical pressure is calculated by using Eq. (2). If the downstream pressure is less than the critical pressure, the flow through the valve is choked and the flow $q$ in standard cubic feet per minute of air through the valve is given by

Install Equation Editor and double-

click here to view equation.

where $N_{2}=22.67, P_{1}$ is the upstream pressure in psia, $T_{1}$ is the upstream temperature in degrees R, $G_{g}$ is the specific gravity of the gas and $C_{v}$ is the coefficient of volume of the valve.. If the downstream pressure is greater than the critical pressure, the flow $q$ in standard cubic feet per minute of air through the valve is given by 
where ? $P$ is the pressure drop across the valve. Equation (11) or (12) is used to calculate the flow into the tank. Equations (1) through (6) are used to calculate the rate of change of density and temperature in the tank.

\section{A.4 - Pipe Flow Velocity}

The pipe flow is assumed to be inviscid and incompressible (this assumption is good if the flow velocity remains less than 0.3 of the speed of sound in the gas) and the pressure, density, and temperature are assumed constant throughout the pipe. With these assumptions, the pipe flow

Install Equation Editor and doubleclick here to view equation.

velocity, $V_{p}$, is given by

where $\underline{\mathrm{m}}_{p}$ is the mass flow through the pipe, $?_{p}$ is the density of the gas in the pipe, and $A_{p}$ is the pipe area.

\section{References for Appendix A}

1. F. J. Moody, Introduction to Unsteady Fluid Mechanics, John Wiley \& Sons, New York,1990.

2. Swagelok Technical Bulletin No. 8, "Valve Sizing Graphs", The Swagelok Companies, August 1994. 


\section{APPENDIX B - ACSL MODEL LISTING}

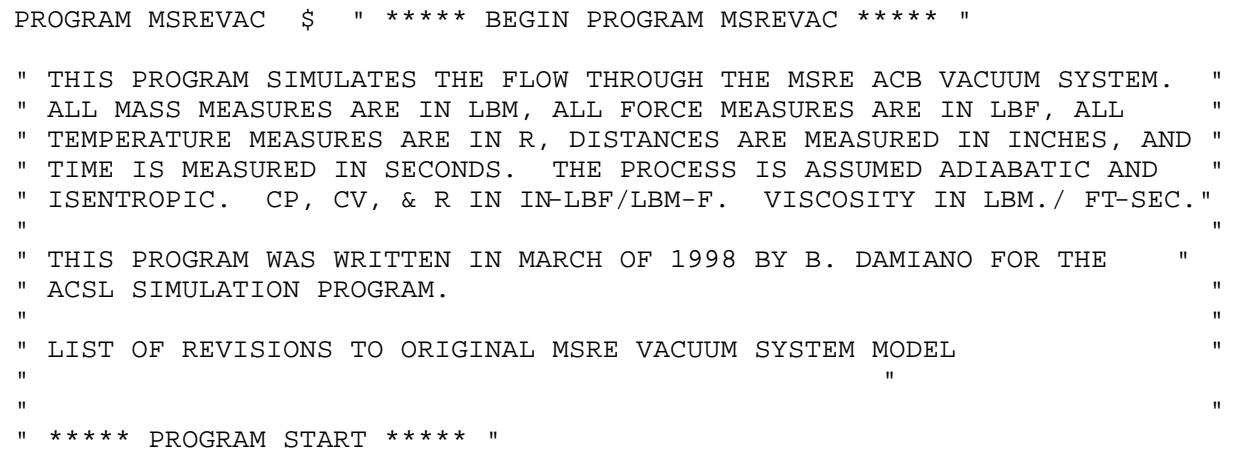

" VARIABES USED TO DESCRIBE FLOW CONTROLLER DYNAMICS

" FMAX = MAX FLOW CONTROLLER FLOW IN SCFM AIR.

CONSTANT FMAX3 $=17.66, \quad$ FMAX4 $=17.66$

"2345678901234567890123456789012345678901234567890123456789012345678901"

" FLOW CONTROL VALVE AREAS (IN^2) MAY BE MADE TIME DEPENDENT IF NEEDED "

" TOC3 - TIME FLOW CONTROLLER FTC3 BEGINS OPENING,

" TOC4 - TIME FLOW CONTROLLER FTC4 BEGINS OP ENING,

" TOCV4 - TIME PCV4 BEGINS OPENING,

" DOTC3 - TIME FLOW CONTROLLER FTC3 TAKES TO OPEN,

" DOTC4 - TIME FLOW CONTROLLER FTC4 TAKES TO OPEN,

" DOTCV4 - TIME PCV4 TAKES TO OPEN.

" TCC3 - TIME FLOW CONTROLLER FTC3 BEGINS CLOSING,

" TCC4 - TIME FLOW CONTROLLER FTC4 BEGINS CLOSING,

" TCCV4 - TIME PCV4 BEGINS CLOSING,

" DCTC3 - TIME FLOW CONTROLLER FTC3 TAKES TO CLOSE, 
" DCTC4 - TIME FLOW CONTROLLER FTC4 TAKES TO CLOSE,

" DCTCV4 - TIME APCV4 TAKES TO CLOSE.

" VALVE OPENING OF PCV4 OVER A TIME INTERVAL

" OF DTCV4 ARE SIMULATED BY USING A RAMP FUNCTION.

" the NUMBer OF tURNS TO FULL OPEN IS SPECIFIED BY NTPCV4.

" THE FLOW IN SCFM AIR IS SPECIFIED BY FPURG \& FBOOST

" NOTE: TOC2 > TOC1 + DOTC1 !

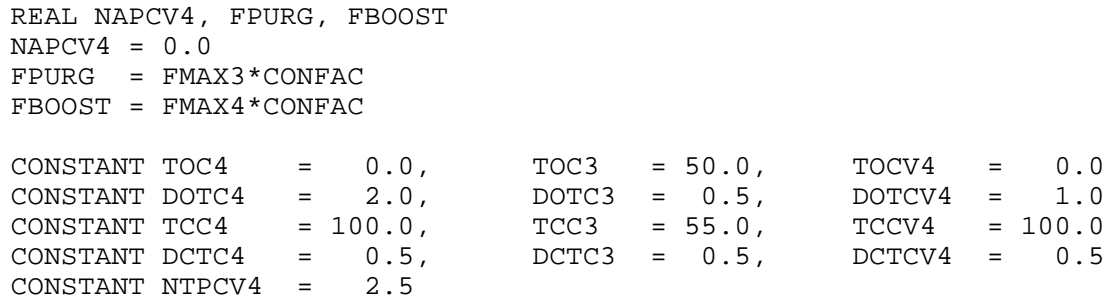

" DEFine VOLUMEtRic FLOW RAtes (CFM) "

REAL CFM1, CFM2, CFM3, CFM4, CFM5, CFM6, CFM7, CFM8, CFM9, CFM12

CFM1 $=0.0$

$\mathrm{CFM} 2=0.0$

$\mathrm{CFM} 3=0.0$

CFM4 $=0.0$

CFM5 $=0.0$

CFM6 $=0.0$

$\mathrm{CFM7}=0.0$

$\mathrm{CFM} 8=0.0$

CFM9 $=0.0$

$\mathrm{CFM} 12=0.0$

" DEFINE PIPE SECTION FLOW VELOCITIES (IN/SEC) "

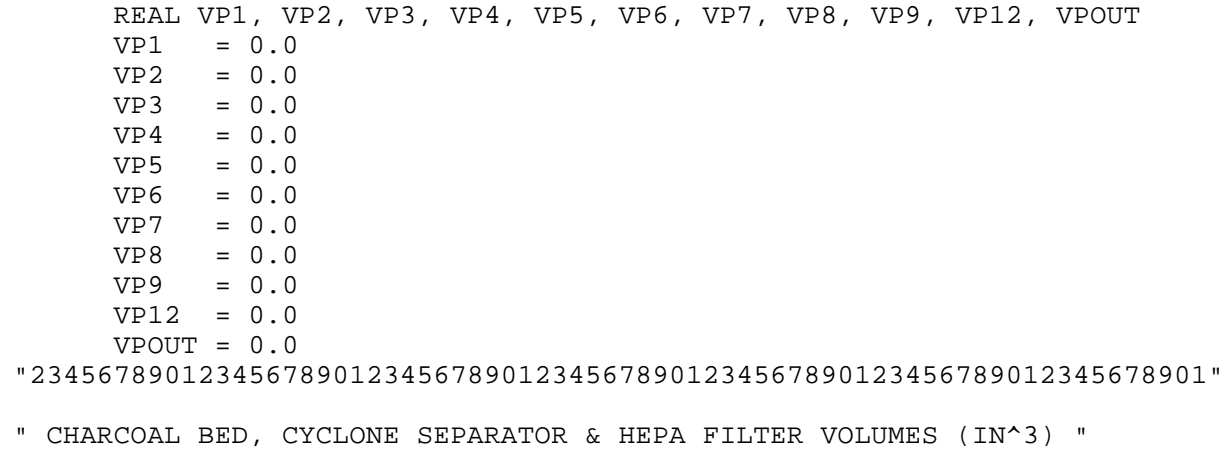




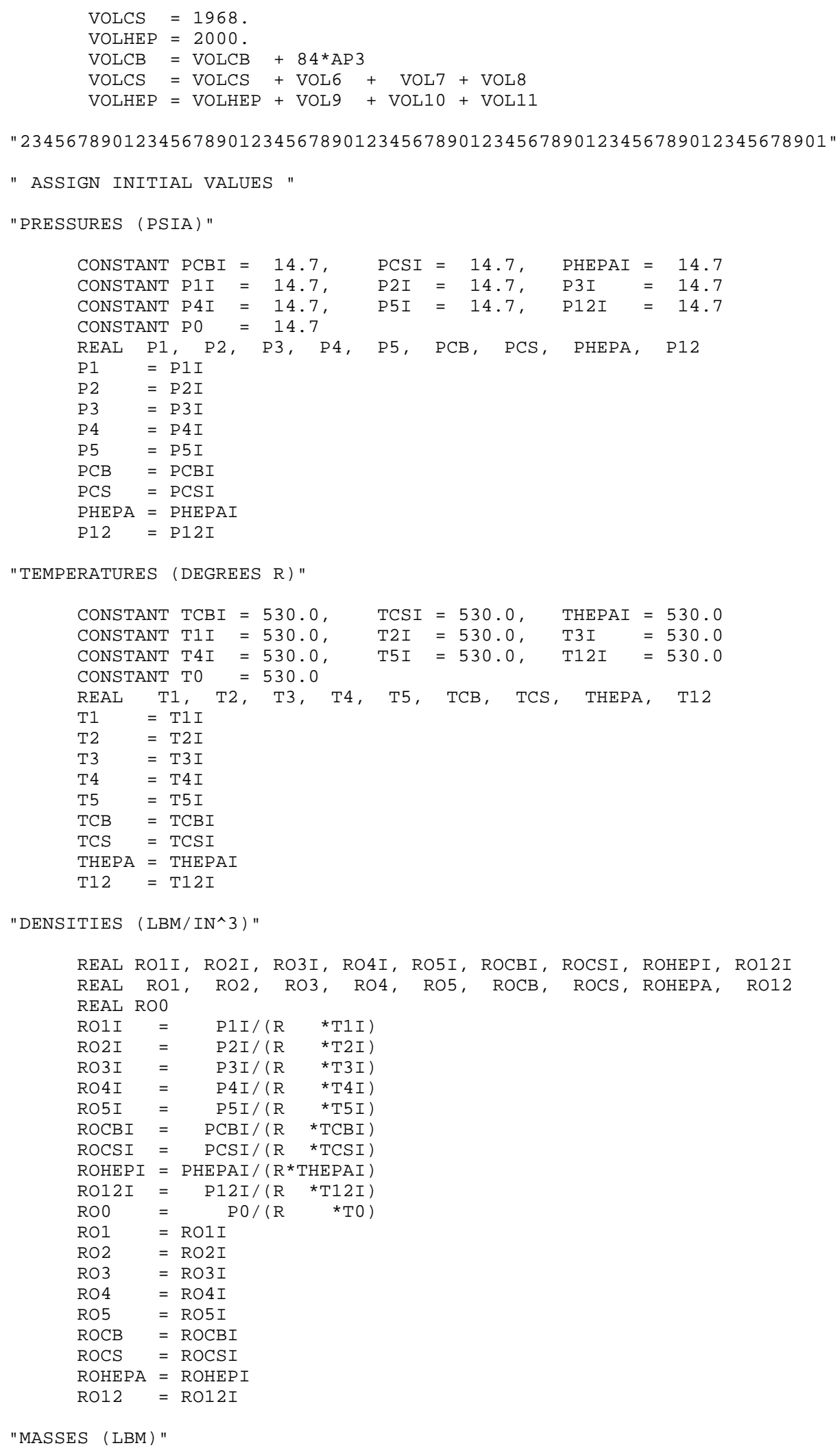

"MASSES (LBM) " 


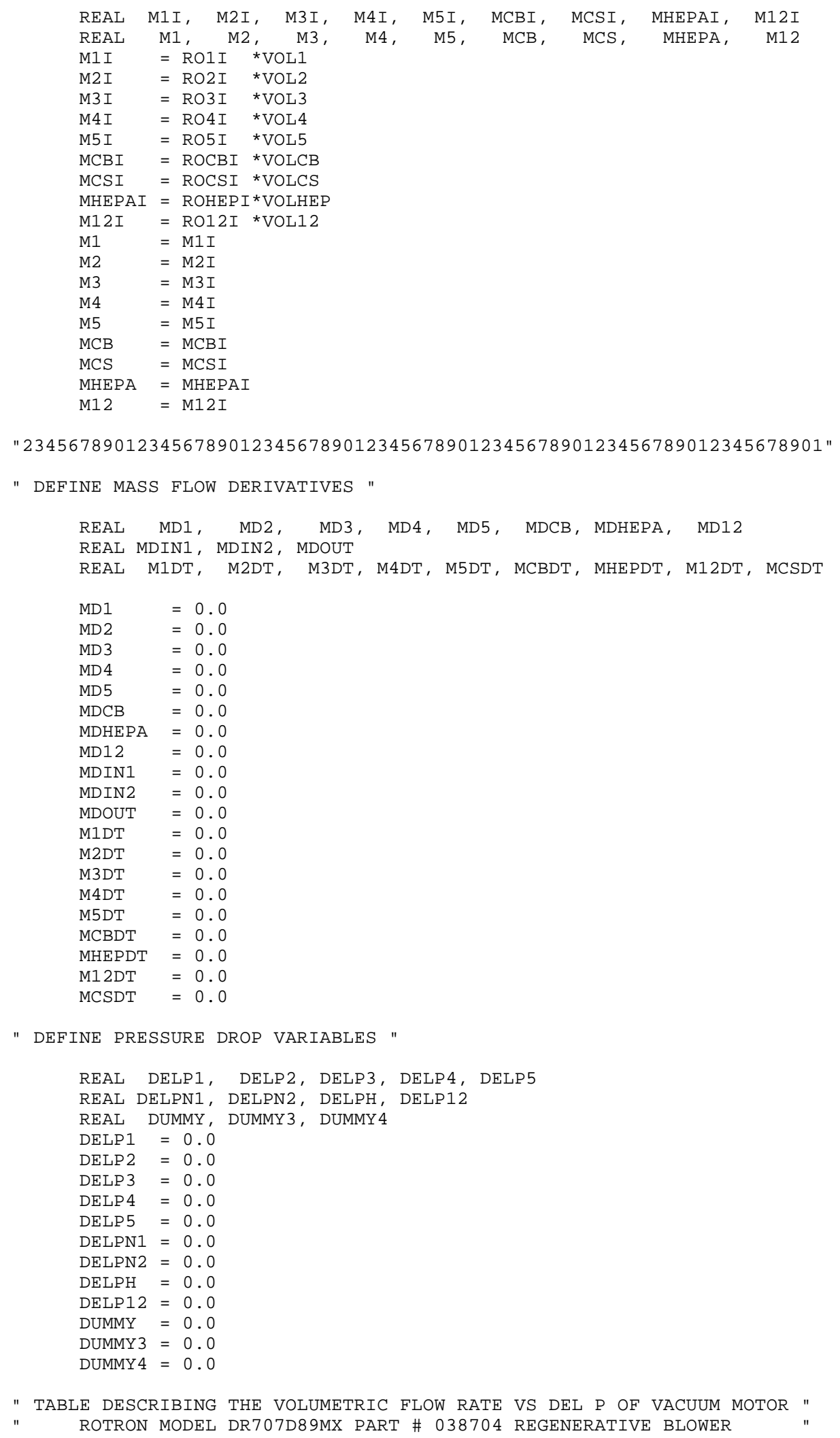

" DEFINE PRESSURE DROP VARIABLES "

" tABLE DESCRIBING THE VOLUMETRIC FLOW RATE VS DEL P OF VACUUM MOTOR "

" ROTRON MODEL DR707D89MX PART \# 038704 REGENERATIVE BLOWER 


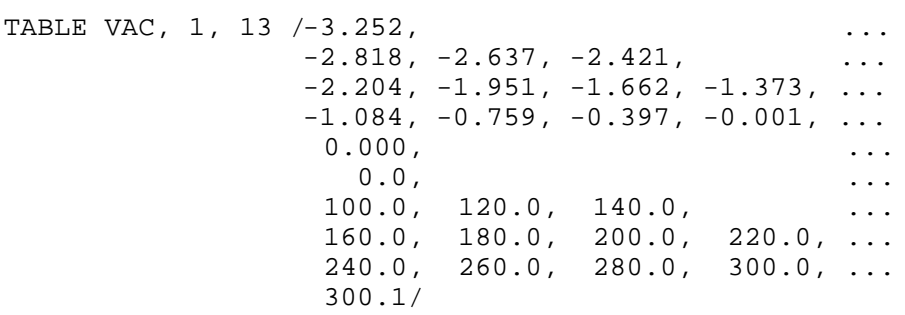

" tABLE DESCRIBING THE FLOW COEFFICIENT VS NUMBER OF tURNS OPEN FOR "

" NUPRO 8B VALVE.

TABLE NUPNT, $1,6 / 0 ., 0.50,1.00,1.500,2.000,2.5, \ldots$ $0 ., 0.24,0.45,0.695,0.905,1.0 /$

" OPEN OUTPUT FILES "

CALL OFILE (11)

CALL OFILE (12)

CALL OFILE (13)

CALL OFILE (15)

" ASSIGN INTEGRATION ERROR TOLERANCES "

XERROR M1 = 2.E-9, M2 = 2.E-9, M3 = 2.E-9, $M 4=2 . E-9, \ldots$

$\mathrm{M} 5=2 . \mathrm{E}-9, \ldots$

$\mathrm{MCB}=2 . \mathrm{E}-9, \mathrm{MCS}=2 . \mathrm{E}-9, \mathrm{MHEPA}=2 . \mathrm{E}-9, \mathrm{M} 12=2 . \mathrm{E}-9$

MERROR M1 $=2 . E-7, \quad M 2=2 . E-7, \quad M 3=2 . E-7, \quad M 4=2 . E-7, \ldots$

$\mathrm{M} 5=2 . \mathrm{E}-7$

$\mathrm{MCB}=2 . \mathrm{E}-7, \mathrm{MCS}=2 . \mathrm{E}-7, \mathrm{MHEPA}=2 . \mathrm{E}-7, \mathrm{M} 12=2 . \mathrm{E}-7$

"2345678901234567890123456789012345678901234567890123456789012345678901"

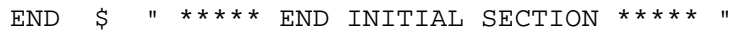

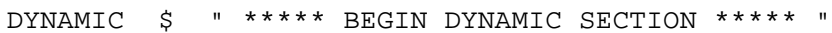

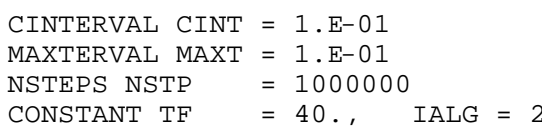

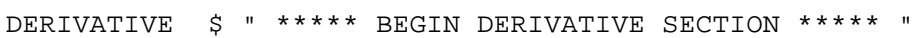

" CONTROL OPENING OF FLOW CONTROLLERS \& VALVES. DUMMY3 \& DUMMY4

" ARE THE VOLUMETRIC FLOW RATE IN SCFM AIR THROUGH FLOW CONTROLLER

" FTC3 AND AND FLOW CONTROLLER FTC4. NAPCV4 IS THE NUMBER OF TURNS

" VALVE PCV4 IS OPEN.

" $\quad \operatorname{STEP}($ TOC4)* (DUMMY3) "

DUMMY $4=($ FBOOST/DOTC 4$) *(\operatorname{RAMP}($ TOC 4$)-\operatorname{RAMP}(\operatorname{TOC} 4+$ DOTC 4$))-\ldots$ $($ FBOOST/DCTC4 $) *(\operatorname{RAMP}(\mathrm{TCC} 4)-\operatorname{RAMP}(\mathrm{TCC} 4+\mathrm{DCTC} 4))$

DUMMY3 $=($ FPURG/DOTC3 $) *($ RAMP $($ TOC3 $)-\operatorname{RAMP}($ TOC3 + DOTC3 $)) \ldots$ $($ FPURG/DCTC3 $) \star(\operatorname{RAMP}(\mathrm{TCC} 3)-\operatorname{RAMP}(\mathrm{TCC} 3+\mathrm{DCTC} 3))$

NAPCV4 $=($ NTPCV4/DOTCV4 $) *(\operatorname{RAMP}($ TOCV4 $)-\operatorname{RAMP}($ TOCV4 + DOTCV4 $))-\ldots$ $(\mathrm{NTPCV} 4 / \mathrm{DCTCV} 4) *(\operatorname{RAMP}(\mathrm{TCCV} 4)-\operatorname{RAMP}(\mathrm{TCCV} 4+\operatorname{DCTCV} 4))$

"2345678901234567890123456789012345678901234567890123456789012345678901"

$\star \star \star \star \star$ VOLUME $1 * \star \star \star \star$

PROCEDURAL (MD1 = DELP1, K, R, G0, DUMMY3, ROSTAN, RO1, AP1, .

$\mathrm{P} 1, \mathrm{MU}, \mathrm{T} 1, \mathrm{~L} 1, \mathrm{CONFAC})$

CALL FTCVOL (MD1， DELP1， K, R, G0， DUMMY3， ROSTAN, RO1, ... $\mathrm{AP} 1, \mathrm{P} 1, \mathrm{MU}, \mathrm{T} 1, \mathrm{~L} 1, \mathrm{CONFAC})$

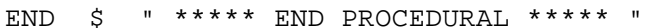




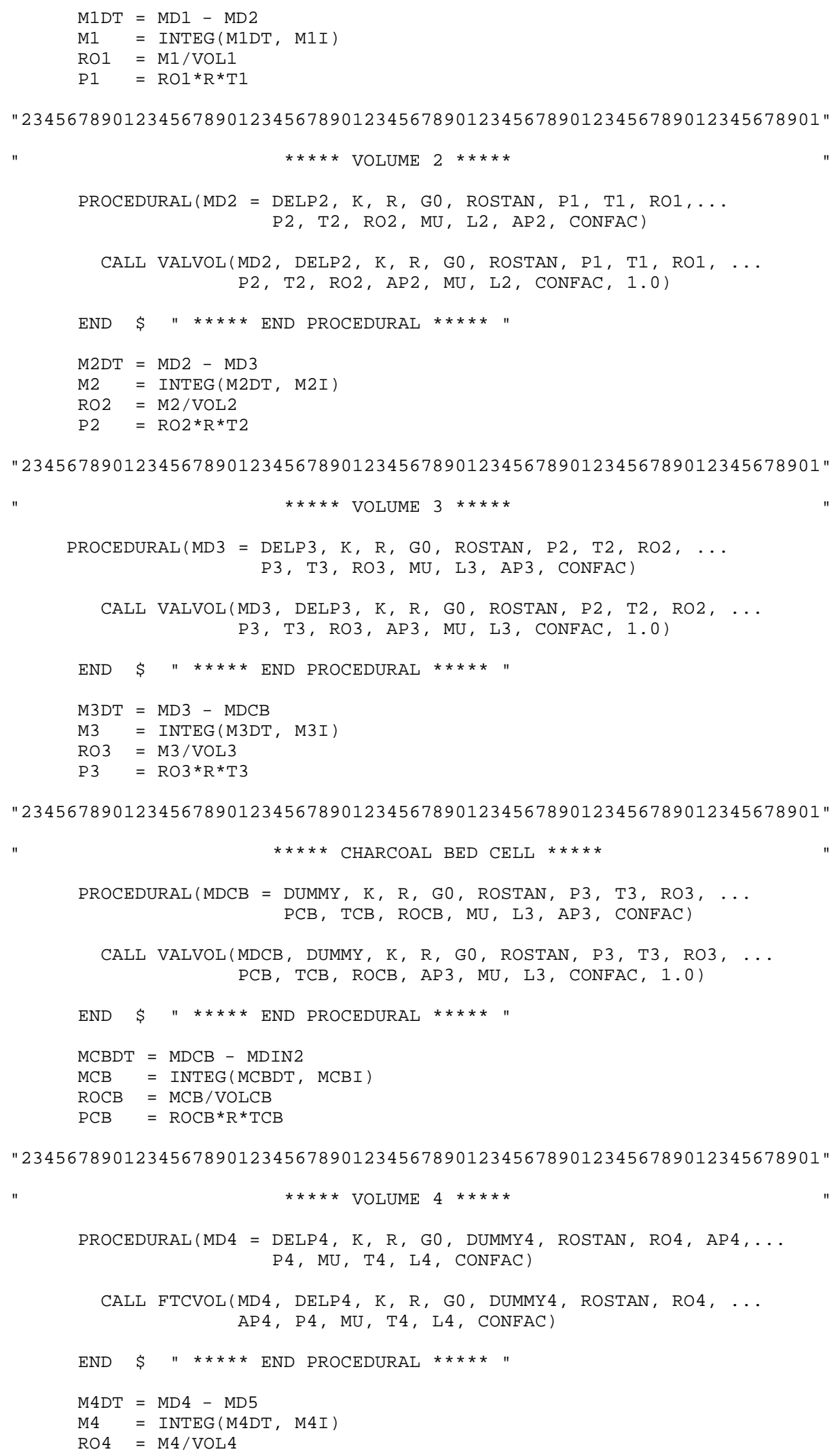


$P 4=R O 4 * R * T 4$

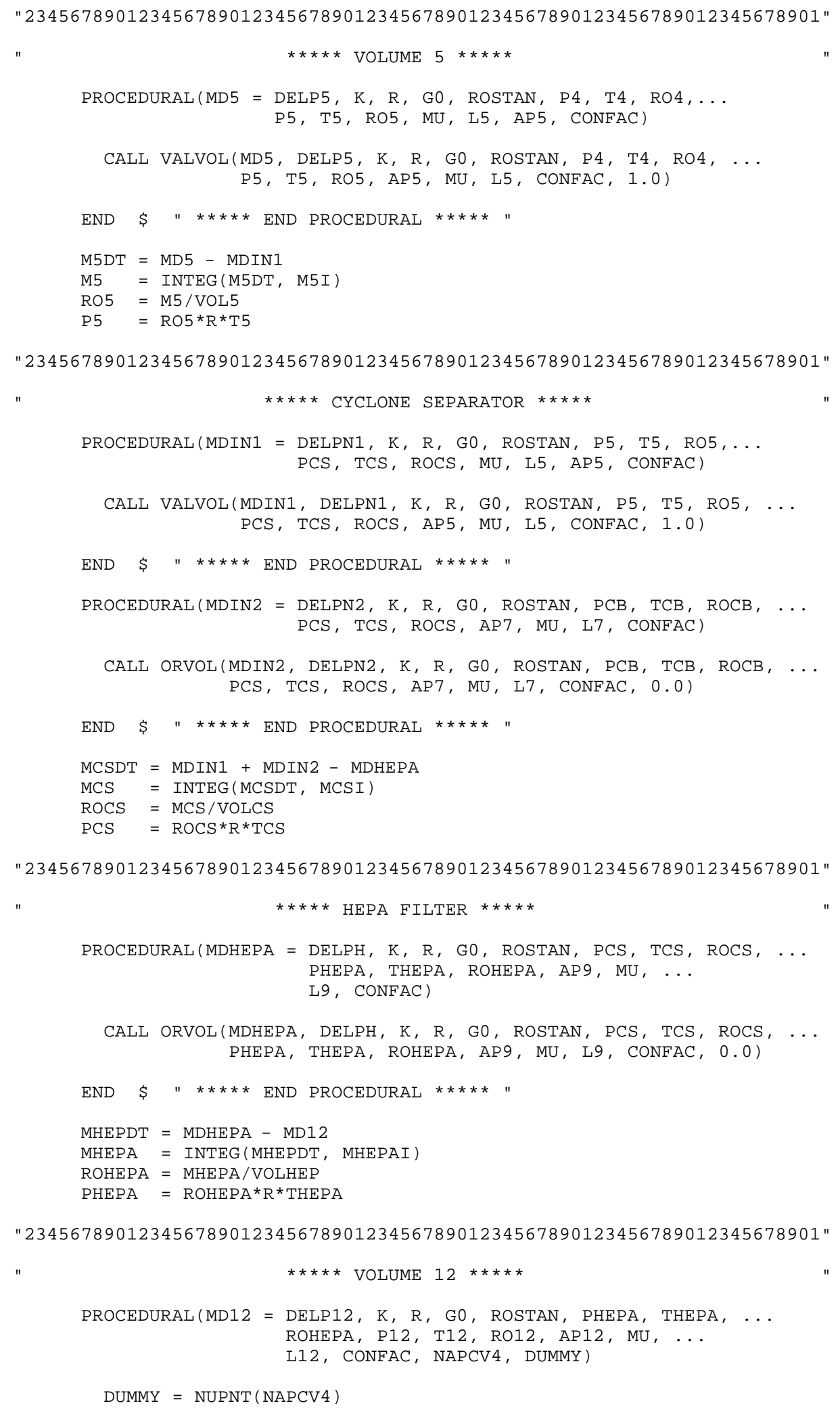




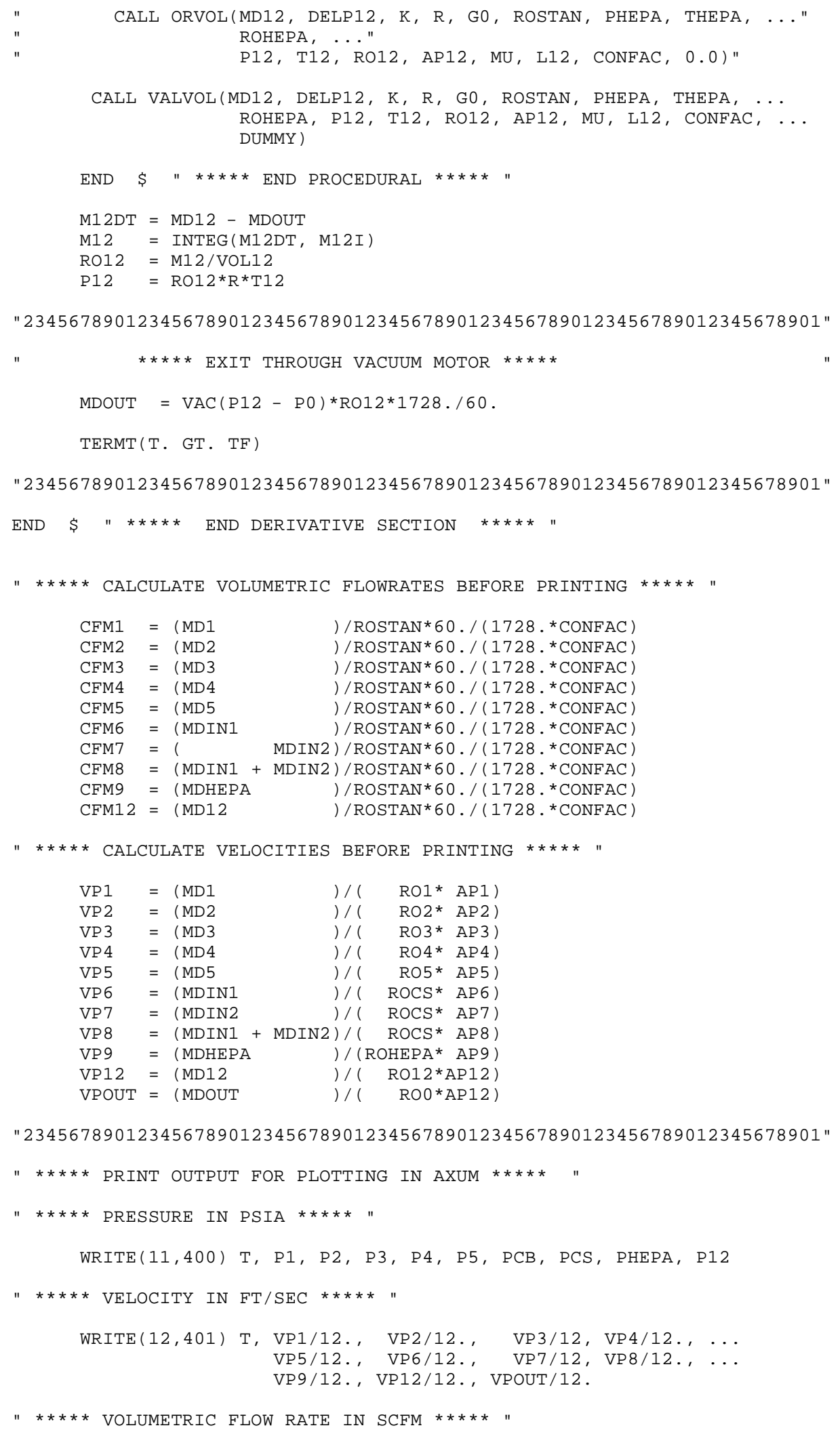




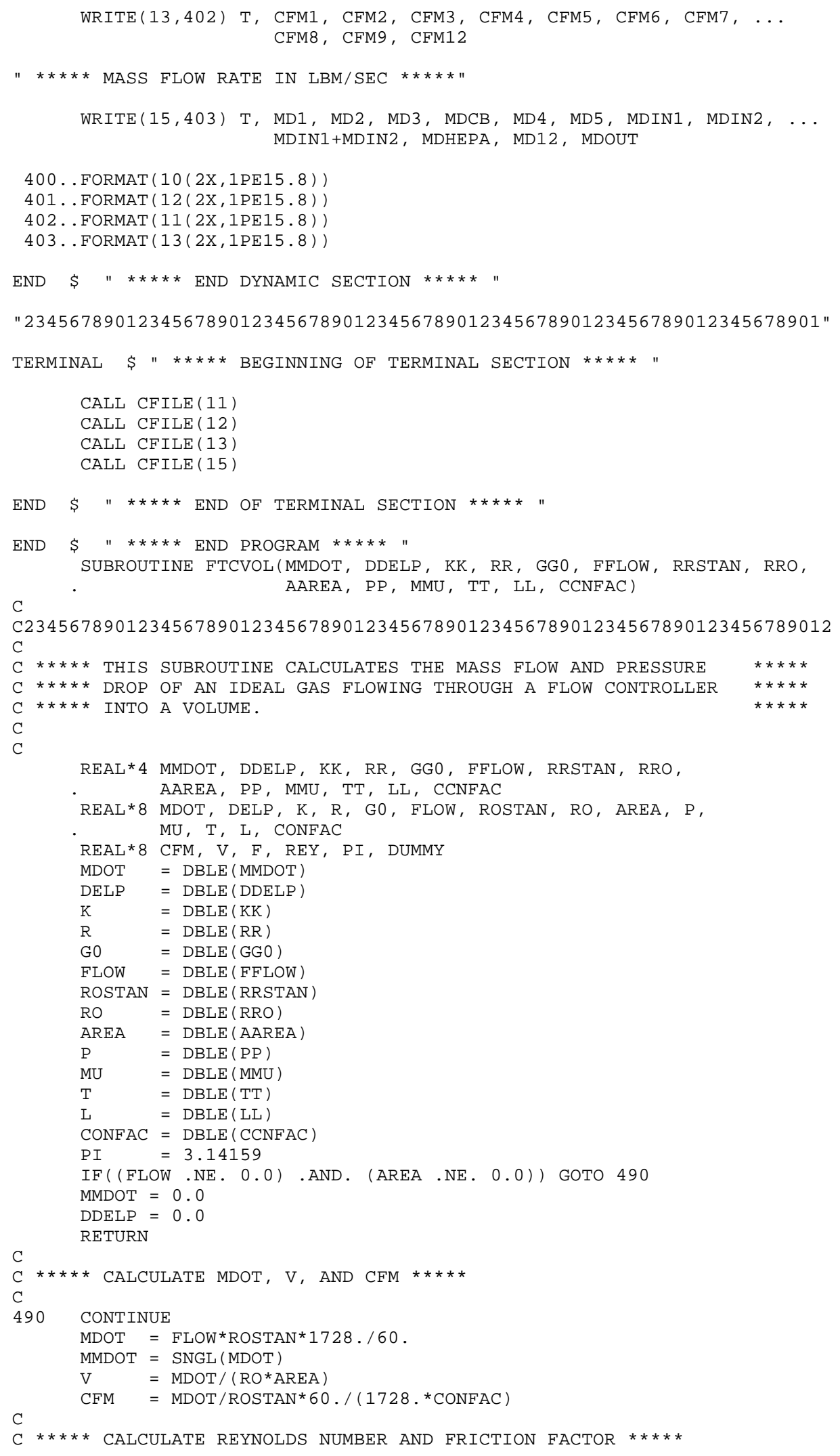




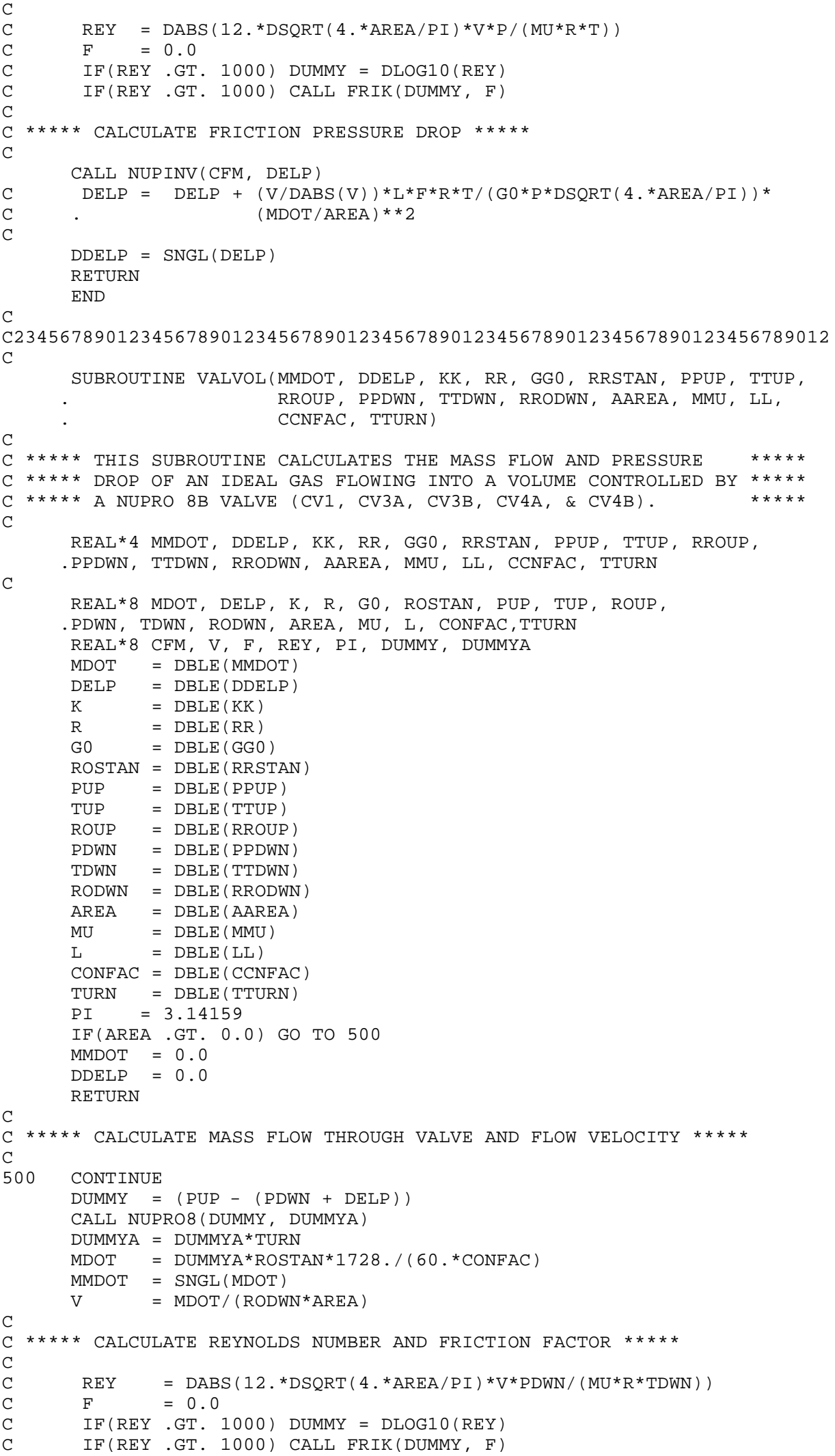




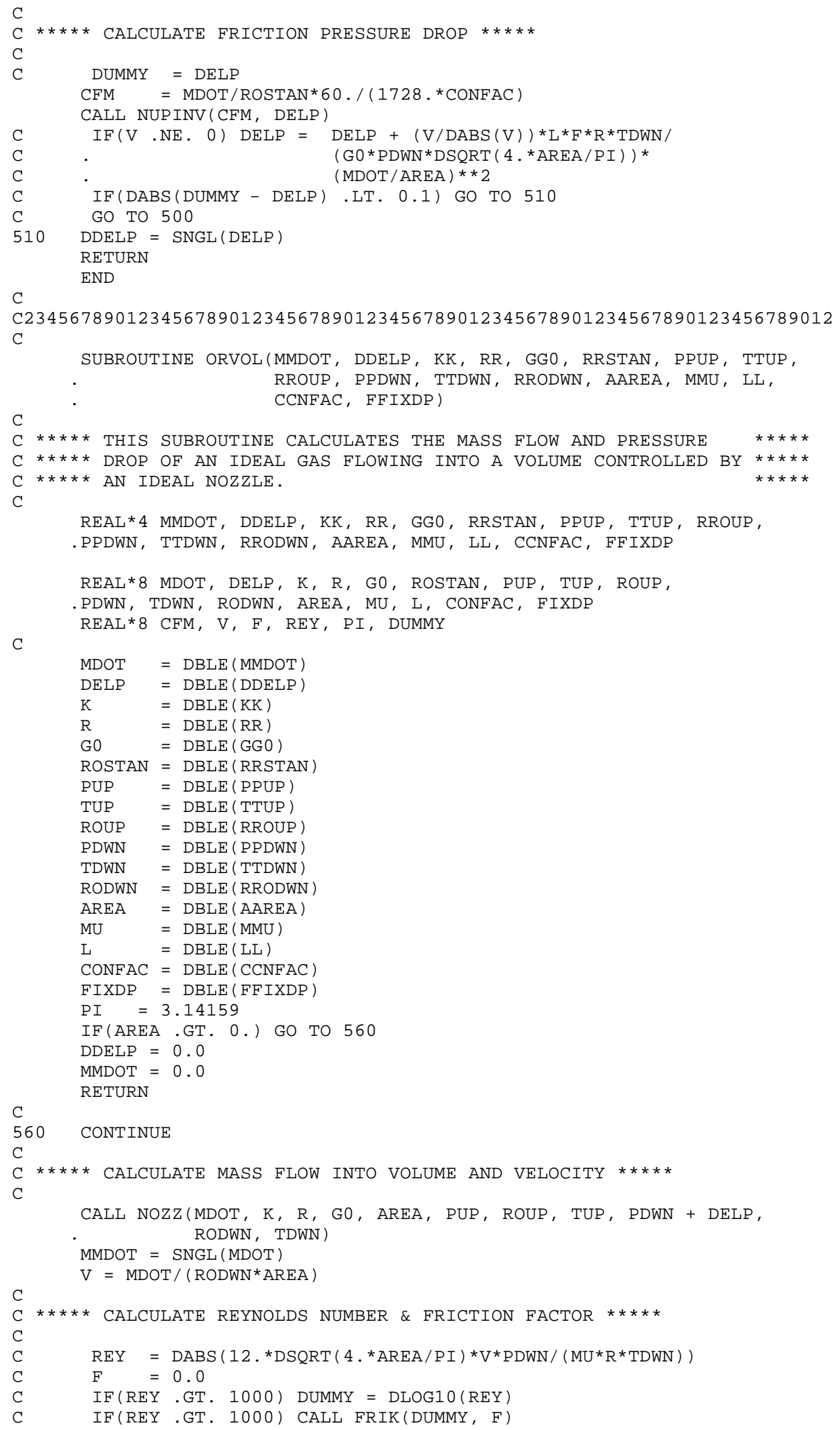




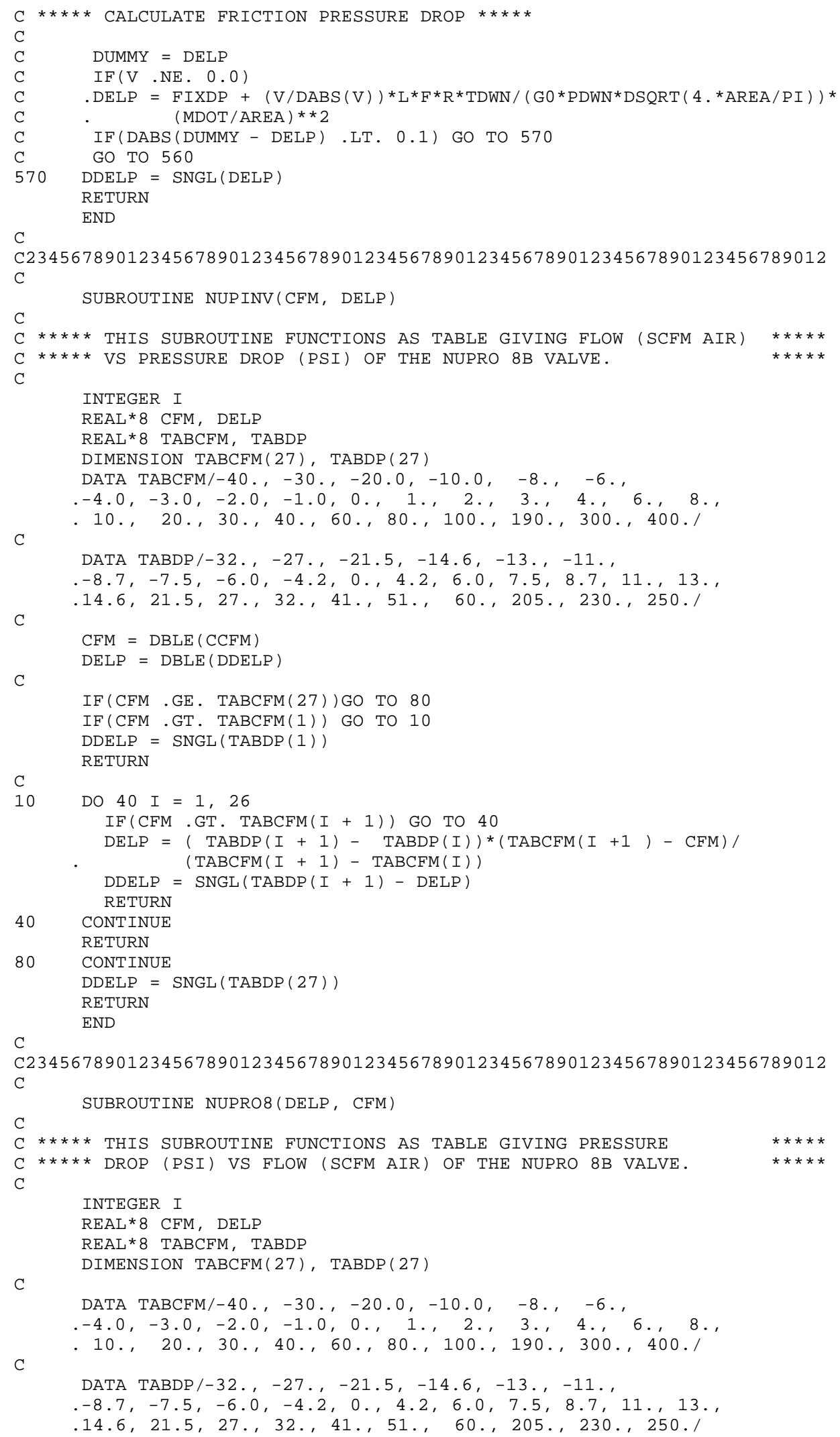


IF (DELP . GE. TABDP (27)) GO TO 80

IF (DELP. . GT. TABDP ( 1$)$ ) GO TO 10

$\mathrm{CFM}=\operatorname{TABCFM}(1)$

C

RETURN

10 DO $40 I=1,26$

IF (DELP.GT. TABDP $(I+1))$ GO TO 40

$\operatorname{CFM}=(\operatorname{TABCFM}(I+1)-\operatorname{TABCFM}(I)) *(\operatorname{TABDP}(I+1)-\operatorname{DELP}) /$

( $\operatorname{TABDP}(I+1)-\operatorname{TABDP}(I))$

$\mathrm{CFM}=\operatorname{TABCFM}(I+1)-\mathrm{CFM}$

RETURN

40 CONTINUE

80 RETURN

$\mathrm{CFM}=\operatorname{TABCFM}(27)$

RETURN

C

END

C23456789012345678901234567890123456789012345678901234567890123456789012

C

C

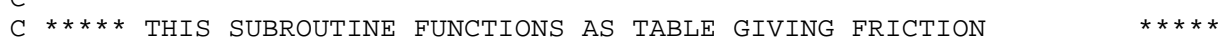

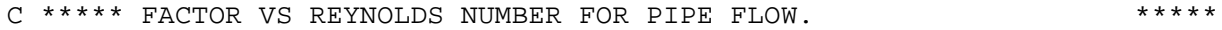

$\mathrm{C}$

REAL* 8 REY, F

INTEGER I

C

REAL* 8 TABF (9), TABR (9)

C

$\mathrm{DATA} \mathrm{TABF} / 0.07,0.05,0.035,0.029,0.023,0.020,0.017$,

. $0.015,0.013 /$

C

DATA TABR/3., 3.477, 4., 4.477, 5., 5.477, 6., 6.477, 7./

IF (REY . GE. TABR (27)) GO TO 80

IF (REY . GT. TABR (1)) GO TO 10

$\mathrm{F}=\mathrm{TABF}(1)$

C

RETURN

10 DO $40 I=1,9$

IF (REY.GT. TABR $(I+1))$ GO TO 40

$F=(\operatorname{TABF}(I+1)-\operatorname{TABF}(I)) *(\operatorname{TABR}(I+1)-\operatorname{REY}) /$

- $\quad(\operatorname{TABR}(I+1)-\operatorname{TABR}(I))$

$F=\operatorname{TABF}(I+1)-F$

RETURN

40 CONTINUE

RETURN

80 CONTINUE

$F=\operatorname{TABF}(27)$

RETURN

C

END

C23456789012345678901234567890123456789012345678901234567890123456789012

C

- RO, T)

C

C $\star \star \star \star \star *$ THIS SUBROUTINE CALCULATES THE MASS FLOW OF AN IDEAL GAS $\star \star \star \star \star *$

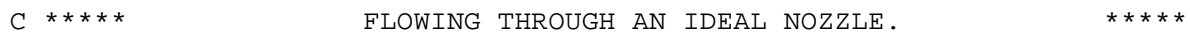

C

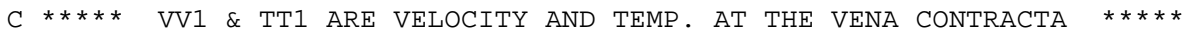

C

$\mathrm{REAL} * 8 \mathrm{MDOT}, \mathrm{K}, \mathrm{R}, \mathrm{G} 0, \mathrm{~A}, \mathrm{PO}, \mathrm{ROO}, \mathrm{TO}, \mathrm{P}, \mathrm{RO}, \mathrm{T}$

C

$\mathrm{REAL} * 8 \mathrm{G} 1, \mathrm{PC}$

$\operatorname{IF}((\mathrm{P} . \mathrm{EQ} . \mathrm{PO})$.OR. (A.LE. O.) ) GO TO 1030

IF (P.GT. PO) GO TO 1010

C

C $\star \star \star \star *$ FORWARD FLOW, $\mathrm{P}<\mathrm{PO}$; CALCULATE CRITICAL PRESSURE $* \star * * *$

C 


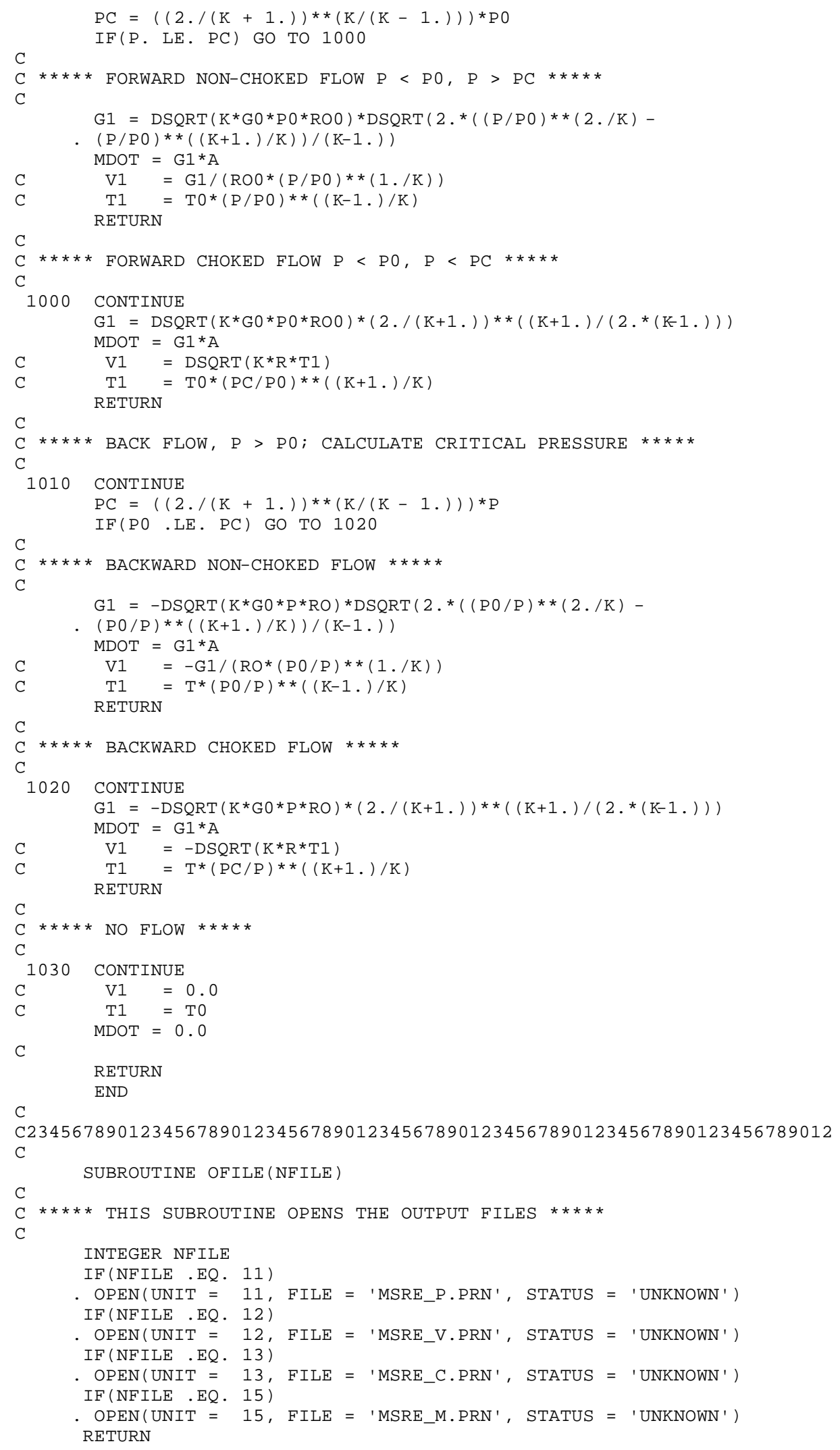




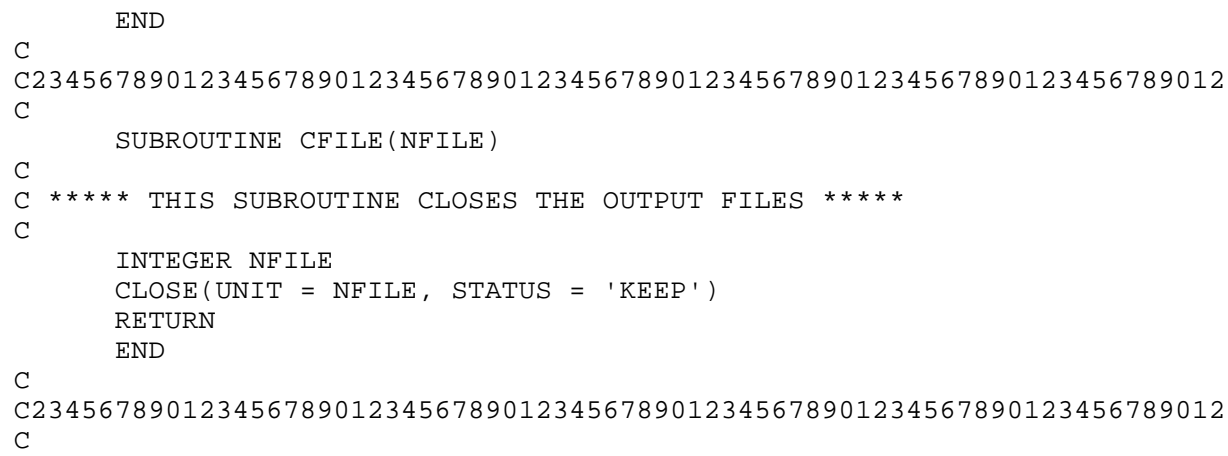

